Camila Seabra Nobre

\title{
Medição de Perdas Dependentes da Polarização Utilizando Mistura de Frequências em Fotodiodos
}

Dissertação apresentada como requisito parcial para obtenção do grau de Mestre pelo Programa de Pós-graduação em Engenharia Elétrica do Departamento de Engenharia Elétrica da PUC-Rio

Orientador: Prof. Guilherme Penello Temporão 


\title{
Camila Seabra Nobre
}

\section{Medição de Perdas Dependentes da Polarização Utilizando Mistura de Frequências em Fotodiodos}

Dissertação apresentada como requisito parcial para obtenção do grau de Mestre pelo Programa de Pós-graduação em Engenharia Elétrica do Departamento de Engenharia Elétrica do Centro Técnico Científico da PUC-Rio. Aprovada pela comissão examinadora abaixo assinada.

\author{
Prof. Guilherme Penello Temporão \\ Orientador \\ Centro de Estudos em Telecomunicações - PUC-Rio \\ Dr.Thiago Ferreira da Silva \\ Inmetro \\ Dr. Giancarlo Vilela de Faria \\ Departamento de Engenharia Mecânica - PUC-Rio \\ Prof. Jean Pierre von der Weid \\ Centro de Estudos em Telecomunicações - PUC-Rio \\ Dr. Rogério Passy \\ MLS Wireless \\ Prof. José Eugêncio Leal \\ Coordenador Setorial do Centro Técnico Científico - PUC-Rio
}

Rio de Janeiro, 28 de julho de 2015 
Todos os direitos reservados. Proibida a reprodução total ou parcial do trabalho sem autorização da universidade, do autor e do orientador.

\section{Camila Seabra Nobre}

Formada em Engenharia de Telecomunicações pela Universidade Católica de Petrópolis em 2012.

Ficha Catalográfica

Nobre, Camila Seabra

Medição de Perdas Dependentes da Polarização Utilizando Mistura de Frequências em Fotodiodos / Camila Seabra Nobre; orientador: Guilherme Penello Temporão. - Rio de Janeiro : PUC-Rio, Departamento de Engenharia Elétrica, 2015.

v., 82 f: il. ; $29,7 \mathrm{~cm}$

1. Dissertação (Mestrado em Engenharia Elétrica) - Pontifícia Universidade Católica do Rio de Janeiro, Departamento de Engenharia Elétrica.

Inclui referências bibliográficas.

1. Engenharia Elétrica - Tese. 2. Perda Dependente de Polarização. 3. Polarização da luz. 4. Frequência de Batimento. 5. Fotodiodos. I. Temporão, Guilherme Penello. II. Pontifícia Universidade Católica do Rio de Janeiro. Departamento de Engenharia Elétrica. III. Título. 


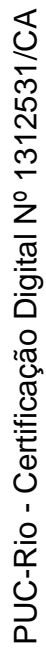

À minha mãe, Virgilina. 


\section{Agradecimentos}

Ao professor Guilherme Temporão pela orientação ao longo do trabalho; Ao Thiago Ferreira, do INMETRO, pelo auxílio desde os tempos de graduação;

Ao CNPq pela concessão da bolsa e à PUC-Rio;

À minha família, em especial minha mãe por todo carinho e incentivo;

Ao Cristiano, por toda paciência e apoio durante esses anos; 


\section{Resumo}

Nobre, Camila Seabra; Temporão, Guilherme Penello. Medição de Perdas Dependentes da Polarização Utilizando Mistura de Frequências em Fotodiodos. Rio de Janeiro, 2015. 82p. Dissertação de Mestrado - Departamento de Engenharia Elétrica, Pontifícia Universidade Católica do Rio de Janeiro.

Este trabalho apresenta um método teórico e experimental para medir Perda Dependente de Polarização (PDL) em sistemas ópticos. Este método basea-se na forma como duas componentes de polarização ortogonais da luz moduladas em amplitude por duas frequências distintas são acopladas no detector após a transmissão pelo dispositivo sob caracterização. No presente trabalho é realizado um estudo acerca das propriedades da luz e das técnicas tradicionais utlizadas para medir PDL. Antes da caracterização das medidas de PDL, foi realizado o alinhamento do dispositivo de teste (DUT), ou seja, do sistema que vai emular a PDL, a fim de garantir que o mesmo estivesse com as perdas ópticas minimizadas. Em seguida, conectou-se o DUT à configuração montada no laboratório, sendo realizado os ajustes de polarização e supressão das portadoras ópticas. Neste método é possível calcular o valor da PDL e da na orientação na Esfera de Poincaré.

\section{Palavras-chave}

Perda Dependente de Polarização ; Polarização da luz ; Frequência de Batimento ; Fotodiodos . 


\section{Abstract}

Nobre, Camila Seabra; Temporão, Guilherme Penello (advisor). Measurement of Polarization Dependent Loss Using Frequency Mixing in Photodiodes. Rio de Janeiro, 2015. 82p. MSc. Dissertation - Departamento de Engenharia Elétrica, Pontifícia Universidade Católica do Rio de Janeiro.

This work presents a theoretic and experimental method for Polarization Dependent Loss (PDL) measurement in optical systems. This method is based on how two orthogonal polarization components both modulated in amplitude by two different frequency are coupled in the detector. In this present work a study is performed about light properties and traditional techniques used to peform PDL measurement. Before the characterization of PDL measures the alignment of the device under test (DUT) was performed to make sure that optical losses were minimized in the system which will emulate the PDL. Then, the DUT was connected to the experimental setup to optical carriers suppression and polarization alignment. In this method is possible to calculate the PDL value and its orientation on the Poincaré sphere.

\section{Keywords}

Polarization Dependent Loss ; Light Polarization ; Beat Frequency ; Photodiodes . 


\section{Sumário}

1 Introdução $\quad 13$

$\begin{array}{lll}1.1 & \text { Motivação } & 13\end{array}$

1.2 Escopo 14

$\begin{array}{lll}1.3 & \text { Metodologia } & 14\end{array}$

$\begin{array}{lll}1.4 & \text { Organização } & 14\end{array}$

2 Polarização da Luz $\quad 16$

$\begin{array}{lll}2.1 & \text { Tipos de Polarização } & 18\end{array}$

2.2 Representação dos Estados de Polarização 23

2.3 Parâmetros de Stokes $\quad 25$

$\begin{array}{lll}2.4 & \text { Formalismo de Mueller } & 27\end{array}$

2.5 Formalismo de Jones 38

2.6 Matrizes de Jones em Dispositivos Ópticos 38

2.7 Coerência 40

2.8 Polarização Parcial 41

§ 3 Perda Dependente de Polarização (PDL) 43

3.1 Método de Varredura da Polarização 45

3.2 Método de Jones 46

3.3 Método de Mueller 47

3.4 Técnica de Muller - Stokes 49

3.5 Método dos Dois Estados 50

3.6 Método da Luz Despolarizada 50

4 Teoria para o Método Proposto $\quad 53$

5 Montagem Experimental $\quad 56$

5.1 Alinhamento do DUT $\quad 56$

5.2 Caracterização das Medidas 60

$\begin{array}{lll}5.3 & \text { Resultados } & 68\end{array}$

6 Conclusão $\quad 80$

$\begin{array}{ll}\text { Referências Bibliográficas } & 81\end{array}$ 


\section{Lista de figuras}

2.1 Onda TEM propagando-se na direção positiva do eixo $z$.

2.2 Tipos de polarização: (A) e (B) Linear, (C) circular e (D) Eliiptica 17

2.3 Onda polarizada elipticamente 19

2.4 Polarização linear na direção: $(A)$ x e (B) y. 21

2.5 Onda polarizada circularmente (11). 22

2.6 Representação da esfera de Poincaré (8). 28

2.7 Polarizador com os coeficientes de atenuação x e y (8). 29

2.8 Polarizador Linear Cruzado (8). 32

2.9 Configuração para uma lâmina de onda. Propagação feixe óptico através da lâmina. (8).

2.10 Eixo de Rotação para as componentes de campo óptico. 35

2.11 Eixo óptico emergindo do elemento de polarização rotacionado. 36

3.1 Representação na esfera de Poincaré de dois SOP's ortognais. Um estado é associado ao $T_{\max }$ e o estado ortogonal ao $T_{\min }$.

3.2 Efeitos da PDL. a) Luz despolarizada torna-se polarizada após passar pelo polarizador. b) Um elemento de PDL parcial altera o estado de polarização de entrada, alterando a intensidade total (3). 44

3.3 Montagem experimental para o método da varredura da polarização. 46

3.4 Montagem experimental para o método de Jones (9). 46

3.5 Montagem experimental para o método de Muller (7). 48

3.6 Montagem experiemental para medição de PDL por meio do método Mueller-Stokes (2).

3.7 Montagem esperimental para o Método dos dois Estados (12). $\quad 51$

3.8 Montagem experimental para o método da luz despolarizada (6) 51

4.1 Configuração para o método proposto, no qual as frequências $f_{1} \mathrm{e}$ $f_{2}$ são associadas aos estados $|H\rangle$ e $|V\rangle$.

5.1 Montagem experimental realizada em para medição da PDL. $\quad 56$

5.2 Montagem experimental para o DUT. $\quad 57$

5.3 Montagem experimental para o alinhamento do feixe de entrada. Suporte de posicionamento $x y z$ para lente fibrada. Posicionamento da iris para garantir a melhor trajetória do feixe óptico.

5.4 Montagem experimental a fim de garantir uma trajetória em linha reta para o feixe óptico.

5.5 Montagem experimental para checar a trajetória do feixe através da íris 1 e 2: (A) ângulo polar positivo; (B) ângulo polar negativo.

5.6 Configuração experimental, mostrando as componentes espectrais dos tons de modulação sem a presença do DUT.

5.7 Espectro Óptico do sinal modulado e suas bandas laterias. Denominando, $f_{1}=230 \mathrm{MHz}$ e $f_{2}=260 \mathrm{MHz}$.

5.8 Curva de operação do modulador operando em um ponto de curvatura 63 
5.9 (a) O espectro óptico dos sinais modulados em amplitude com portadora suprimida. (b) O Espectro elétrico com o tom heterodino de cada braço óptico. Os traços são independentes.

5.10 Espectro para $H W P_{1}$ fixada em $0^{\circ}, 2 f_{2}$ variando à medida que $H W P_{2}$ alcança $45^{\circ}$. (A) $H W P_{2}$ em $0^{\circ}$, ausência de PDL. (B) $H W P_{2}$ em $22,5^{\circ}$. (C) $H W P_{2}$ em $45^{\circ}, P D L$ máxima. (D) $H W P_{2}$ em $90^{\circ}$.

5.11 Espectro para o $S O P$ fixado em $45^{\circ}$ por meio da $H W P_{1}, 2 f_{1}$ variando à medida que $H W P_{2}$ alcança $45^{\circ}$. (A) $H W P_{2}$ em $0^{\circ}$, ausência de PDL. (B) $H W P_{2}$ em $22,5^{\circ}$. (C) $H W P_{2}$ em $45^{\circ}$, PDL máxima. (D) $H W P_{2}$ em $90^{\circ}$.

5.12 Espectro elétrico medido com os batimentos entre as componentes com a $H W P_{1}$ fixada em $22,5^{\circ}$.

5.13 Transmitância obtida com a $H W P_{1}$ em $0^{\circ}$ para $2 f_{1}$ e $2 f_{2}$ em função da $H W P_{2}$.

5.14 Transmitância obtida com a $H W P_{1}$ em $45^{\circ}$ para $2 f_{1}$ e $2 f_{2}$ em função da $H W P_{2}$.

5.15 Transmitância obtida com a $H W P_{1}$ em $22,5^{\circ}$ para $2 f_{1}$ e $2 f_{2}$ em função da $H W P_{2}$.

5.16 Valor da PDL medida e esperada para cada em função de cada $\theta$ da $H W P_{2}$ com a $H W P_{1}$ fixada em $0^{\circ}$.

5.17 Valor da PDL medida e esperada para cada em função de cada $\theta$ da $H W P_{2}$ com a $H W P_{1}$ fixada em $45^{\circ}$.

5.18 Valor da PDL medida e esperada para cada em função de cada $\theta$ da $H W P_{2}$ com a $H W P_{1}$ fixada em $30^{\circ}$.

5.19 Valor da PDL medida e esperada para cada em função de cada $\theta$ da $H W P_{2}$ com a $H W P_{1}$ fixada em $20^{\circ}$.

5.20 Ângulo de orientação $\chi$ na esfera de Poincaré, com a $H W P_{1}$ fixada em $0^{\circ}$, em função de cada $\theta$ da $H W P_{2}$.

5.21 Ângulo de orientação $\chi$ na esfera de Poincaré, com a $H W P_{1}$ rotacionada em $45^{\circ}$, em função de cada $\theta$ da $H W P_{2}$.

5.22 Ângulo de orientação $\chi$ na esfera de Poincaré com a $H W P_{1}$ rotacionada em $20^{\circ}$ em função de cada $\theta$ da $\mathrm{HWP}_{2}$.

5.23 Ângulo de orientação $\chi$ na esfera de Poincaré com a $H W P_{1}$ rotacionada em $30^{\circ}$ em função de cada $\theta$ da $H W P_{2}$. 
"Science is the attempt to make the chaotic diversity of our sense-experience correspond to a logically uniform system of though",

Albert Einstein, Out of my Later Years (1950), 98. 


\section{Lista de Abreviaturas}

AM Amplitude Modulation.

BER Bit Error Rate.

DFB Distributed Feedback.

DUT Device Under Test.

DOP Degree Of Polarization.

ESA Electrical Spectrum Analyser.

HWP Half-Wave Plate.

LD Laser Diode.

LCVR Liquid Crystal Regulator.

PBS Polarization Beam Splitter.

Ð $\quad$ PDL Polarization Dependent Loss.

PDM Polarization Dependent Modulation.

PDS Polarization Dependent Sensinbility.

PWD Polarization Dependent Wavelength.

QWP Quarter-Wave Plate.

SOP State of Optical Polarization.

TEM Transversal Electromagnetic Mode. 


\section{1 \\ Introdução}

\section{1}

\section{Motivação}

A polarização é uma propriedade fundamental da luz, sendo importante em vários fenômenos, por exemplo na propagação em fibras ópticas. Na física clássica, a luz é modelada como uma onda eletromagnética com um campo elétrico e magnético oscilante ao longo do eixo de propagação, sendo definida em termos de padrão traçado no plano transversal pelo vetor de campo elétrico em função do tempo.

Devido à natureza aleatória dos modos de acoplamento na fibra óptica diversos efeitos da polarização ocorrem, levando à degradação do sinal em sistemas de transmissão óptica à longa distância e com elevadas taxas de bit. Tais efeitos incluem, a perda dependente de polarização (PDL, do inglês Polarization Dependent Loss) nos componentes ópticos passivos, dispersão dos modos de polarização (PMD, do ingls Polarization Mode Dispersion) na fibras óptica, modulação dependente de polarização (PDM, do inglês Polarization Dependent Modulation) nos moduladores eletro-ópticos, polarização dependente de ganho (PDG, do inglês Polarization Dependent Gain) nos amplificadores ópticos, polarização do comprimento de onda central (PDW, do inglês Polarization Dependent Wave length) em filtros WDM, resposta dependente de polarização (PDR) nos receptores e a sensibilidade dependente de polarização (PDS, do inglês Polarization Dependent Sensinbility) nos sensores ópticos e sistemas de detecção coerente.

Os componentes ópticos passivos (acopladores, isoladores, etc.) em sistemas de telecomunicações possuem sensibilidade à polarização, causando efeito indesejáveis nos sinais analógicos e digitais. Os efeitos causados pela PDL estão associados à distorção do sinal e ao aumento da taxa de erro de bit (BER, do inglês Bit Error Rate).

A PDL é definida como a diferença na transmissão entre dois estados de polarização ortogonais. Um estado de polarização corresponde ao coeficiente de transmissão máximo e o estado ortogonal vai corresponder ao coeficiente de transmissão mínimo e partir dessa diferença é encontrado o valor da PDL.

As técnicas para realizar medidas de PDL são divididas em duas categorias: determinísticas e não determinística. No primeiro caso, os valores de PDL são encontrados a partir das matrizes de Jones ou Mueller dos dispositivos ópticos, medindo os parâmetros de Stokes para um conjunto de estados de po- 
larização (SOP, State of Optical Polarization) de entrada. Para os métodos não determinísticos, a sensibilidade de polarização é medida para todos os SOPs de entrada possíveis.

\section{2}

\section{Escopo}

O objetivo do presente trabalho foi desenvolver teoricamente e a implementar experimentamente um novo método para medir PDLs, considerando o modo como os fotodiodos realizam a transdução dos sinais luminosos em sinais elétricos, ou seja, quando dois modos ortogonais de polarização são modulados em amplitude com frequências distintas, o sinal elétrico resultante é diferente em conteúdo espectral com relação à situação em que só existe um único modo de polarização com duas frequências de modulação.

\section{3}

\section{Metodologia}

Foi realizado um estudo acerca das propriedades da luz e das principais técnicas, já existentes, para medidas de PDL.

Primeiramente, houve um preparo do dispositivo de teste (DUT, do inglês Device Under Test) por meio do alinhamento dos componentes de óptica bulk, a fim de garantir que o sistema possua menor perda possível para a caracterização das medidas.

Na sequência, foi realizado o ajuste de polarização da luz e supressão das portadoras óptica.

E por último, os espectros do analisador de espectro elétrico (ESA, do inglês Electrical Spectrum Analyser) foram obtidos e analisados a partir do comportamento para cada estado de polarização da entrada do DUT.

\section{4}

\section{Organização}

Este trabalho é composto por cinco capítulos, sendo que o primeiro faz menção acerca do tema objeto desse estudo. O capítulo 2 descreve a fundamentação teórica referente à polarização da luz e a interação da mesma com componentes ópticos que compõem um sistema óptico. O capítulo 3 apresenta as técnicas tradicionais para medir perdas dependentes de polarização. O capítulo 4 apresenta a teoria para a modelagem teórica para o problema. O capítulos 5 e 6 descrevem a metodologia empregada para o desenvolvimento 
Medição de Perdas Dependentes da Polarização Utilizando Mistura de Frequências em Fotodiodos

deste trabalho e os resultados do experimento, respectivamente. Finalmente, o capítulo 7 as conclusões para o trabalho realizado. 


\section{2}

\section{Polarização da Luz}

A luz que se propaga no espaço livre ou na fibra é representada pelos vetores de campos elétrico $(E)$ e magnético $(H)$, que são perpendiculares entre si e ambos estão contidos em um plano transversal à direção de propagação conhecida como onda transversal eletromagnética (TEM). Uma onda propagando-se na direção positiva do eixo $z$ possui as componentes dos campos $E$ e $H$, sendo perpendicular ao eixo $z$ (plano $x y$ ). Onde $k$ é o vetor número de onda e descreve a direção de propagação em todos os instantes de tempo.

A Figura 2.1 mostra uma onda TEM onde a componente $E_{x}$ é perpendicular ao plano de incidência, sendo denominada s-polarizada, e a componente $E_{y}$ ortogonal ao plano de incidência denominada p-polarizada. A notação $s$ e $p$ originaram-se de palavras alemãs para paralelo (parallelle) e perpendicular (senkrecht).

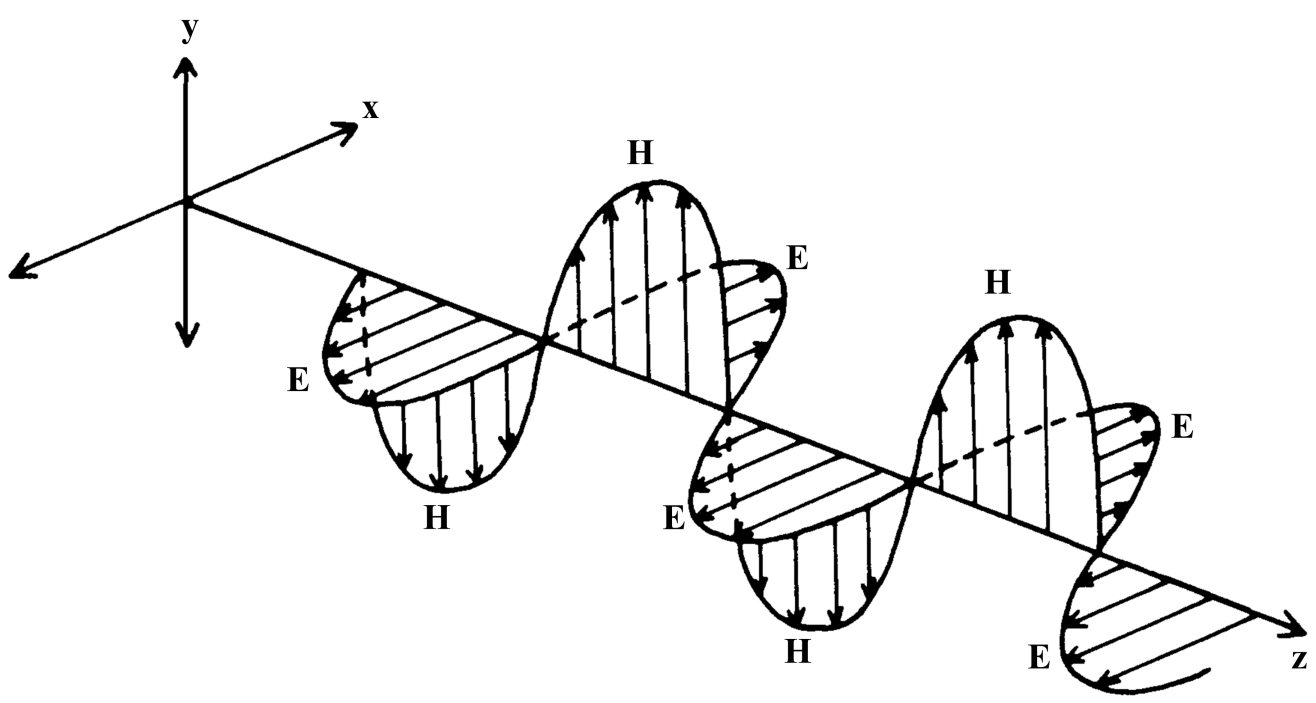

Figura 2.1: Onda TEM propagando-se na direção positiva do eixo z.

A polarização é definida em termos do padrão traçado no plano transversal pelo vetor de campo elétrico que se move em função do tempo. Assim, as ondas eletromagnéticas podem ser classificadas como: linear, elíptica e circular. Quando o vetor $E$ não se altera ao longo da direção de propagação, este tipo de onda é dita onda linearmente polarizada. Se a figura traçada pelo campo elétrico for uma elípse, tem-se uma onda polarizada elipticamente, e quando esses eixos desenhados pela eliipse forem idênticos denomina-se polarização 
circular. As polarizações linear e circular representam casos de polarização elíptica.

A Figura 2.2 ilustra os três tipos de polarização.
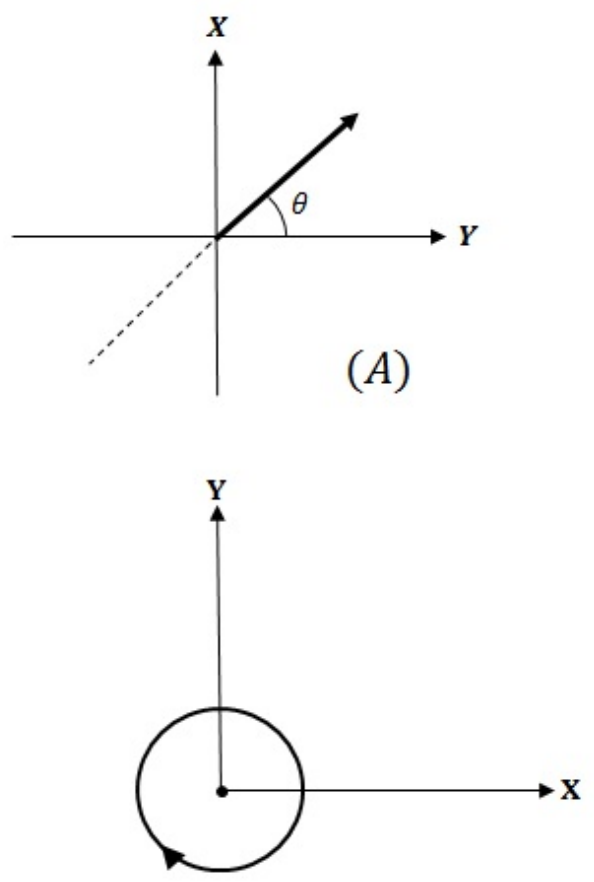

$(C)$
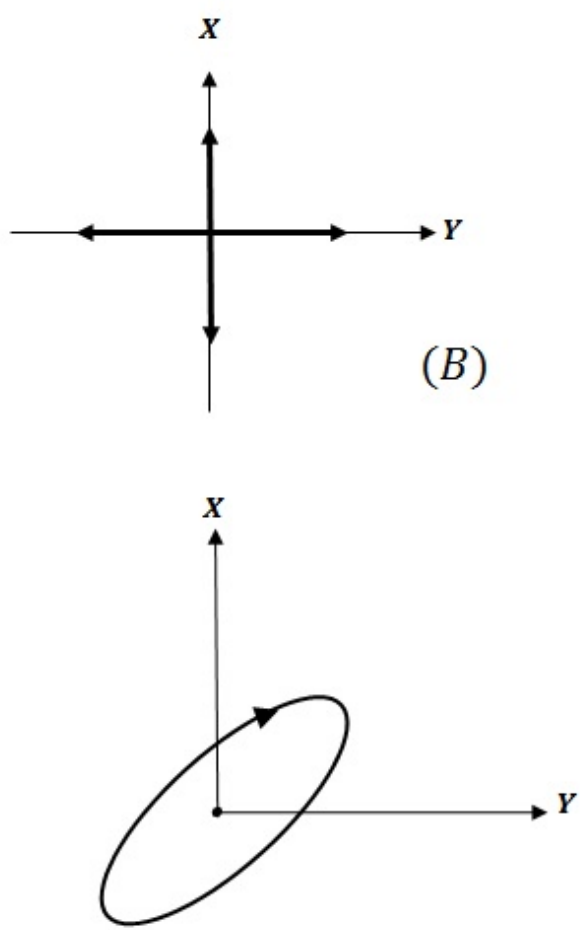

$(D)$

Figura 2.2: Tipos de polarização: (A) e (B) Linear, (C) circular e (D) Eliiptica

Nem sempre é possvel descrever a luz em termos de um vetor campo elétrico (4). A luz despolarizada pode ser representada como um vetor $E$, possuindo a cada instante orientações aleatórias no plano $x y$. Já a luz parcialmente polarizada pode ser considerada como uma superposição da luz polarizada e despolarizada, situando-se entre os limites das mesmas.

O parâmetro grau de polarização (DOP, do inglês Degree Of Polarization) expressa a quantidade relativa de luz polarizada e despolarizada na mesma onda:

$$
D O P=\frac{P_{\text {polarizada }}}{P_{\text {polarizada }}+P_{\text {despolarizada }}}
$$

Uma onda luminosa viajando no espaço livre mantém o sua DOP indefinidamente. 


\section{1}

\section{Tipos de Polarização}

O movimento do campo elétrico no plano $x y$ determina a polarização da onda (8). Assim, a luz polarizada pode ser representada matematicamente em termos de projeções dos eixos $x$ e $y$ dos vetores de campo elétrico. Para uma onda TEM que se propaga na direção positiva do eixo z a expressão geral é:

$$
E=E_{o} x(t) \cos \left(\omega t-k z+\phi_{x}\right) \hat{a}_{x}+E_{o} y(t) \cos \left(\omega t-k z+\phi_{y}\right) \hat{a}_{y}
$$

Onde, $\hat{a}_{x}$ e $\hat{a}_{y}$ são vetores unitários nas direções $x$ e $y, k$ é a constante de propagação, $\omega$ é a frequência ângular e $\phi_{x}$, $\phi_{y}$ são as fases relativas de cada componente. $\mathrm{O}$ tipo de polarização é especificada pelos valores de $E_{x}, E_{y}, \phi_{x}$ e $\phi_{y}$.

\subsection{1}

\section{Polarização Elíptica}

As componentes transversas são descritas por:

$$
\begin{aligned}
& E_{x}(z, t)=E_{\mathrm{xo}} \cos \left(\tau+\phi_{x}\right) \\
& E_{y}(z, t)=E_{\mathrm{yo}} \cos \left(\tau+\phi_{y}\right)
\end{aligned}
$$

Onde $\tau=\omega t-k z$ é o propagador, as componentes $E_{\text {xо }}$ e $E_{\text {yо }}$ são as amplitudes máximas, $\phi_{x}$ e $\phi_{y}$ são as fases, respectivamente. Conforme os campos $E_{x}(z, t)$ e $E_{y}(z, t)$ se propagam, origina-se um vetor resultante que descreve um conjunto de pontos no espaço, gerando uma curva elíptica. Então as equações (2-3) e (2-4) são reescritas na forma:

$$
\begin{aligned}
& \frac{E_{x}}{E_{\mathrm{xo}}}=\cos \tau \cos \phi_{x}-\sin \tau \sin \phi_{x} \\
& \frac{E_{y}}{E_{\mathrm{yo}}}=\cos \tau \cos \phi_{y}-\sin \tau \sin \phi_{x}
\end{aligned}
$$

Assim,

$$
\frac{E_{x}}{E_{\mathrm{xo}}} \sin \phi_{x}=\cos \tau \sin \left(\phi_{y}-\phi_{x}\right)
$$


Medição de Perdas Dependentes da Polarização Utilizando Mistura de Frequências em Fotodiodos

$$
\frac{E_{y}}{E_{\text {yo }}} \sin \phi_{y}=\cos \tau \sin \left(\phi_{y}-\phi_{x}\right)
$$

Em (2-3) e (2-4), soma-se os quadrados dos campos $E_{\text {xо }}$ e $E_{\text {yo }}$, resultando:

$$
\left(\frac{E_{x}}{E_{\mathrm{xo}}}\right)^{2}+\left(\frac{E_{y}}{E_{\text {yо }}}\right)^{2}-2 \frac{E_{x}}{E_{\text {хо }}} \frac{E_{y}}{E_{\text {уо }}} \cos (\phi)=\sin ^{2}(\theta)
$$

Onde,

$$
\phi=\phi_{y}-\phi_{x}
$$

A equação (2-9) é a forma geral para o traçado da elipse e mostra que em qualquer instante de tempo o lugar geométrico dos pontos descritos pelo campo óptico é uma elipse. A figura 2.3 mostra a elípse inscrita em um retângulo cujos lados são paralelos aos eixos de coordenadas e os comprimentos são $2 E_{\text {хо }}$ e $2 E_{\text {yo }}$.

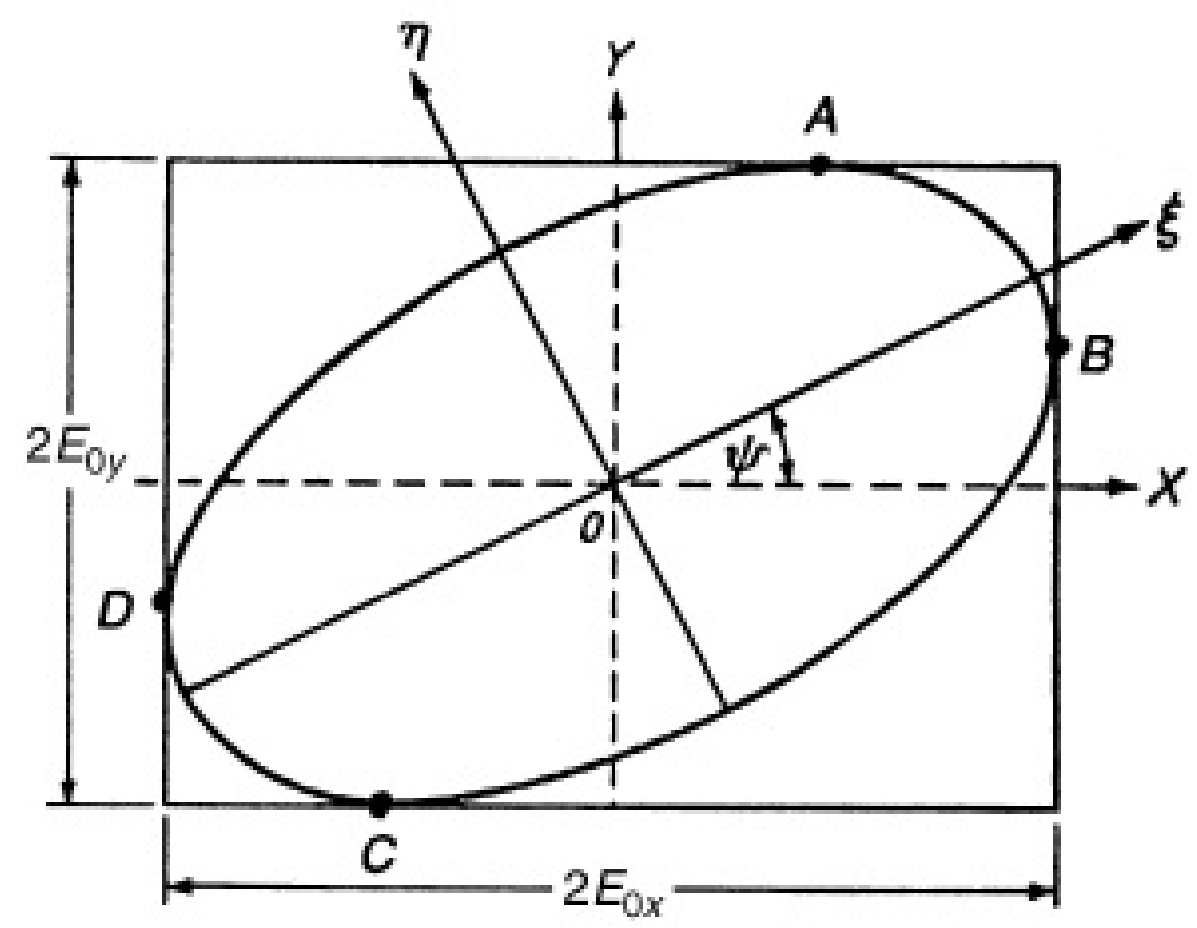

Figura 2.3: Onda polarizada elipticamente

(8).

A polarização da elipse tem sua forma descrita pela equação (2-9), na qual não representa os eixos da eliipse nas direções de origem $O X$ e $O Y$. É 
conveniente introduzir um ângulo auxiliar $\alpha\left(0 \leq \pi \leq \frac{\pi}{2}\right)$, cujo o eixo da elípse faz um ângulo de rotação $\alpha$ relativo ao eixo $x$.

Os parâmetros elípticos $E_{\text {xo }}$ e $E_{\text {yo }}$ e $\phi$ estão relacionados ao ângulo de elipsidade $\chi\left(-\frac{\pi}{4} \leq \chi \leq \frac{\pi}{4}\right)$ e ao ângulo de orientação $\psi(0 \leq \psi \leq \pi)$ pelas seguintes equações:

$$
\begin{aligned}
& \tan (2 \psi)=\tan (\alpha) \cos (2 \phi) \\
& \sin (2 \chi)=\sin (\alpha) \sin (2 \phi)
\end{aligned}
$$

A rotação do vetor de campo elétrico descrito pela equação (2-2) exibe um sentido que depende da diferença de fase $\phi$. Para o intervalo $-\pi \leq \phi \leq 0$, a evolução da elipse ocorrerá no sentido horário. E caso, o vetor de campo elétrico esteja no intervalo $0 \leq \phi \leq \pi$, a evolução da elipse será no sentido antihorário.

A luz completamente polarizada é elipticamente polarizada. No entanto, outras formas especiais de polarização elíptica serão descritas nas secões seguintes.

\subsection{2}

\section{Polarização Linear}

A partir de (2-2) uma das componentes do eixo é sempre nula $\left(E_{y}=0\right)$ e o vetor campo elétrico determina a parametrização da curva no plano xy $(\mathrm{z}=0)$ :

$$
\begin{gathered}
E_{x}(t)=\cos \left(\omega t+\phi_{x}\right) \\
E_{y}=0
\end{gathered}
$$

O módulo do campo elétrico varia harmonicamente em função do tempo e sua direção está no eixo x, então a luz é linearmente polarizada na direção de $x$. Caso contrário, a luz seria linearmente polarizada na direção de y, conforme ilustrado na Figura 2.4.

A onda é, também, linearmente polarizada se

$$
\phi=\phi_{1}-\phi_{2}=m \pi(m=0, \pm 1, \pm 2, \ldots)
$$




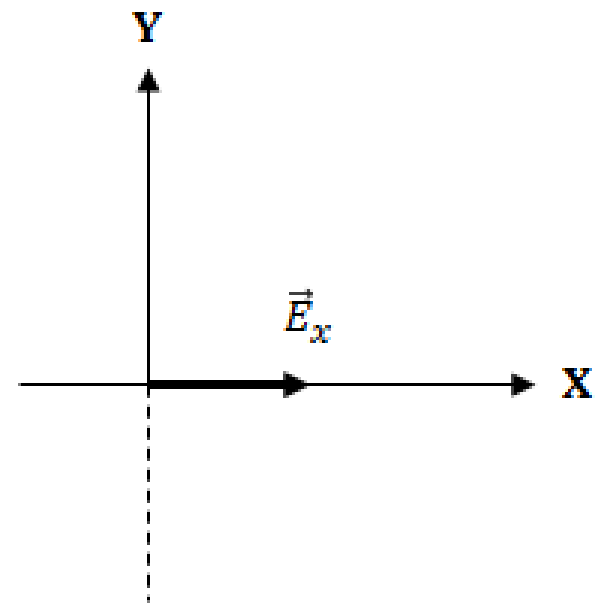

(A)

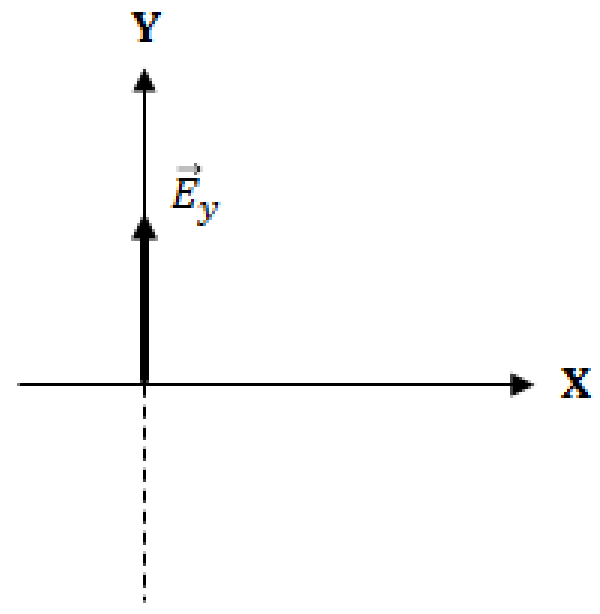

(B)

Figura 2.4: Polarização linear na direção: (A) x e (B) y.

Então,

$$
\frac{E_{y}}{E_{x}}=(-1) m \frac{E_{y o}}{E_{x o}}
$$

E os vetores $E_{x}(t)$ e $E_{y}(t)$ parametrizam uma reta passando pela origem. Logo, o ângulo que a reta forma com o eixo x é dado por:

$$
\theta=\tan ^{-1}\left(\frac{E_{\text {yo }}}{E_{\text {xo }}}\right)
$$

Assim, este tipo de polarização é chamada polarização linearmente polarizada na direção $\theta$, como mostrado na Figura 2.2 (A).

\subsection{3}

\section{Polarização Circular}

Considere, a partir da equação (2-2), o caso particular:

$$
\begin{gathered}
E_{x o}=E_{y o}=E_{0} \\
\phi_{x}=\phi_{y}+\frac{\pi}{2}
\end{gathered}
$$

Resultando nas seguintes equações paramétricas em relação ao plano do observador $(z=0)$ :

$$
E_{x}(t)=E_{o x} \cos \left(\omega t+\phi_{x}\right)
$$




$$
E_{y}(t)=E_{\text {oy }} \cos \left(\omega t+\frac{\pi}{2}\right)=-E_{\text {oy }} \sin \left(\omega t+\phi_{y}\right)
$$

Na paramétrica de uma circunferência o campo elétrico gira ao longo do tempo no sentido horário com frequência angular $\omega$. Por isso, a onda eletromagnética apresenta uma polarização circular à direita.

Então alterando a equação (2-19).

$$
\begin{gathered}
E_{x o}=E_{y o}=E_{0} \\
\phi_{x}=\phi_{y}-\frac{\pi}{2}
\end{gathered}
$$

Resulta nas equações paramétricas em $z=0$ :

$$
\begin{gathered}
E_{x}(t)=E_{\text {ox }} \cos \left(\omega t+\phi_{x}\right) \\
E_{y}(t)=E_{\text {oy }} \cos \left(\omega t-\frac{\pi}{2}\right)=E_{\text {oy }} \sin \left(\omega t+\phi_{y}\right)
\end{gathered}
$$

Para o caso do vetor de campo elétrico se propagar no sentido antihorário, a onda eletromagnética descreve uma palarização circular à esquerda. A figura 2.5 descreve a trajetória do campo elétrico de uma onda circularmente polarizada.
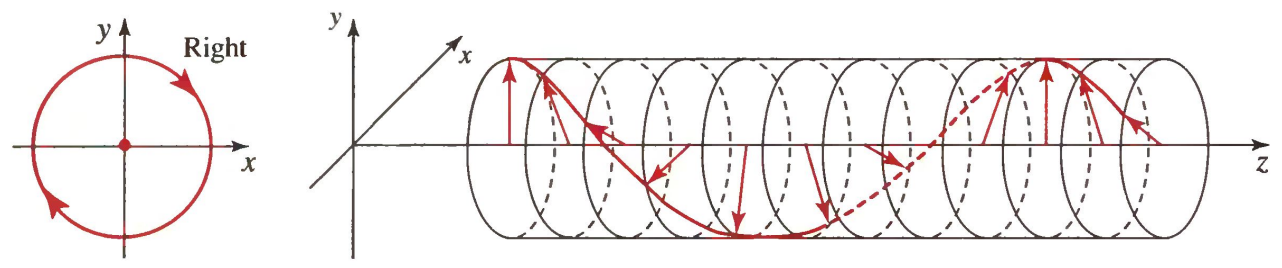

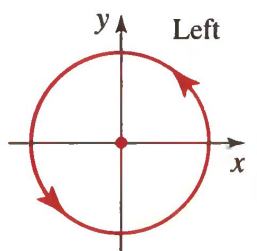

(a)

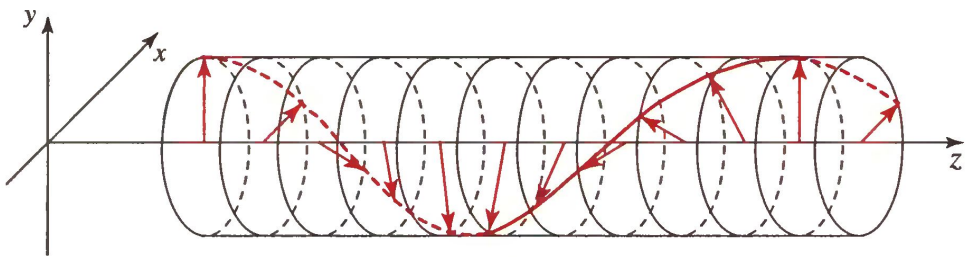

(b)

Figura 2.5: Onda polarizada circularmente (11). 


\section{2}

\section{Representação dos Estados de Polarização}

As seções a seguir descrevem um sistema capaz de representar todas as configurações dos parâmetros $E_{x}, E_{y}, \phi_{x}$ e $\phi_{y}$, sendo denominados estados de polarização.

R.C Jones (1940) e Sir George Stokes (1852) desenvolveram seus trabalhos a fim de encontrar uma representação para os estados de polarização.

\subsection{1}

\section{Representação por Vetor de Jones}

Os componentes da onda plana podem ser escritos em termos de quantidade complexa:

$$
\begin{aligned}
& E_{x}(z, t)=E_{o x} e^{i \phi_{x}} \\
& E_{y}(z, t)=E_{o y} e^{i \phi_{y}}
\end{aligned}
$$

As equações (2-26) e (2-27) são rearranjadas em uma matriz coluna E $2 \times 1:$

$$
E=\left[\begin{array}{l}
E_{o x} e^{i \phi_{x}} \\
E_{o y} e^{i \phi_{y}}
\end{array}\right]
$$

O vetor acima é chamado vetor de Jones. O valor total da intensidade $I$ do campo elétrico óptico é dado por:

$$
I=E_{o x}^{2}+E_{o y}^{2}=E^{\dagger} E
$$

Onde $E^{\dagger}$ (transposto conjugado) representa o hermitiano de E, podendo ser dito que o vetor de Jones está normalizado, pois é levado em consideração que a luz possui intensidade unitária.

O vetor de Jones pode ser somente utilizado para descrever luz completamente polarizada. O formalismo de Jones é utilizado quando é tratado o fenômeno de interferência ou problemas onde a amplitude dos campos devem ser superpostas (1).

Para um estado de polarização linear onde as componentes $x$ e $y$ estão em fase ou em oposição de fase $(\theta=0, \pi)$, obtemos: 


$$
E=\left[\begin{array}{c}
\cos \theta \\
\pm \sin \theta
\end{array}\right]
$$

Os estados de polarização linear que estão associados com o eixo x ou com o eixo y nas direções $\theta=0$ e $\theta=\frac{\pi}{2}$, são denominados estados de polarização em X ou $\mathrm{Y}$, respectivamente:

$$
X=\left[\begin{array}{l}
1 \\
0
\end{array}\right] \quad Y=\left[\begin{array}{l}
0 \\
1
\end{array}\right]
$$

Para os estados de polarização cirdular, as componentes $x$ e $y$ possuem a mesma amplitude de campo elétrico, encontrando-se em quadratura de fase $\left(\phi=\frac{\pi}{2}, 3 \frac{\pi}{2}\right)$. Assim, os vetores de Jones normalizados para a polarização circular são representados por:

$$
E=\frac{1}{\sqrt{2}}\left[\begin{array}{l}
1 \\
j
\end{array}\right] \quad D=\frac{1}{\sqrt{2}}\left[\begin{array}{c}
1 \\
-j
\end{array}\right]
$$

O vetor $E$ é associado a luz circularmente polarizada à esquerda e $D$ representa a luz circulamente polarizada à direita. Esses vetores são ortogonormais e satisfazem a condição $E^{\dagger} E$, sendo escritos como:

$$
X=\frac{1}{\sqrt{2}}[E+D] \quad Y=\frac{j}{\sqrt{2}}[E-D]
$$

Os estados de polarização elípticos podem ser representados como uma combinação linear dos estados lineares ou circulares e pelo vetor de Jones normalizado que depende de dois parâmetros, o ângulo $\chi$ e a diferençe fase $\phi$ entre os componentes cartesianos, que é:

$$
E=\left[\begin{array}{c}
\cos \chi \\
\sin \chi e^{j \phi}
\end{array}\right]
$$


O vetor de Jones descreve componentes de amplitudes de campo elétrico $E_{x}$ e $E_{y}$ que caracterizam os estados de polarização da luz em termos não observáveis em laboratório. Além disso, a representação por vetor de Jones somente é aplicável para a luz completamente polarizada, excluindo os casos de luz despolarizada e parcialmente polarizada.

\section{3}

\section{Parâmetros de Stokes}

Em 1852, Sir George Gabriel Stokes descobriu que qualquer estado de luz polarizada poderia ser descrito por quatro quantidades mensuráveis denominadas parâmetros de Stokes . Os parâmetros de Stokes são agrupados em um vetor coluna $S$ com quatro elementos, definido como:

$$
S=\left[\begin{array}{c}
S_{o} \\
S_{1} \\
S_{2} \\
S_{3}
\end{array}\right]=\left[\begin{array}{c}
I_{x}+I_{y} \\
I_{x}-I_{y} \\
I_{+45}-I_{-45} \\
I_{E}-I_{D}
\end{array}\right]
$$

Assim, $I_{x}$ e $I_{y}$ representam as intensidades nos eixos $x$ e $y$, respectivamente; $I_{+45}$ e $I_{-45}$ são as intensidades das componentes em $45^{\circ}$ nos eixos $x$ e $y ; I_{C}$ e $I_{D}$ são as intensidades das componentes circularmente polarizadas à direita e à esquerda.

Os parâmetros de Stokes para uma onda plana são obtidos a partir de:

$$
\begin{gathered}
S_{0}=E_{x} E_{x}^{*}+E_{y} E y^{*} \\
S_{1}=E_{x} E_{x}^{*}-E_{y} E y^{*} \\
S_{2}=E_{x} E_{y}^{*}-E_{y} E x^{*} \\
S_{3}=i\left(E_{x} E_{y}^{*}-E_{y} E x^{*}\right)
\end{gathered}
$$

Substituindo as amplitudes complexas da onda plana (2-26) e (2-27) na representação complexa dos parâmetros de Stokes da equação em (2-36), obtém-se: 


$$
\begin{array}{r}
S_{0}=E_{o x}^{2}+E_{o y}^{2} \\
S_{1}=E_{o x}^{2}-E_{o y}^{2} \\
S_{2}=2 E_{o x} E_{o y} \cos \delta \\
S_{3}=2 E_{o x} E_{o y} \sin \delta
\end{array}
$$

O parâmetro $S_{o}$ representa a intensidade total da luz para as componentes polarizadas e despolarizadas:

$$
S_{o}=S_{\text {polarizada }}+S_{\text {despolarizada }}
$$

Os parâmetros de Stokes relacionam-se com os ângulos de orientação e elipsidade, $\psi$ e $\chi$, associando-se à esfera de Poncaré:

$$
\begin{gathered}
S_{1}=S_{o} \cos (2 \psi) \cos (2 \chi) \\
S_{2}=S_{o} \cos (2 \psi) \sin (2 \chi) \\
S_{3}=S_{o} \sin (2 \psi)
\end{gathered}
$$

Rearrumando (2-39) para a forma de vetor, tem-se:

$$
S=S_{0}\left[\begin{array}{c}
1 \\
\cos (2 \psi) \cos (2 \chi) \\
\cos (2 \psi) \sin (2 \chi) \\
S_{o} \sin (2 \psi)
\end{array}\right]
$$

Onde,

$$
\psi=\frac{1}{2} \tan ^{-1}\left(\frac{S_{2}}{S_{1}}\right) \quad 0 \leq \psi \leq \pi
$$




$$
\chi=\frac{1}{2} \sin ^{-1}\left(\frac{S_{3}}{S_{0}}\right) \quad-\frac{\pi}{4} \leq \psi \leq \frac{\pi}{4}
$$

Os parâmetros de Stokes definem grau de polarização ou DOP para qualquer estado de polarização:

$$
D O P=\frac{I_{\text {pol }}}{I_{\text {total }}}=\frac{\left(S_{1}^{2}+S_{2}^{2}+S_{3}^{2}\right)^{\frac{1}{2}}}{S_{o}} \quad 0 \leq D O P \leq 1
$$

Onde cada $s_{i}=\frac{S_{i}}{S_{o}}$ é denominado parâmetro de Stokes normalizado, $I_{\text {pol }}$ é a soma das componenentes e $I_{t o t}$ a intensidade total do feixe. Para $D O P=1$ a luz é completamente polarizada, $D O P=0$ corresponde a luz despolarizada e $0 \leq D O P \leq 1$ à luz parcialmente polarizada.

O espaço geométrico onde todos os estados possíveis de polarização podem ser representados por um ponto $\left(s_{1}, s_{2}, s_{3}\right)$ na superfície de raio unitário, com coordenadas $(r=1, \theta=90-2 \psi, \phi=2 \chi)$ em um sistema de coordenada esférica é chamado Esfera de Poincaré.

Cada ponto na esfera representa um estado de polarização em termos de $\chi$ e $\psi$, descrevendo a elipsidade e a orientação, respectivamente. Os estados de polarização situados no equador da esfera descreve o estado de polarização linear, os estados de polarização circular à direita e esquerda estão nos polos norte e sul e os demais pontos da esfera respresentam os estados de polarização elípticos.

\section{4}

\section{Formalismo de Mueller}

Um feixe incidente pode interagir com um ou mais elementos de polarização, onde adquire um novo $S O P(8)$. O feixe de entrada é caracterizado pelos parâmetros de Stokes $S_{i}^{\prime}$ e o feixe de saída é dado por $S_{i}$, sendo $i=0,1,2,3$. Assim, os parâmetros de Stokes podem ser expressos forma de uma combinação linear: 
Medição de Perdas Dependentes da Polarização Utilizando Mistura de Frequências em Fotodiodos

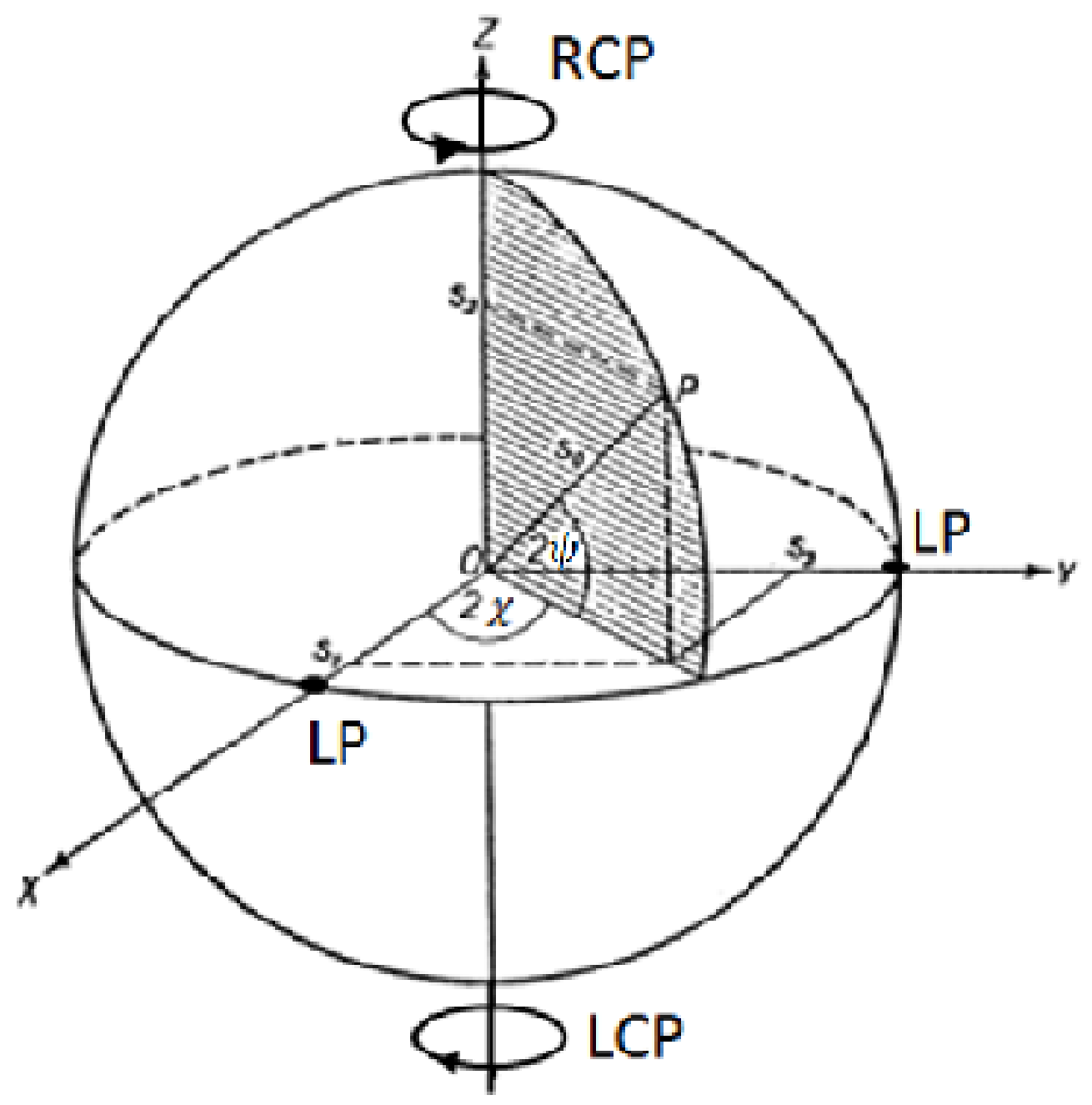

Figura 2.6: Representação da esfera de Poincaré (8).

$$
\begin{aligned}
& S_{0}^{\prime}=m_{00} S_{0}+m_{01} S_{1}+m_{02} S_{2}+m_{03} S_{3} \\
& S_{1}^{\prime}=m_{10} S_{1}+m_{11} S_{1}+m_{12} S_{2}+m_{13} S_{3} \\
& S_{2}^{\prime}=m_{20} S_{1}+m_{21} S_{1}+m_{22} S_{2}+m_{23} S_{3} \\
& S_{3}^{\prime}=m_{30} S_{1}+m_{31} S_{1}+m_{32} S_{2}+m_{33} S_{3}
\end{aligned}
$$

Escrita na forma de matriz: 


$$
\left[\begin{array}{c}
S_{0}^{\prime} \\
S_{1}^{\prime} \\
S_{2}^{\prime} \\
S_{3}^{\prime}
\end{array}\right]=\left[\begin{array}{llll}
m_{10} & m_{11} & m_{12} & m_{13} \\
m_{20} & m_{21} & m_{22} & m_{23} \\
m_{30} & m_{31} & m_{32} & m_{33} \\
m_{40} & m_{41} & m_{42} & m_{43}
\end{array}\right]\left[\begin{array}{c}
S_{0} \\
S_{1} \\
S_{2} \\
S_{3}
\end{array}\right]
$$

Ou na forma,

$$
S^{\prime}=M \cdot S
$$

Todos os elementos na matriz de Mueller $4 \times 4$ são quantidades reais e foram introduzidos por Hans Mueller em 1940, sendo este o primeiro a descrever componentes de polarização em termos de matriz de Mueller.

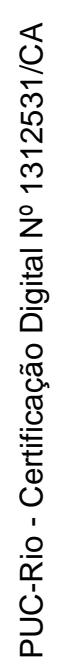

\subsection{1}

Matriz de Mueller de uma PDL

O elemento de polarização que altera a amplitude do feixe é denominado polarizador linear, que são caracterizados por dois coeficientes de atenuação, $p_{x}$ e $p_{y}$, ao longo dos eixos x e y, como mostra a Figura 2.7.

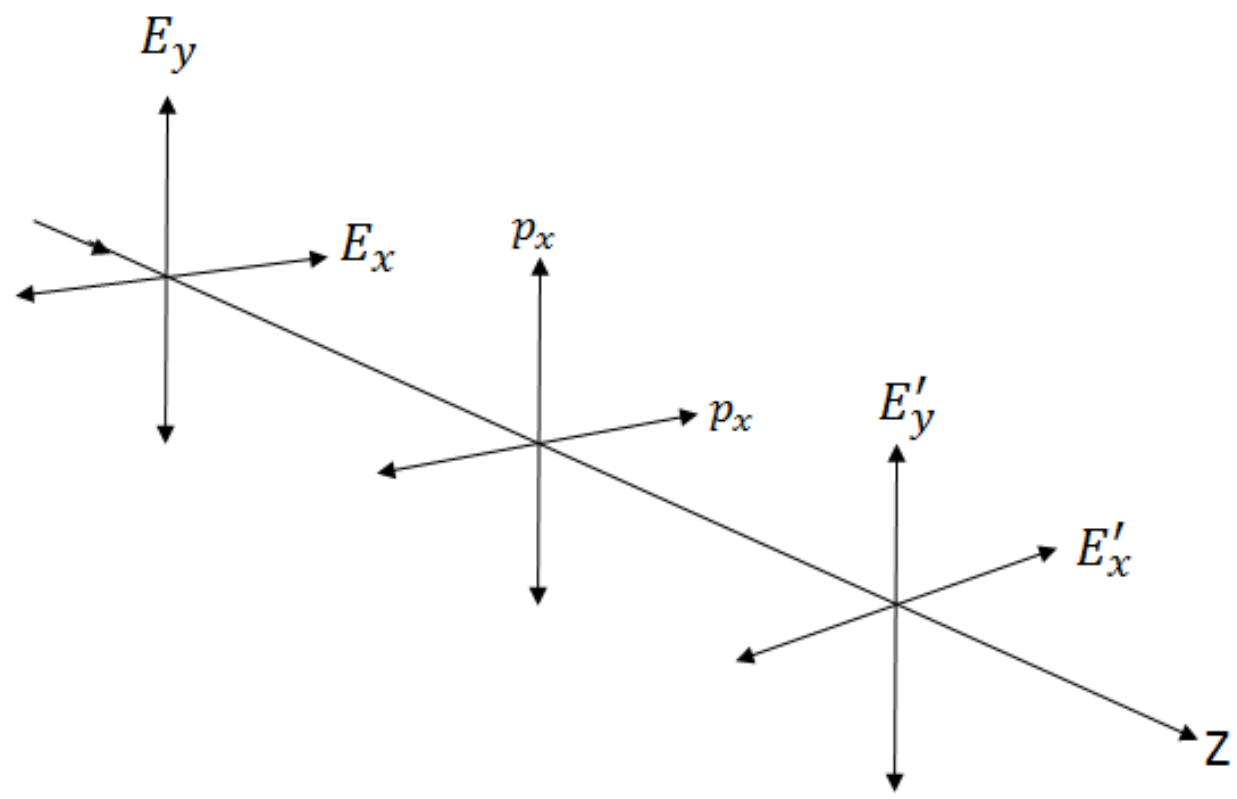

Figura 2.7: Polarizador com os coeficientes de atenuação x e y (8). 
Os campos são relacionados por:

$$
\begin{array}{ll}
E_{x}^{\prime}=p_{x} E_{x} & 0 \leq p_{x} \leq 1 \\
E_{y}^{\prime}=p_{y} E_{y} & 0 \leq p_{y} \leq 1
\end{array}
$$

Os fatores $p_{x}$ e $p_{y}$ são os coeficientes de atenuação ao longo do eixo de transmissão. Para uma transmissão perfeita ou sem atenuação $p_{x}\left(p_{y}\right)$ possui valor 1 e zero para uma atenuação total $p_{x}\left(p_{y}\right)$.

Substituindo a equação (2-45) em (2-47) obtém-se a matriz de Mueller para um polarizador linear com atenuaes ao longo dos eixos $p_{x}$ e $p_{y}$ :

$$
M=\frac{1}{2}\left[\begin{array}{cccc}
p_{x}^{2}+p_{y}^{2} & p_{x}^{2}-p_{y}^{2} & 0 & 0 \\
p_{x}^{1}-p_{y}^{2} & p_{x}^{2}+p_{y}^{2} & 0 & 0 \\
0 & 0 & 2 p_{x} p_{y} & 0 \\
0 & 0 & 0 & 2 p_{x} p_{y}
\end{array}\right]
$$

Quando as componentes ortogonais do feixe de incidência são atenuadas igualmente, o polarizador torna-se um filtro de densidade neutra $p_{x}=p_{y}=p$ e a Equação (2-48) passa a ser:

$$
M=p^{2}\left[\begin{array}{llll}
1 & 0 & 0 & 0 \\
0 & 1 & 0 & 0 \\
0 & 0 & 1 & 0 \\
0 & 0 & 0 & 1
\end{array}\right]
$$

Na equação (2-49) o estado de polarização não é alterado, mas a intensidade do feixe de entrada é reduzido por um fator de $p^{2}$.

Um polarizador linear ideal possui transmissão somente ao longo de um dos eixos ortogonais e a matriz de Mueller em $p_{y}=0$ que descreve comportamento é dada por: 


$$
M=\frac{p_{x}}{2}\left[\begin{array}{llll}
1 & 1 & 0 & 0 \\
1 & 1 & 0 & 0 \\
0 & 0 & 0 & 0 \\
0 & 0 & 0 & 0
\end{array}\right]
$$

A matriz para um polarizador linear perfeito com fator unitário $\left(p_{x}=1\right)$ na direção $x$ é:

$$
M=\frac{1}{2}\left[\begin{array}{llll}
1 & 1 & 0 & 0 \\
1 & 1 & 0 & 0 \\
0 & 0 & 0 & 0 \\
0 & 0 & 0 & 0
\end{array}\right]
$$

E para um polarizador linear vertical em $p_{y}=0$ :

$$
M=\frac{1}{2}\left[\begin{array}{cccc}
1 & -1 & 0 & 0 \\
-1 & 1 & 0 & 0 \\
0 & 0 & 0 & 0 \\
0 & 0 & 0 & 0
\end{array}\right]
$$

Um polarizador fixo na direção $x$ e outro orientado na direção $y$ tem-se um polarizador cruzado, conforme Figura 2.8.

O vetor de Stokes que se propaga até o segundo polarizador é:

$$
S^{\prime \prime}=M_{h} S=M_{h} M_{v} S
$$

Substituindo a equação (2-51) e (2-52) na equação (2-53), a matriz de Mueller para o polarizador cruzado : 


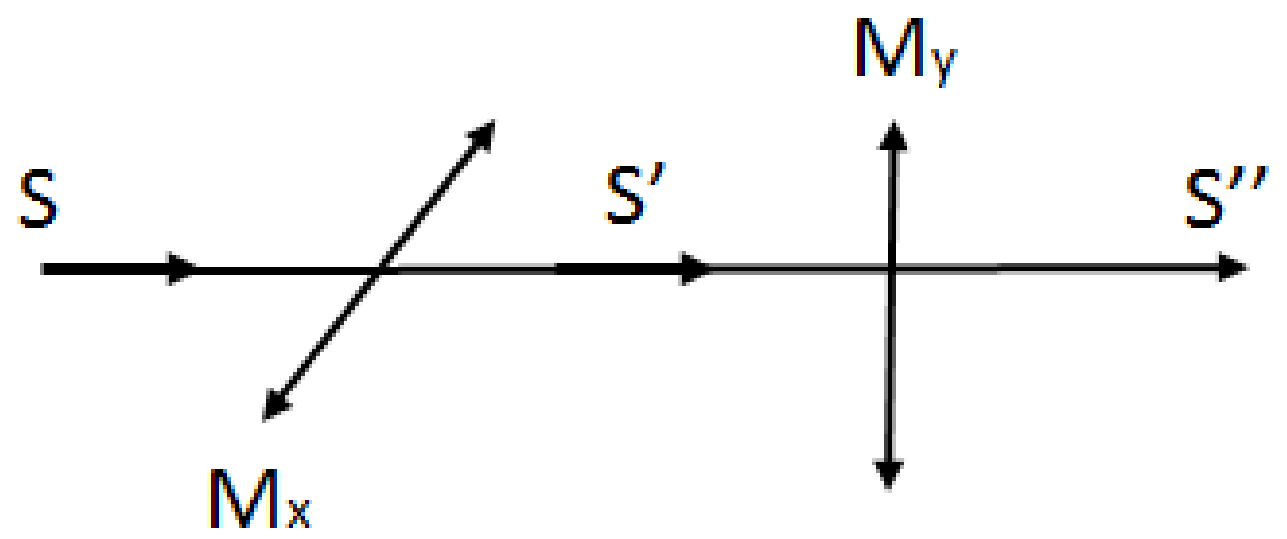

Figura 2.8: Polarizador Linear Cruzado (8).

$$
M=\frac{1}{4}\left[\begin{array}{cccc}
1 & -1 & 0 & 0 \\
-1 & 1 & 0 & 0 \\
0 & 0 & 0 & 0 \\
0 & 0 & 0 & 0
\end{array}\right]\left[\begin{array}{llll}
1 & 1 & 0 & 0 \\
1 & 1 & 0 & 0 \\
0 & 0 & 0 & 0 \\
0 & 0 & 0 & 0
\end{array}\right]=\left[\begin{array}{llll}
0 & 0 & 0 & 0 \\
0 & 0 & 0 & 0 \\
0 & 0 & 0 & 0 \\
0 & 0 & 0 & 0
\end{array}\right]
$$

A matriz nula obtida na Equação 2-54 mostra que a luz não emerge quando os polarizadores são cruzados.

\subsection{2}

\section{Matriz de Mueller para Lâminas de Onda}

As Lâminas de onda possuem a propriedade de alterar a fase do feixe óptico, introduzindo uma fase de $+\phi / 2$ na componente $x$ do campo e, de modo semelhante no eixo $y$ uma fase de $-\phi / 2$. A Figura 2.9 mostra a propagação de um feixe óptico através de uma lâmina de onda.

A matriz de Mueller para uma lâmina de onda é dada por:

$$
M=\left[\begin{array}{cccc}
1 & 0 & 0 & 0 \\
0 & 1 & 0 & 0 \\
0 & 0 & \cos \phi & \sin \phi \\
0 & 0 & -\sin \phi & \cos \phi
\end{array}\right]
$$




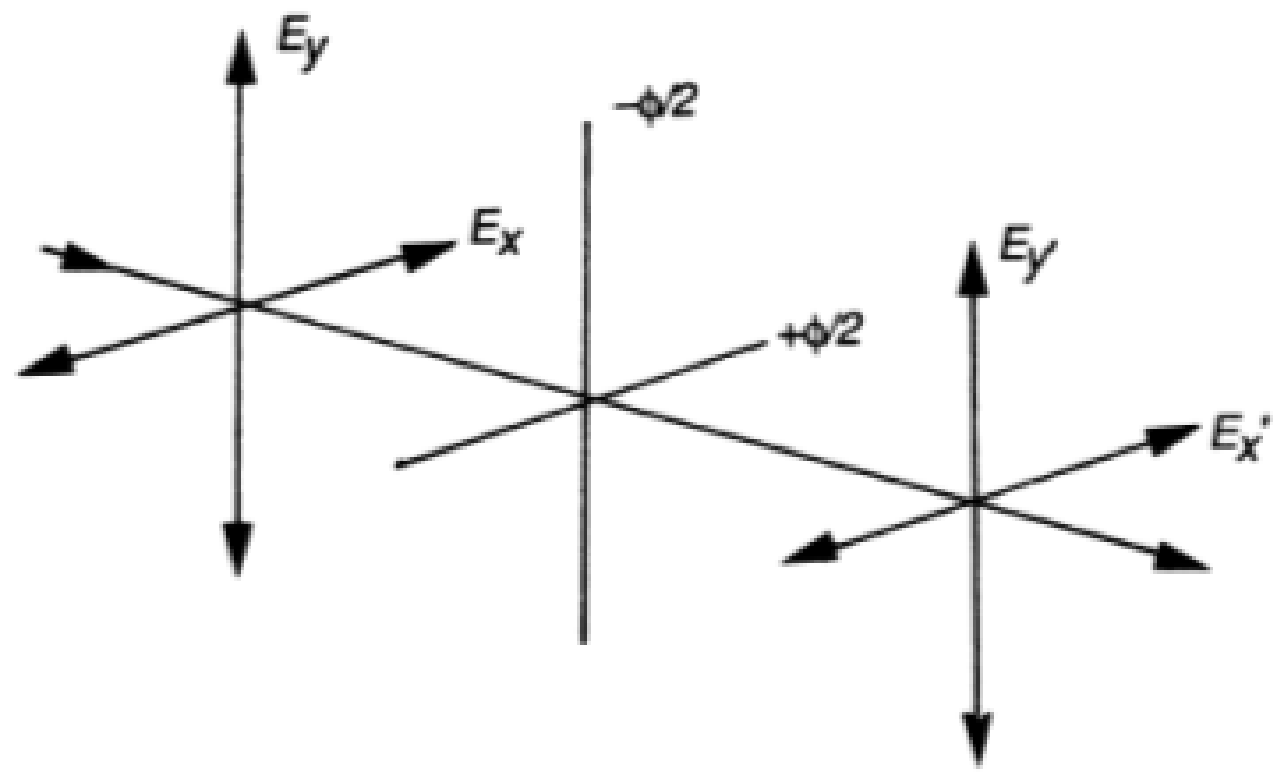

Figura 2.9: Configuração para uma lâmina de onda. Propagação feixe óptico através da lâmina. (8).

Onde é a diferença de fase entre os componentes do feixe.

$$
\begin{aligned}
\phi & =\phi_{x}-\phi_{y} \\
& =+\frac{\phi}{2}-\left(-\frac{\phi}{2}\right)
\end{aligned}
$$

As lâminas de onda possuem duas formas importantes: a lâmina de um quarto de onda (quarter-wave plate - QWP) com $\phi=\pi / 2$, e a lâmina de meia onda (half-wave plate - HWP) $\operatorname{com} \phi=\pi$.

$$
M_{Q W P}=\left[\begin{array}{cccc}
1 & 0 & 0 & 0 \\
0 & 1 & 0 & 0 \\
0 & 0 & 0 & -1 \\
0 & 0 & -1 & 0
\end{array}\right] \quad M_{H W P}=\left[\begin{array}{cccc}
1 & 0 & 0 & 0 \\
0 & 1 & 0 & 0 \\
0 & 0 & -1 & 0 \\
0 & 0 & 0 & -1
\end{array}\right]
$$

A $Q W P$ possui uma propriedade que transforma luz com polarização linear $+45^{\circ}$ em luz $R C P$. Isto é mostrado seguindo os cálculos do vetor de Stokes: 


$$
S_{\text {out }}=\left[\begin{array}{cccc}
1 & 0 & 0 & 0 \\
0 & 1 & 0 & 0 \\
0 & 0 & 0 & -1 \\
0 & 0 & -1 & 0
\end{array}\right]\left[\begin{array}{l}
1 \\
0 \\
1 \\
0
\end{array}\right]=\left[\begin{array}{l}
1 \\
0 \\
0 \\
1
\end{array}\right]
$$

Para a luz $R C P$ ser transformada em luz com polarizao linear $+45^{\circ}$ :

$$
S_{\text {out }}=\left[\begin{array}{cccc}
1 & 0 & 0 & 0 \\
0 & 1 & 0 & 0 \\
0 & 0 & 0 & -1 \\
0 & 0 & 1 & 0
\end{array}\right]\left[\begin{array}{l}
1 \\
0 \\
0 \\
1
\end{array}\right]=\left[\begin{array}{c}
1 \\
0 \\
-1 \\
0
\end{array}\right]
$$

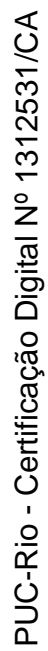

A $H W P$ tem a propriedade de inverter os ângulos de elipsidade e a orientação da polarização elíptica:

$$
S_{\text {out }}=\left[\begin{array}{cccc}
1 & 0 & 0 & 0 \\
0 & 1 & 0 & 0 \\
0 & 0 & -1 & 0 \\
0 & 0 & 0 & -1
\end{array}\right]\left[\begin{array}{c}
1 \\
\cos 2 \chi \cos 2 \psi \\
\cos 2 \chi \sin 2 \psi \\
\sin 2 \chi
\end{array}\right]=\left[\begin{array}{c}
1 \\
\cos 2 \chi \cos 2 \psi \\
-\cos 2 \chi \sin 2 \psi \\
-\sin 2 \chi
\end{array}\right]
$$

\subsection{3}

\section{Matriz de Mueller de um Rotator}

O rotator é um elemento de polarização que altera o $S O P$ de um campo óptico girando as componentes ortogonais $E_{x}(z, t)$ e $E_{y}(z, t)$ em torno de um ângulo $\theta$, que descreve a rotação de $E_{x}$ para $E_{x}^{\prime}$ e de $E_{y}$ para $E_{y}^{\prime}$, conforme a Figura 2.10.

A matriz de Mueller para um rotator é: 


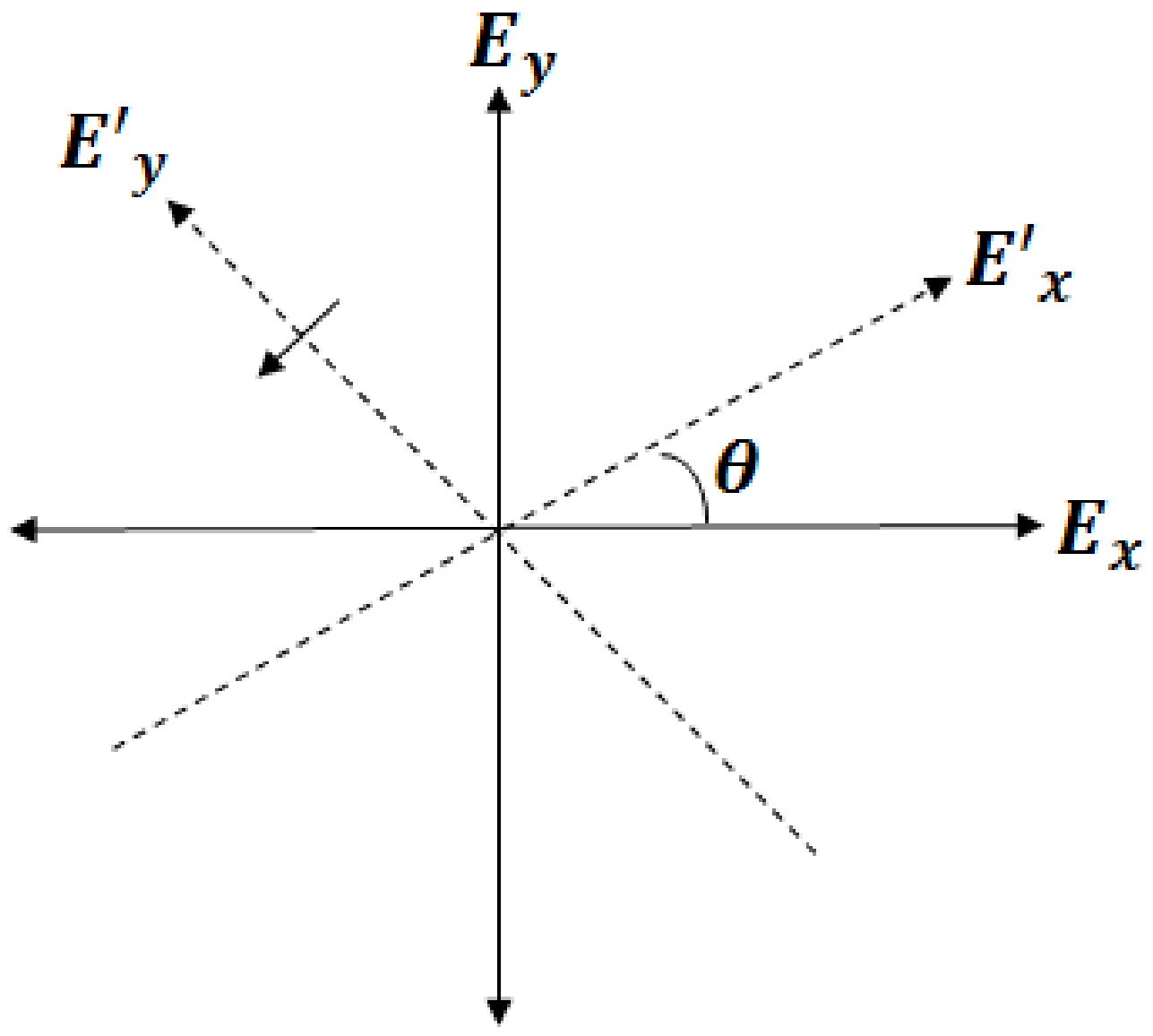

Figura 2.10: Eixo de Rotação para as componentes de campo óptico.

$$
M_{R o t}(2 \theta)=\left[\begin{array}{cccc}
1 & 0 & 0 & 0 \\
0 & \cos 2 \theta & \sin 2 \theta & 0 \\
0 & -\sin 2 \theta & \cos 2 \theta & 0 \\
0 & 0 & 0 & 1
\end{array}\right]
$$

Os rotatores são utilizados para alterar o ângulo de orientação da polarização elípse, mas não afeta a elipsidade $(\chi)$.

O eixo dos componentes de polarização são rotacionados em torno do ângulo $\theta$ ao longo dos eixos $x^{\prime}$ e $y^{\prime}$. Vamos considerar o vetor de Stokes $S$ do feixe incidente, tem-se:

$$
S^{\prime}=M_{R}(2 \theta) S
$$

Onde $M_{R}(2 \theta)$ é a matriz de Mueller da equação (2-61) e $S^{\prime}$ é o vetor de Stokes para o feixe que vai incidir nos eixos $x^{\prime}$ e $y^{\prime}$ e interagir com a sua 
matriz de Mueller $M$, gerando o vetor $S$ " a partir do elemento de polarização rotacionado:

$$
S^{\prime \prime}=M M_{R}(2 \theta) S
$$

Em seguida, $S^{\prime \prime}$ sofrerá uma rotação no sentido antihorário $(-\theta)$ a fim de retornar ao eixo $x$ e $y$ inicial, então

$$
\begin{aligned}
S^{\prime \prime \prime}= & M S^{\prime}=M M_{R}(-2 \theta) S^{\prime \prime} \\
& =M_{R}(-2 \theta) M M_{R}(2 \theta)
\end{aligned}
$$

A figura 2.11 mostra as componentes ópticas emergindo do elemento de polarização rotacionado.

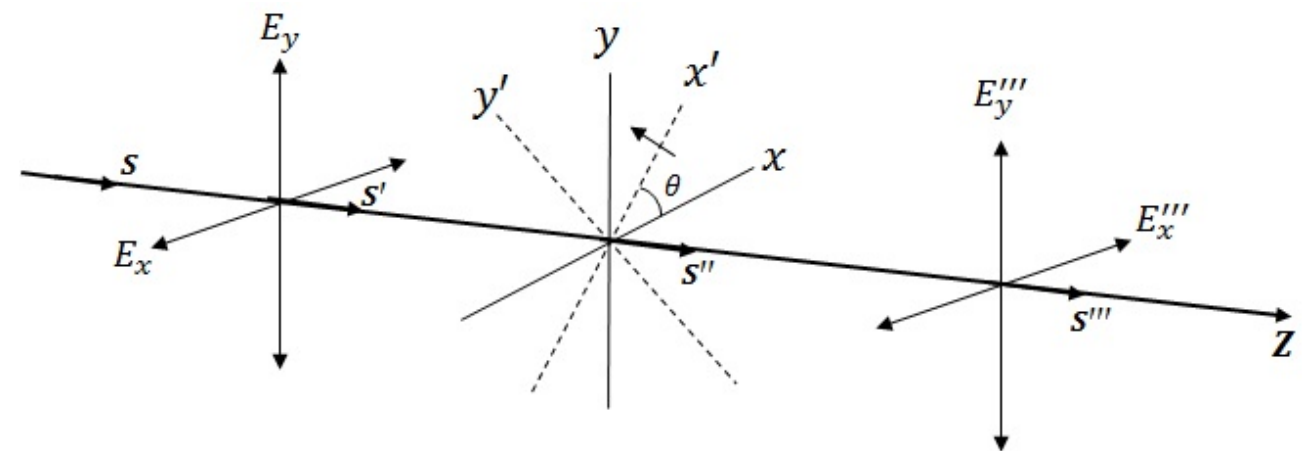

Figura 2.11: Eixo óptico emergindo do elemento de polarização rotacionado.

A matriz de Mueller para um polarizador ideal com seu eixo de transmissão paralelo à $x$, paralelo à $y$, e rotacionado em relação à um ângulo $\theta$ :

$$
M_{P}(2 \theta)=\frac{1}{2}\left[\begin{array}{cccc}
1 & \cos 2 \theta & \sin 2 \theta & 0 \\
\cos 2 \theta & \cos ^{2} 2 \theta & \sin 2 \theta \cos 2 \theta & 0 \\
\sin 2 \theta & \sin 2 \theta \cos 2 \theta & \sin ^{2} 2 \theta & 0 \\
0 & 0 & 0 & 0
\end{array}\right]
$$

A Matriz (2-65) para $\theta=0^{\circ}, 45^{\circ}$ e $90^{\circ}$ se reduz à: 


$$
\begin{gathered}
M_{L H P}=\frac{1}{2}\left[\begin{array}{llll}
1 & 1 & 0 & 0 \\
1 & 1 & 0 & 0 \\
0 & 0 & 0 & 0 \\
0 & 0 & 0 & 0
\end{array}\right] \quad M_{L+45 P}=\frac{1}{2}\left[\begin{array}{cccc}
1 & 0 & 1 & 0 \\
0 & 0 & 0 & 0 \\
1 & 0 & 1 & 0 \\
0 & 0 & 0 & 0
\end{array}\right] \\
M_{L V P}=\frac{1}{2}\left[\begin{array}{cccc}
1 & -1 & 0 & 0 \\
-1 & 1 & 0 & 0 \\
0 & 0 & 0 & 0 \\
0 & 0 & 0 & 0
\end{array}\right] \quad M_{L H P}=\frac{1}{2}\left[\begin{array}{cccc}
1 & -1 & 0 & 0 \\
-1 & 1 & 0 & 0 \\
0 & 0 & 0 & 0 \\
0 & 0 & 0 & 0
\end{array}\right]
\end{gathered}
$$

A matriz de Mueller para uma lâmina de onda rotacionada é dada por:

$$
M_{P}(2 \theta)=\left[\begin{array}{cccc}
1 & 0 & 0 & 0 \\
1 & \cos ^{2} 2 \theta+\cos \phi \sin ^{2} 2 \theta & (1-\cos \phi) \sin 2 \phi \cos 2 \theta & \sin \phi \sin 2 \theta \\
0 & (1-\cos \phi) \sin 2 \theta \cos 2 \theta & \sin ^{2} 2 \theta+\cos 2 \phi \cos ^{2} 2 \theta & -\sin \phi \sin 2 \theta \\
0 & -\sin 2 \phi \sin 2 \theta & \sin 2 \theta \cos 2 \theta & \cos \phi
\end{array}\right]
$$

Uma forma importante da matriz (2-68) para um deslocamento de fase $\phi=180^{\circ}$ é a matriz para uma HWP rotacionada:

$$
M_{H W P}(\theta)=\left[\begin{array}{cccc}
1 & 0 & 0 & 0 \\
1 & \cos 4 \theta & \sin 4 \theta & 0 \\
0 & \sin 4 \theta & \cos 4 \theta & 0 \\
0 & 0 & 0 & -1
\end{array}\right]
$$




\section{5}

\section{Formalismo de Jones}

Como visto na seção 2.2 é possível representar os estados de polarização da luz na forma de vetor de Jones. Quando a luz atravessa ou é refletida por um dispositivo óptico seu estado de polarização é alterado (11).

Seja, $J$ um operador linear que descreve um sistema óptico, $E$ o vetor de Jones que representa o estado de polarização na estrada do dispositivo óptico e o estado final do mesmo é representado por:

$$
E^{\prime}=J E
$$

Podendo ser escrita na forma de matriz:

$$
\left[\begin{array}{c}
E_{x}^{\prime} \\
E_{y}^{\prime}
\end{array}\right]=\left[\begin{array}{ll}
J_{x x} & J_{x y} \\
J_{y x} & J_{y y}
\end{array}\right]\left[\begin{array}{c}
E_{x} \\
E_{y}
\end{array}\right]
$$

Onde $T$ é uma matriz linear $2 \times 2$ denominada Matriz de Jones, sendo possível determinar uma matriz de Jones para qualquer dispositivo óptico.

Assume-se que os componentes de um feixe emergente, a partir de um elemento de polarização, está linearmente relacionado aos componentes do feixe emergente, descrita como:

$$
\begin{aligned}
& E_{x}^{\prime}=J_{x x} E_{x}+J_{x y} E_{y} \\
& E_{y}^{\prime}=J_{y x} E_{x}+J_{y y} E_{y}
\end{aligned}
$$

Onde, $E_{x}$ e $E_{y}$ são as componenentes dos feixes de entrada ou incidentes e $E_{x}^{\prime}$ e $E_{y}^{\prime}$ descrevem as componentes de saída da onda, refletido ou transmitido.

\section{6}

\section{Matrizes de Jones em Dispositivos Ópticos}

Um polarizador é caracterizado pelas relações:

$$
\begin{aligned}
& E_{x}^{\prime}=p_{x} E_{x} \\
& E_{y}^{\prime}=p_{y} E_{y}
\end{aligned}
$$


Para transmissão completa $p_{x, y}=1$, e quando ocorre atenuação $p_{x, y}=0$. Tal que a matriz de Jones para um polarizador é:

$$
J_{p}=\left[\begin{array}{cc}
p_{x} & 0 \\
0 & p_{y}
\end{array}\right] \quad 0 \leq p_{x, y} \leq 1
$$

Um polarizador linear ideal com transmissão ao longo do eixo $x$, sendo $p_{x}=1$ e $p_{y}=0$ é definido por:

$$
J_{p H}=\left[\begin{array}{ll}
1 & 0 \\
0 & 0
\end{array}\right]
$$

De modo semelhante, o polarizador linear no eixo vertical é definido como:

$$
J_{p V}=\left[\begin{array}{ll}
0 & 0 \\
0 & 1
\end{array}\right]
$$

Para um elemento de polarização deslocado por um ângulo $\theta$, a matriz de Jones é dada por:

$$
J(\theta)=J_{R O T}(-\theta) J J_{R O T}(\theta)
$$

Onde $J(\theta)$ é a matriz de rotação:

$$
J(\theta)=\left[\begin{array}{cc}
\cos \theta & \sin \theta \\
-\sin \theta & \cos \theta
\end{array}\right]
$$

Substituindo (2-76) e (2-80) em (2-79), obtem-se a matriz de Jones para o polarizador:

$$
J_{p}(\theta)=\left[\begin{array}{ll}
p_{x} \cos ^{2} \theta+p_{y} \sin ^{2} \theta & \left(p_{x}-p_{y}\right) \sin ^{2} \theta \cos \theta \\
\left(p_{x}-p_{y}\right) \sin ^{2} \theta \cos \theta & p_{x} \sin ^{2} \theta+p_{y} \cos ^{2} \theta
\end{array}\right]
$$


Seja $p_{x}=1$ e $p_{y}=0$, a matriz para um polarizador linear é:

$$
J_{p}(\theta)=\left[\begin{array}{cc}
\cos ^{2} \theta & \sin \theta \cos \theta \\
\sin \theta \cos \theta & \sin ^{2} \theta
\end{array}\right]
$$

Se o elemento óptico sofrer uma defasagem $\phi$ ao longo dos eixos de $x$ e $y$, terá um comportamento descrito por:

$$
J(\theta)=\left[\begin{array}{cc}
e^{+\frac{\phi}{2}} & 0 \\
0 & e^{+\frac{\phi}{2}}
\end{array}\right]
$$

\section{7}

\section{Coerência}

Os feixes de luz apresentam flutuações em função do tempo e do espaço (11). Essas flutuações são descritas em termos de médias estatísticas da função da onda, tornando-se aleatórias.

A intensidade é uma propriedade estatística da luz aleatória, sendo caracterizada pelo número de médias estatísticas:

$$
I(r, t)=\left\langle|E(r, t)|^{2}\right\rangle
$$

Onde o símbolo $\langle$.$\rangle representa a média de várias realizações do processo.$

A função de autocorrelação $G(\tau)$, ou coerência temporal, representa a média temporal para produto do campo elétrico no instante $t$ pelo seu complexo conjugado no instante $t-\tau$, sendo definida por:

$$
G(\tau)=\left\langle E^{*}(t) E(t+\tau)\right\rangle
$$

O sinal periódico pode ser escrito na forma:

$$
G(\tau)=\int_{-T / 2}^{T / 2} E^{*}(t) E(t+\tau) d t
$$

Para uma medida de coerência da luz que é independente da intensidade define-se a partir da normalização da função de autocorrelação: 


$$
g(\tau)=\frac{G(\tau)}{G(0)}=\frac{\left\langle E^{*}(t) E(t+\tau)\right\rangle}{\left\langle E^{*}(t) E(t)\right\rangle}
$$

Denominada grau complexo de coerência temporal, sendo o valor de $|g(\tau)|$ o grau de correlação entre $E(t)$ e $E(t+\tau)$. Caso, $|g(\tau)|=0$ a luz é incoerente, quando $|g(\tau)|=1$ a luz é classificada como coerente e parcialmente coerente para os casos intermediários.

Se $|g(\tau)|$ decresce monotonicamente de acordo com o atraso, o tempo de coerência $\tau_{c}$ atua como uma medida referente ao tempo de memória das flutuações. Para $\tau<\tau_{c}$ as flutuações são correlacionadas, o contrário ocorre $\tau>\tau_{c}$.

O tempo de coerência é dado por:

$$
\tau_{c}=\int_{-\infty}^{\infty}|g(\tau)|^{2} d \tau
$$

Para a luz com $\tau_{c}$ maior em relação a diferença entre os tempos no qual a luz percorre no sistema óptico, ela apresenta um comportamento coerente. $\mathrm{O} \tau_{c}$ varia de forma inversamente proporcional em relação a largura de linha do laser, $\Delta \nu$, sendo:

$$
\tau_{c}=\frac{1}{\Delta \nu}
$$

O comprimento de coerência da luz é definido:

$$
l_{c}=\nu_{g} \tau_{c}
$$

Onde, $\nu_{g}=\frac{c}{n_{g}}$ é a velocidade de grupo e $n_{g}$ refere-se ao índice da velocidade de grupo. Assim, a luz é coerente se a distância $c \tau_{c}$ for maior que a diferença entre a trajetória óptica.

\section{8}

\section{Polarização Parcial}

Uma fonte que emite luz monocromática é polarizada sempre que as fases das componentes $E_{x}$ e $E_{y}$ permaneçam contante ao longo de sua trajetória. Essa relação entre as componentes ortogonais determina o grau de polarização. Se elas estiverem totalmente descorrelacionadas a luz é denominada despolarizada e tem-se luz parcialmente polarizada para uma correlação parcial entre as componentes.

A luz parcialmente polarizada pode ser representada pela matriz de coerência. Para a onda for quasi-monocromática tem-se a representação de 
Jones é na forma:

$$
V(t)=\left[\begin{array}{l}
A_{x}(t) e^{i \phi(t)} \\
A_{x}(t) e^{i \Psi(t)}
\end{array}\right]=\left[\begin{array}{l}
V_{1}(t) \\
V_{2}(t)
\end{array}\right]
$$

Considerando a matriz de coerência $J$, na qual os elementos $J_{i j}$ $(i, j=1,2)$, é dada:

$$
\Gamma_{i j}=\left\langle V_{i}(t) V_{j}(t)\right\rangle
$$

A matriz de coerência é obtida em termos de componentes de vetor, sendo escrita:

$$
\Gamma=\left[\begin{array}{cc}
\left\langle\left|A_{x}(t)\right|^{2}\right\rangle & \left\langle A_{x}(t) A_{y}^{*}(t) e^{i[\phi(t)-\Psi(t)]}\right\rangle \\
\left\langle A_{x}(t)^{*} A_{y}^{*}(t) e^{-i[\phi(t)-\Psi(t)]}\right\rangle & \left\langle\left|A_{y}(t)^{2}\right|\right\rangle
\end{array}\right]
$$

Sendo traço desta matriz

$$
\operatorname{Tr} J=J_{x x}+J_{y y}=\left\langle E_{x} E_{x}^{*}\right\rangle+\left\langle E_{y} E_{y}^{*}\right\rangle
$$

a intensidade total da luz.

A ligação direta entre os parâmetros de Stokes e os elementos da matriz de coerência é definido por:

$$
\begin{array}{r}
S_{0}=\left\langle E_{x} E_{x}^{*}\right\rangle+\left\langle E_{y} E_{y}^{2}\right\rangle \\
S_{1}=\left\langle E_{x} E_{x}^{*}\right\rangle-\left\langle E_{y} E_{y}^{2}\right\rangle \\
S_{2}=\left\langle E_{x} E_{y}^{*}\right\rangle+\left\langle E_{y} E_{x}^{2}\right\rangle \\
S_{3}=i\left(\left\langle E_{x} E_{y}^{*}\right\rangle-\left\langle E_{y} E_{x}^{2}\right\rangle\right)
\end{array}
$$




\section{3}

\section{Perda Dependente de Polarização (PDL)}

Perda Dependente de Polarização (PDL, polarization dependent Loss) é a diferença na transmissão entre duas componentes ortogonais, sendo que uma polarização corresponde à transmissão máxima $\left(T_{\max }\right)$ e a polarização ortogonal à transmissão mínima $\left(T_{m i n}\right)$, conforme a Figura 3.1.

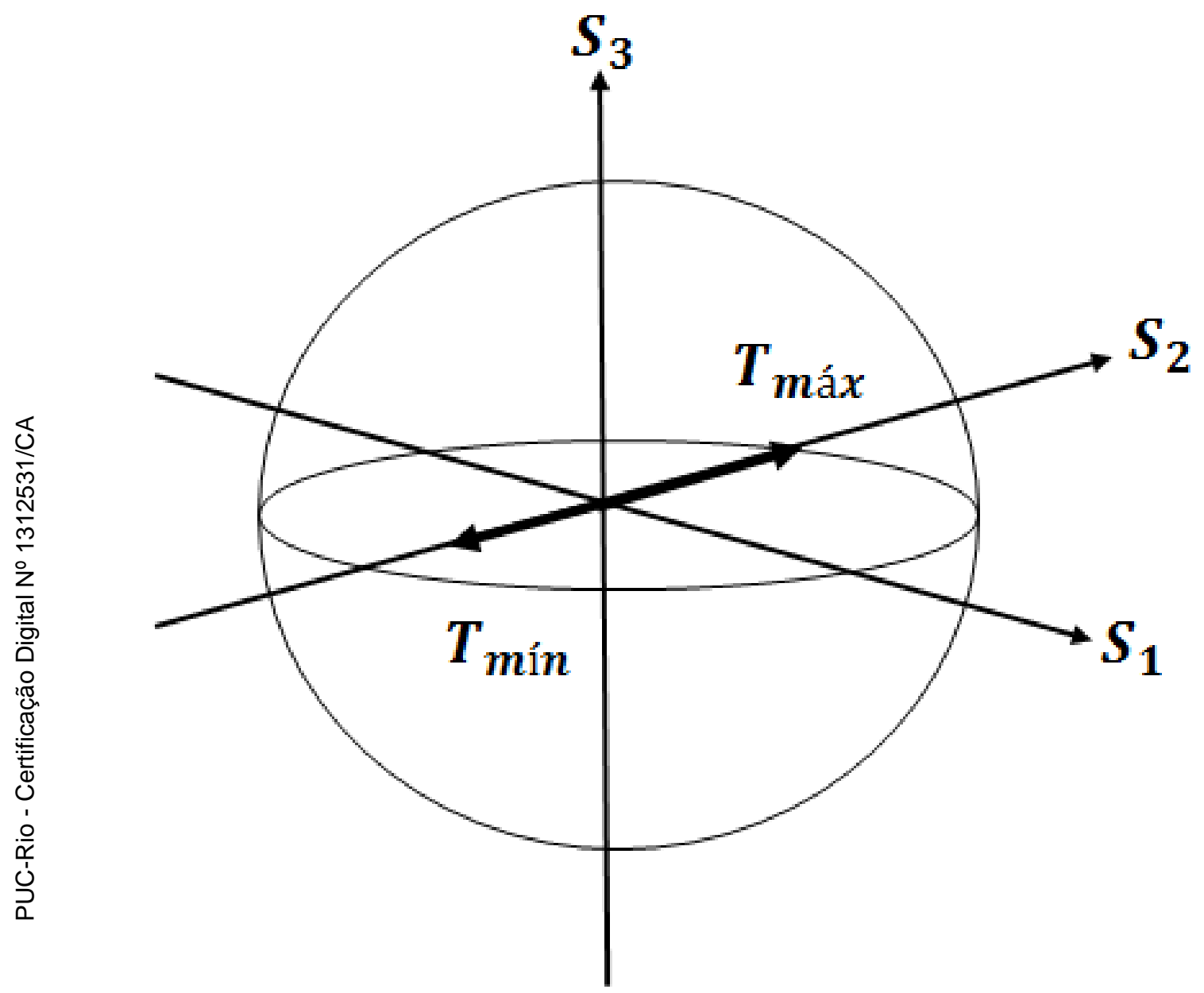

Figura 3.1: Representação na esfera de Poincaré de dois SOP's ortognais. Um estado é associado ao $T_{\max }$ e o estado ortogonal ao $T_{\min }$.

Os coeficientes de transmissão $T$ através de um dispositivo com $P D L$, dependem do estado de polarização de entrada, podendo ser caracterizados entre 0 (opaco) e 1 (transparente). A intensidade máxima de transmissão ocorre quando o estado de polarização de um feixe polarizado estiver completamente alinhado ao eixo de máxima transmissão do elemento $P D L$ em qualquer lugar da esfera de Poincarè. Já a mínima transmissão acontece para a polarização ortogonal. 
A partir da diferença entre os coeficientes de transmissão máximo e mínimo, é possível encontrar o valor em $d B$ da $P D L$ :

$$
P D L_{d B}=10 \log \frac{T_{\max }}{T_{\min }}
$$

O exemplo mais conhecido de PDL é ilustrado na Figura 3.2 (a). Quando a luz despolarizada incide no polarizador, o mesmo deixa passar somente um estado de polarização $\left(T_{\max }=1\right)$, absorvendo a componente ortogonal $\left(T_{\text {min }}=0\right)$. Assim, pela Equação (3-1) temos um caso de $P D L$ infinita.

a)

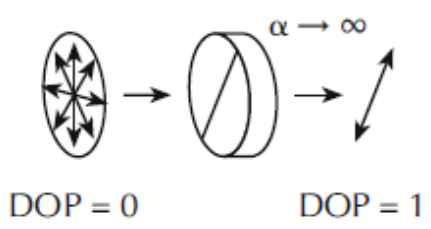

b)

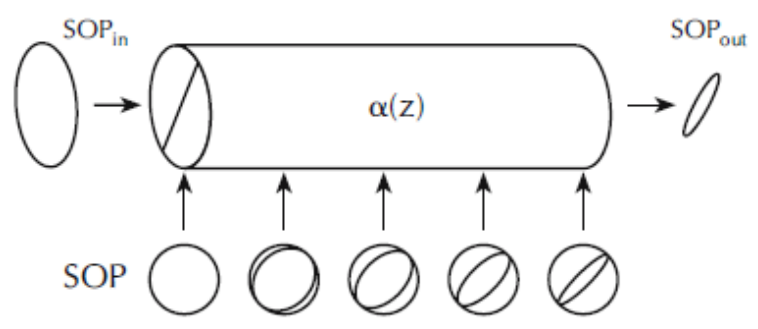

Figura 3.2: Efeitos da PDL. a) Luz despolarizada torna-se polarizada após passar pelo polarizador. b) Um elemento de PDL parcial altera o estado de polarização de entrada, alterando a intensidade total (3).

A Figura 3.2 (b) não é um caso de $P D L$ infinita, mas ilustra a evolução de um estado inicialmente numa polarização circular sendo alterado à medida que atravessa um elemento de perda distribuída, resultando numa polarização elíptica. Conforme a luz viaja ao longo do eixo da $P D L$ o seu estado não é alterado, ocorrendo o contrário para as demais direções.

Os pontos da superfície na esfera de Poincaré, definidos pelo vetor $s$ de norma unitária, representam estados de grau de polarização máximo, enquanto que os pontos internos representam os estados de menor grau de polarização.

O grau de polarização é o comprimento do vetor $|s|$ :

$$
D O P=|s|
$$

Os estados de polarização $\vec{s}_{\max }$ e $\vec{s}_{\text {min }}$ podem ter seu eixo em qualquer lugar na esfera de Poincaré e seu grau de polarização é sempre máximo $\left|\vec{s}_{\text {max }}\right|=\left|\vec{s}_{\text {min }}\right|=1$, sendo ortogonais, ou seja, opostos na esfera de Poincaré $\vec{s}_{\text {max }}=-\vec{s}_{\text {min }}$.

O operador da PDL é definido por:

$$
P=e^{-\frac{\alpha}{2}} \exp \left(\frac{\vec{\alpha} \cdot \vec{\sigma}}{2}\right)
$$


Onde, o vetor $P D L|\alpha\rangle=\alpha \hat{\alpha}$ e $\hat{\alpha}$ é um vetor unitário no espaço de Stokes que aponta na direção de transmissão máxima. A matriz exponencial do operador é expandida em (3), resultando:

$$
P=e^{-\frac{\alpha}{2}}\left(I \cosh \left(\frac{\alpha}{2}\right)+(\hat{\alpha} \cdot \vec{\sigma}) \sinh \left(\frac{\alpha}{2}\right)\right)
$$

Um estado de polarização de entrada é alterado pelo elemento de $P D L$ de acordo:

$$
|t\rangle=P|s\rangle
$$

Assim, a alteração causada pelo elemento $P D L$, o $T_{\max }$ e $\vec{\alpha}$ no vetor Jones de entrada $|s\rangle$ é descrito por:

$$
|t\rangle=e^{-\frac{\alpha}{2}}\left(I \cosh \left(\frac{\alpha}{2}\right)+(\hat{\alpha} \cdot \vec{\sigma}) \sinh \left(\frac{\alpha}{2}\right)\right)|s\rangle
$$

\section{1}

\section{Método de Varredura da Polarização}

Essa técnica pode ser considerada como um método de 'força bruta', pois são lançadas todas as polarizações no $D U T$, cobrindo ao máximo a esfera até conseguir identificar qual o eixo que transmite mais e menos luz. A $P D L$ é medida por meio da potência máxima e mínima que chega no power meter.

O método de varredura da polarização (Polarization-Scanning Method) é uma técnica não determinística para medir PDL, podendo ser realizada como deterministic all-states ou all-states pseudo-ramdom(13). Para o primeiro caso, o método "varre" a esfera ao longo de trajetórias pré - determinadas de modo que se aproxime de uma cobertura completa. Já o all-states pseudoramdom abrange boa parte da esfera aleatoriamente, variando o controlador de polarização.

Este método mede as variações na potência óptica à medida que o estado de polarização é alterado. A razão entre a potência máxima e o mínima determina o valor para a PDL do DUT, podendo ser calculada em dB por meio da Equação (3-1).

A Figura 3.3 mostra o set up de implementação para o método da varredura da polarização. 


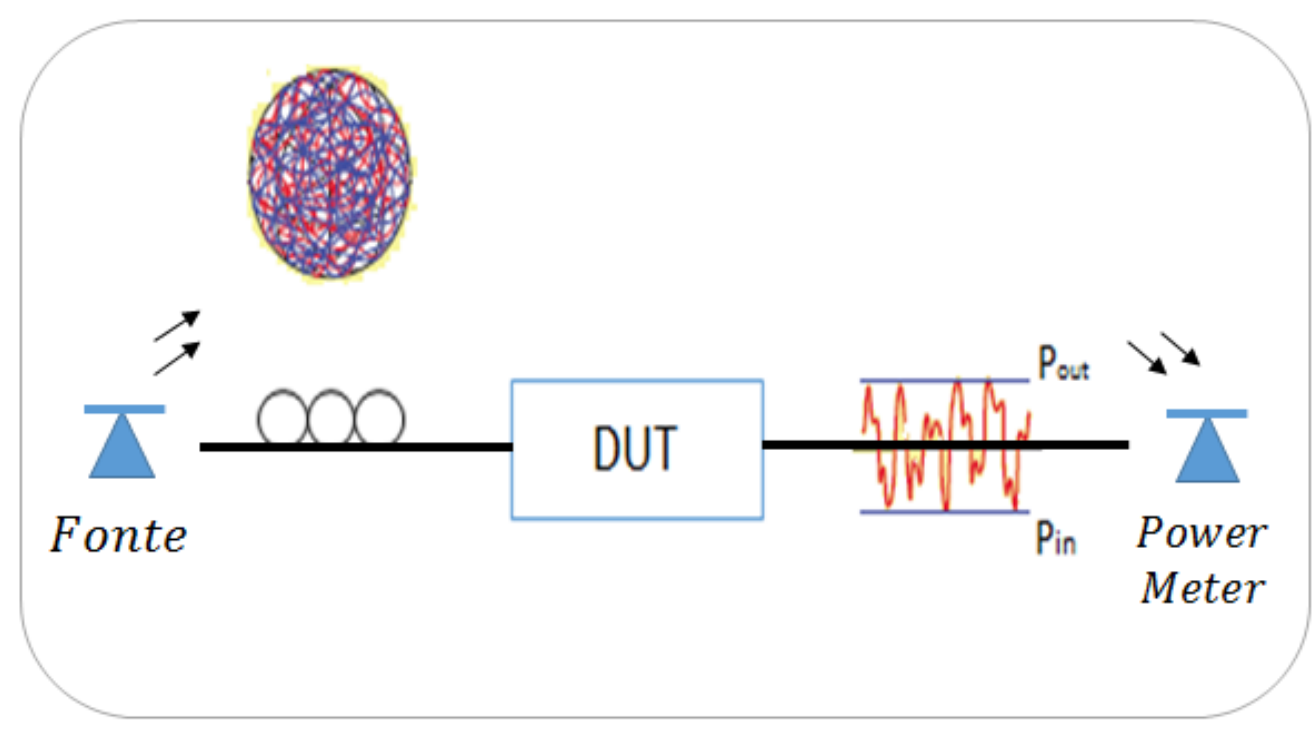

Figura 3.3: Montagem experimental para o método da varredura da polarização.

O controlador de polarização gera vários estados de polarização, incluindo os estados linear, elíptico e circular.

\section{2}

\section{Método de Jones}

O método de Jones proposto por (9) é uma técnica determinística que mede, por meio da matriz de Jones, a resposta de polarização do DUT para três SOP's de entrada de acordo com o comprimento de onda de interesse.

A configuração para a caracterização da medida é mostrada na figura 3.4 .

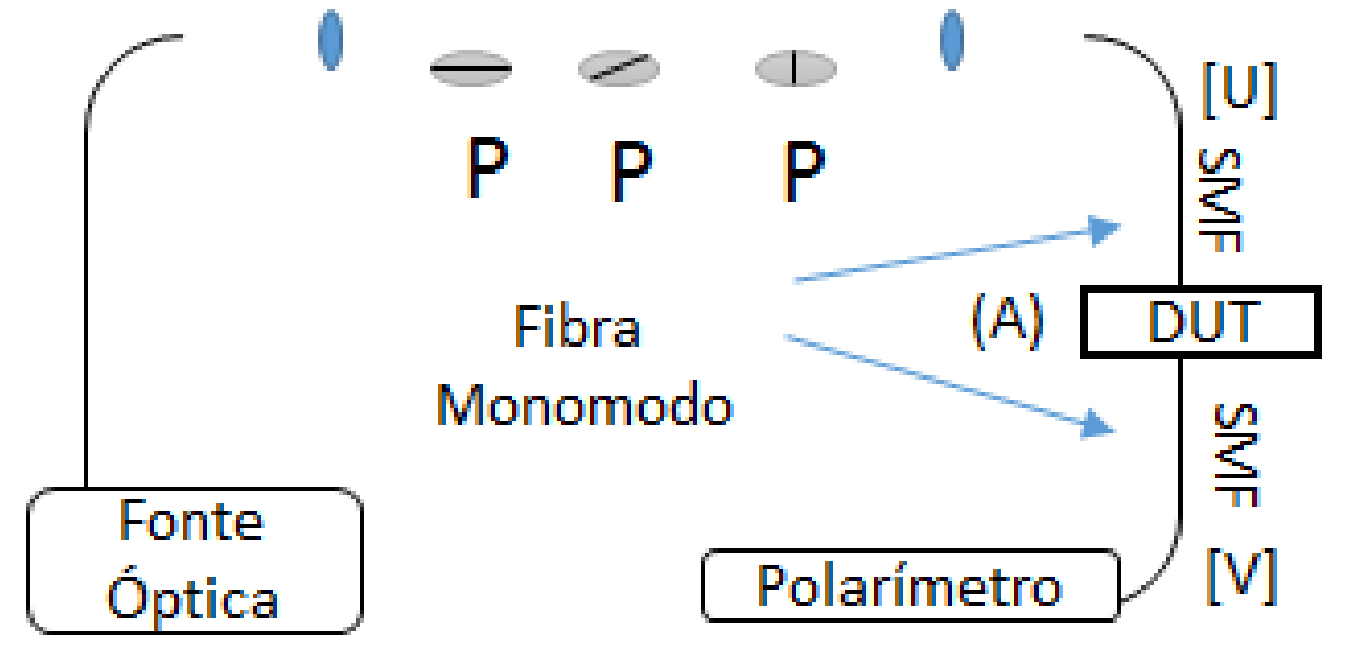

Figura 3.4: Montagem experimental para o método de Jones (9). 
O vetor de Jones $x$ representa o campo elétrico de entrada e o campo de saída é dado por $A x$, sendo $A$ a representação da matriz de Jones para o DUT. É necessário encontrar o produto interno $(A x, A x)$ para todas as entradas de $x$ de intensidade constante. Os valores para a transmissão máxima e mínima são encontradas por meio de $(A x, A x)=(H x, x)$ onde $H=A^{\dagger} A=s^{2}(A)$, que nos dá o extremo dos valores de $H$, sendo dado pelos autovalores de $H$.

O DUT é interconectado por pigtail de fibra, por isso não é possivel realizar a medida diretamente a partir de $A$. Então a matriz de Jones para $D U T$ conectado aos restante do setup é $B=V A U$.

$$
\frac{T_{\min }}{T_{\max }}=\frac{s_{1}^{2}(V A U)}{s_{2}^{2}(V A U)}=\frac{s_{1}^{2}(A)}{s_{2}^{2}(A)}=P D L_{D U T}
$$

A perdas geradas a partir das bobinas e conectores com $P D L$ podem ser desprezadas, assumindo que as suas matrizes $U$ e $V$ são untitárias.

O método de Jones é considerado um método de rápida implementação, aproximadamente 2 ou 3 segundos são necessários para a realização da medida de um comprimento de onda (13).

\section{3 Método de Mueller}

O método de Mueller, proposto primeiramente por (7), é uma técnica determinística para medir PDL por meio da representação da matriz de Muller do DUT, através de quatro estados de polarização de entrada bem definidos: polarização linear horizontal (LHP, do inglês linear horizontal polarization), polarização linear vetical (LVP, do inglês vertical horizontal polarization), polarização linear $45^{\circ}$ (do inglês, $45^{\circ}$ linear polarization) e a luz polarizada circularmente à direita (RHC, do inglês rigth circular polarization).

O setup para a medida da PDL, é mostrado na figura 3.5, que inclui uma fonte óptica para geração do sinal, um controlador de polarização, afim de produzir os estados de polarização, conectado ao DUT seguido por um power meter. 


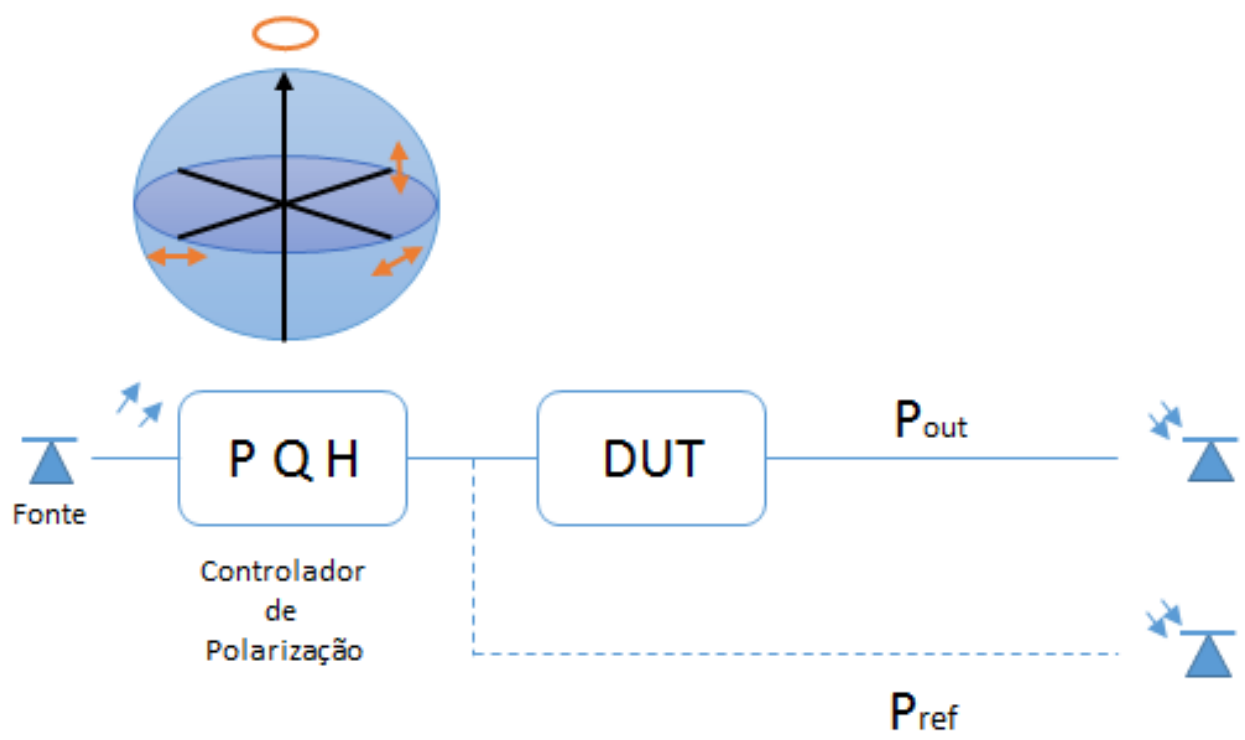

Figura 3.5: Montagem experimental para o método de Muller (7).

O polarizador posicionado antes das lâminas de ondas garantem um sinal polarizado com orientação fixa. Para realizar este método, primeiramente deve-se girar o polarizador $\left(\alpha_{p}\right)$ afim de combiná-lo com o sinal de entrada e a transmissão máxima seja alcançada. As lâminas também precisam estar alinhadas em relação ao $\alpha_{p}(4)$.

Considerando o formalismo de Mueller já descrito na seção 2.4 e utilizando somente os elementos da primeira linha da matriz $\left(m_{11}\right.$ até $\left.m_{14}\right)$ necessários para o cálculo da $P D L$.

$$
\left[\begin{array}{l}
m_{11} \\
m_{12} \\
m_{13} \\
m_{14}
\end{array}\right]=\left[\begin{array}{c}
\frac{1}{2}\left(\frac{P_{A}}{P_{a}}+\frac{P_{B}}{b}\right) \\
\frac{1}{2}\left(\frac{P_{A}}{P_{a}}-\frac{P_{B}}{b}\right) \\
\frac{P_{C}}{P_{c}}-m_{11} \\
\frac{P_{D}}{P_{d}}-m_{11}
\end{array}\right]=\left[\begin{array}{c}
\frac{T_{1}+T_{2}}{2} \\
\frac{T_{1}-T_{2}}{2} \\
T_{3}-m_{11} \\
T_{4}-m_{11}
\end{array}\right]
$$

A equação (3-8), mostra que estes elementos podem ser calculados a partir do coeficientes de transmissão $T$.

As transmissões máximas e mínimas são dadas por:

$$
\begin{aligned}
& T_{\text {max }}=m_{11}+\sqrt{m_{12}^{2}+m_{13}^{2}+m_{14}^{2}} \\
& T_{\text {min }}=m_{11}-\sqrt{m_{12}^{2}+m_{13}^{2}+m_{14}^{2}}
\end{aligned}
$$


Assim, a $P D L$ é calculada:

$$
P D L_{d B}=10 \log \frac{T_{\max }}{T_{\min }}
$$

O método da matriz de Mueller é rápido, sendo necessário apenas alguns segundos por potência medida em cada comprimento de onda.

\section{4}

\section{Técnica de Muller - Stokes}

O método de Muller-Stokes é uma variação do método de matriz de Mueller proposto por (7), sendo um método determinístico que define quatro estados fixos de polarização necessários para determinar a primeira linha da matriz de Muller (2).

Nesta técnica, os estados de polarização são produzidos por dois liquid crystal regulator (LCVR) dispostos em série, modulando o estado de polarização de um feixe de baixa coerência, a fim de produzir estados de polarização equivalentes aos produzidos pela combinação QWP e HWP com rotações independentes.

O experimento realizado consiste de uma fonte, a cavidade LCVR, detector e o controle realizado por um computador, mostrado na figura 3.6.

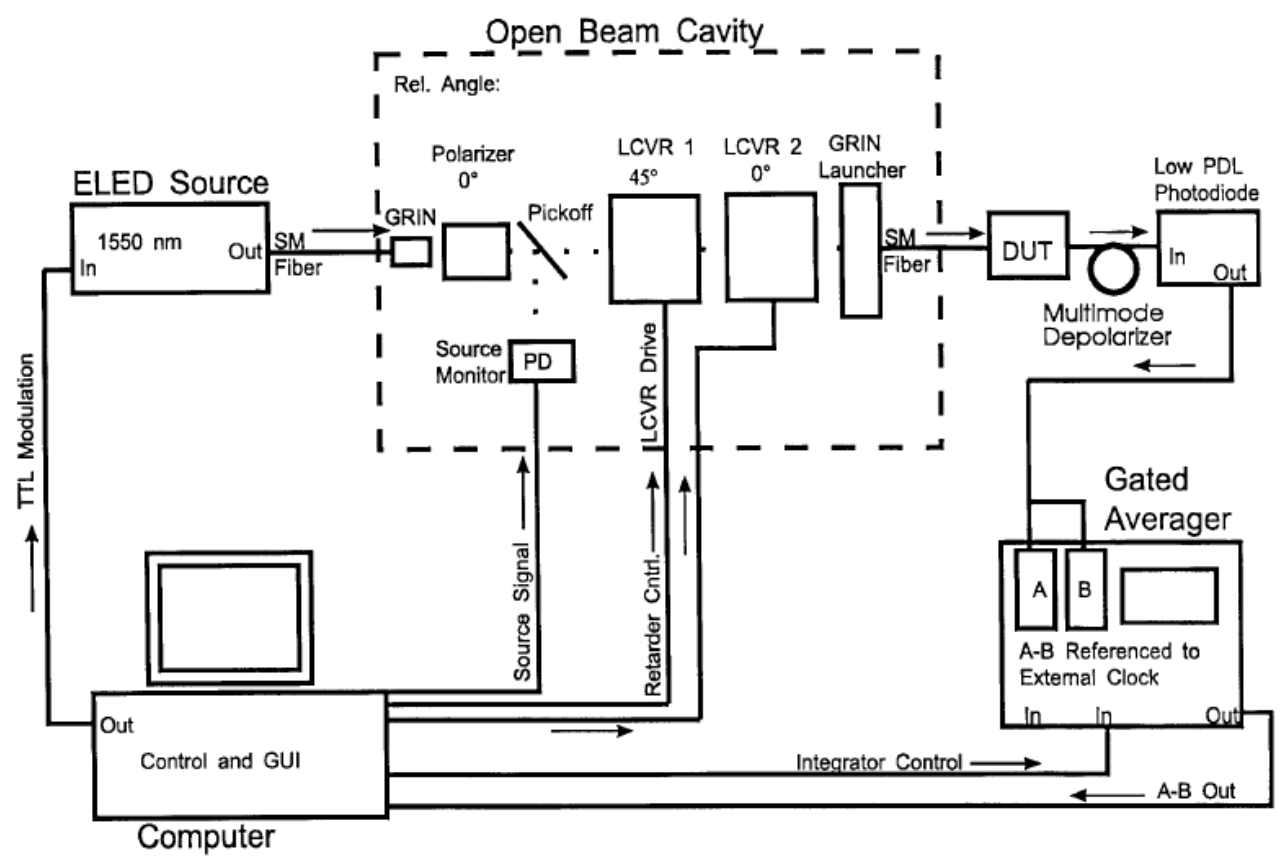

Figura 3.6: Montagem experiemental para medição de PDL por meio do método Mueller-Stokes (2). 
A luz do ELED é colimada por uma lente GRIN, após passar pelo polarizador a luz é divida por um BS de polarização e parte da luz é monitorada por um fotodetector. A primeira LCVR é fixada em $45^{\circ}$ e o segundo LCVR segue com $0^{\circ}$, com um retardo de $2 \pi$. Em seguida, a luz é lançada no DUT por meio de outra lente GRIN.

Uma das vantagens desta técnica é a rápida realização das medidas, assim como questões de estabilidade.

\section{5}

\section{Método dos Dois Estados}

O método dos dois estados mede PDL por meio de dois estados de polarização de entrada, satisfazendo a propriedade de Lorentz para dispositivos ópticos com PDL e birrefringência (5)(12) e considerando o formalismo de Mueller descrito na seção 2.4.

$\mathrm{O}$ valor da PDL é obtido:

$$
P D L=10 \log \left(\frac{R_{a}+R_{b}+\sqrt{R_{a}^{2}+R_{b}^{2}+2 R_{a} R_{b} \chi}}{R_{a}+R_{b}-\sqrt{R_{a}^{2}+R_{b}^{2}+2 R_{a} b \chi}}\right)
$$

Sendo $R=S_{\text {out } 0} / S_{i n 0}$ é a razão entre a potência de saída e entrada, e $\chi=\sum_{i=1}^{3} S_{\text {outia }} S_{\text {outib }}$ é o produto entre dois SOP's de saída normalizados.

O experimento realizado é constituído por um polarímetro in line, que monitora os SOP's de entrada e a potência óptica de entrada, o polarímetro 2 mede os parâmetros de Stokes de saída correspondente os DUT são uma bobina e uma fibra polida lateralmente e CP para gerar dois estados ortogonais de entrada, como mostra a figura 3.7.

O primeiro SOP é gerado arbitrariamente e medido pelo polarímetro 1. O segundo SOP, é originado girando o PC até o polarímetro 1 indicar que o SOP é ortogonal ao primeiro. O laser tunable $D F B$ é utilizado como fonte de luz polarizada e o sistema é monitorado por um computador.

A vantagem deste método relaciona-se à necessidade de somente dois estados de polarização na entrada e a rápida implementação com erro reduzido.

\section{6}

\section{Método da Luz Despolarizada}

Este método para medir PDL utiliza a saída de luz quase monocromática despolarizada de um despolarizador (6).

A luz é despolarizada utilizando laser diodo (LD, laser diode) de feedback distribuído (DFB, do inglês distributed feedback) e um tradicional despolari- 


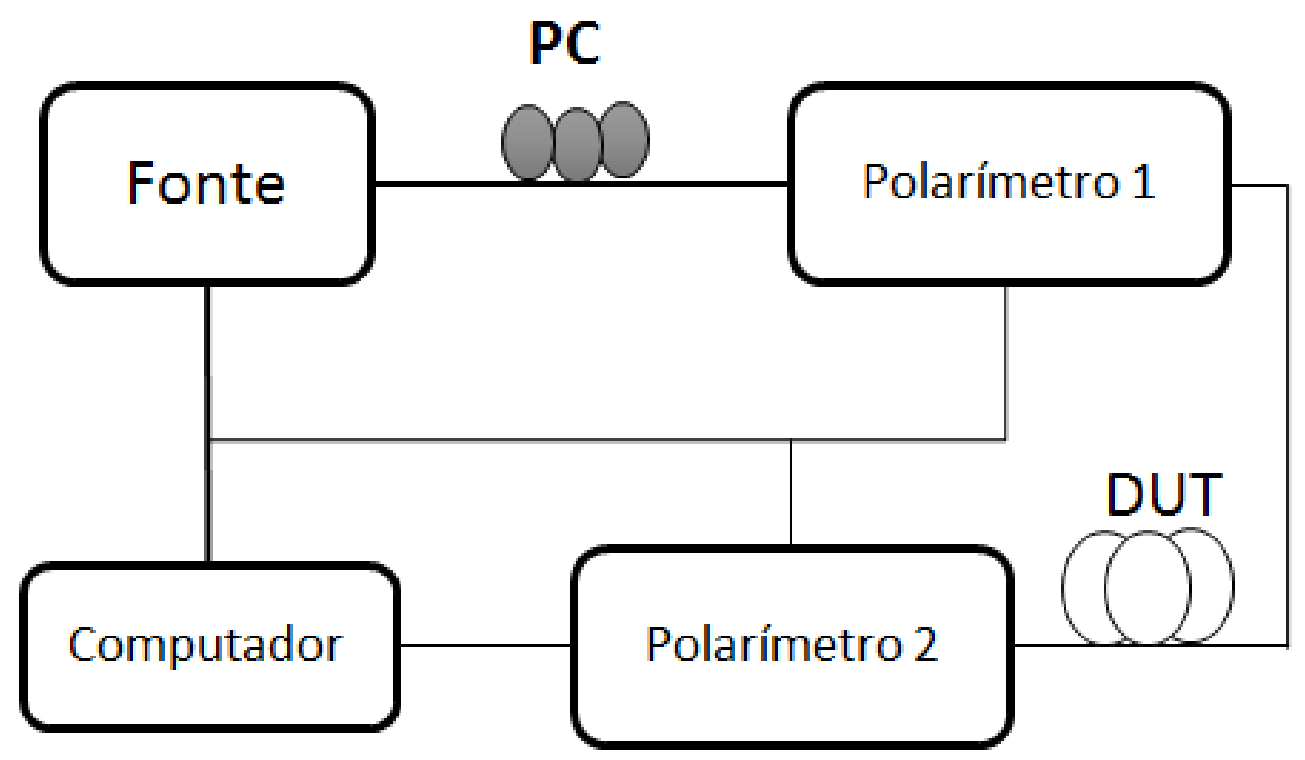

Figura 3.7: Montagem esperimental para o Método dos dois Estados (12).

zador de banda larga com um dispositivo de PDL variável conforme a figura 3.8 .

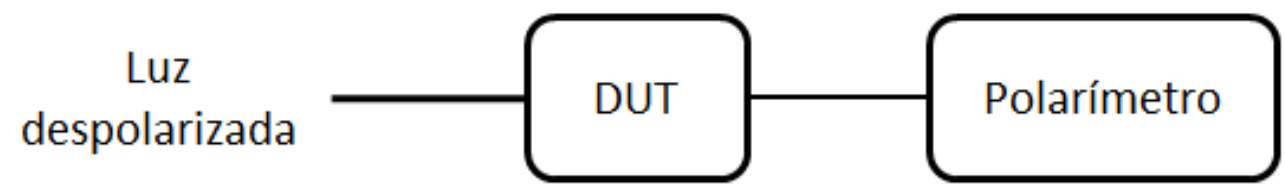

Figura 3.8: Montagem experimental para o método da luz despolarizada (6)

O componente de PDL variável pode ser produzido por dois beam splitters de polarização seguido por um atenuador variável. Em (6) o efeito da PDL é induzido por curvatura em uma sessão de fibra Hi-Bi e o seu valor é ajustado alterando o comprimento das dobras ou o número de bobinas da fibra Hi-Bi.

Esta técnica é baseada na propriedade de Lorentz (5) e na relação entre os DOPs de entrada e saída através de um dispositivo óptico. Sendo $D O P_{i n}=0$ e $D O P_{\text {out }}=D$, a PDL é calculada por:

$$
P D L=10 \log \left(\frac{1+D O P_{\text {out }}}{1-D O P_{\text {out }}}\right)
$$

O método para medir PDL através da luz despolarizada não sofre com os efeitos da birrefringência, além de evitar erros induzidos pelo ajuste dos $S O P^{\prime} s$. Outra vantagem para o método descrito está na rapidez da realização 
Medição de Perdas Dependentes da Polarização Utilizando Mistura de Frequências em Fotodiodos

da medida. Uma desvantagem, seria a dificuldade de obtenção da luz quase monocromática despolarizada de qualidade. 


\section{Teoria para o Método Proposto}

A luz, em um estado de polarização $|H\rangle$ associado a uma frequência $f_{1}$ e um estado $|V\rangle$ à uma frequência $f_{2}$, vai ser lançada no DUT, o dispositivo que vai emular a $P D L$ e, em princípio, está sendo considerado como uma caixa preta. Após passar pelo DUT, o sinal vai ser detectado e seu espectro mostrado no ESA, conforme 4.1.

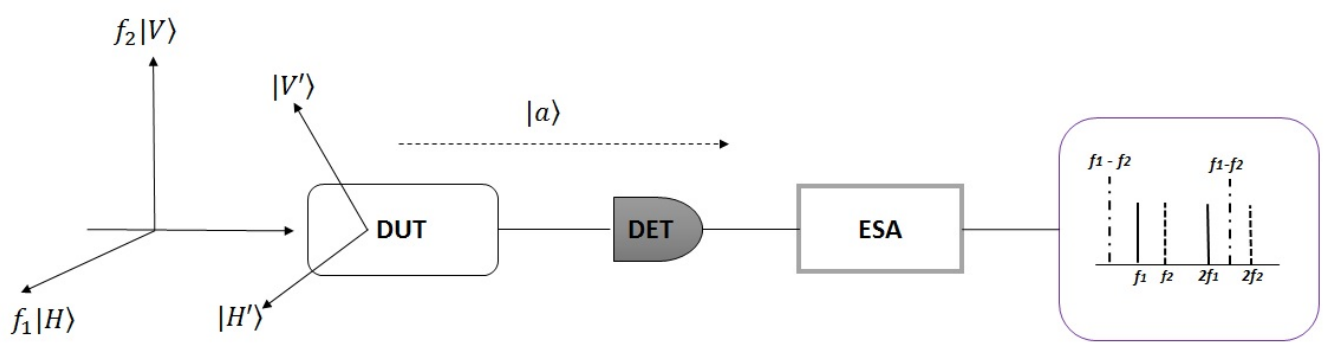

Figura 4.1: Configuração para o método proposto, no qual as frequências $f_{1} \mathrm{e}$ $f_{2}$ são associadas aos estados $|H\rangle$ e $|V\rangle$.

O método proposto associa modos de batimentos em diferentes frequências à PDL do dispositvo de teste (DUT).

Um DUT generérico é modelado a partir de uma matriz de tranferência no qual o estado de polarização a uma porta de entrada e saída. Considerando um elemento de PDL qualquer com os eixos $(\hat{x}, \hat{y})$ alinhados aos autovalores $(\hat{h}, \hat{v})$ da base de polarização linear, tem-se:

$$
\mid \text { out }\rangle=\left[\begin{array}{ll}
\alpha & 0 \\
o & \beta
\end{array}\right]|i n\rangle
$$

Onde in e out são vetores de Jones e os valores dos campos de transmitância dos estados de polarização ortogonais $(\hat{h}, \hat{v})$ são, respectivamente, por $\alpha$ e $\beta, \operatorname{com}|\alpha|^{2}+|\beta|^{2}=1$.

O elemento de PDL genérico é rotacionado por um ângulo $\theta$ relativo ao vetor $\hat{h}$, resultando em:

$$
\operatorname{DUT}(\theta)=\left[\begin{array}{ll}
\alpha \cos ^{2} \theta+\beta \sin ^{2} \theta & (\alpha-\beta) \cos \theta \sin \theta \\
(\alpha-\beta) \cos \theta \sin \theta & \alpha \sin ^{2} \theta+\beta \cos ^{2} \theta
\end{array}\right]
$$


Considere agora o estado de entrada composto por dois estados independentes polarizados ortoganalmente associado às frequências $f_{1}$ e $f_{2}$ :

$$
i n=\left[\begin{array}{l}
1 \\
0
\end{array}\right] \sqrt{P_{i n 1}} \hat{f}_{1}+\left[\begin{array}{l}
0 \\
1
\end{array}\right] \sqrt{P_{i n 2}} \hat{f}_{2}
$$

O estado de saída é computado como

$$
\mid \text { out }\rangle=D U T(\theta) \mid \text { out }\rangle
$$

resultando em

$$
\text { out }=\left[\begin{array}{l}
\alpha \cos ^{2} \theta+\beta \sin ^{2} \theta \\
(\alpha-\beta) \cos \theta \sin \theta
\end{array}\right] \sqrt{P_{\text {in } 1}} \hat{f}_{1}+\left[\begin{array}{c}
(\alpha-\beta) \cos \theta \sin \theta \\
\alpha \sin ^{2} \theta+\beta \cos ^{2} \theta
\end{array}\right] \sqrt{P_{\text {in } 2}} \hat{f}_{2}
$$

A potência óptica é obtida a partir:

$$
\left.P_{\text {opt }} \propto\langle\text { out }| \text { out }\right\rangle
$$

Caso $P_{i n 1}=P_{i n 2}=P_{i n} / 2$, tem-se os valores de potência de saída óptica relativo nos quais podem podem ser separados de acordo com as suas frequências $f_{1}, f_{2}$ e as frequências misturadas $f_{ \pm \Delta}$ :

$$
\begin{aligned}
& P_{o p t}^{f_{1}}=\left(t_{h} \cos ^{2} \theta+t_{v} \sin ^{2} \theta\right) / 2 \\
& P_{o p t}^{f_{2}}=\left(t_{h} \sin ^{2} \theta+t_{v} \cos ^{2}\right) / 2 \\
& P_{o p t}^{f_{\Delta}}=\left(t_{h}-t_{v}\right) / 2
\end{aligned}
$$

Onde $t_{h}=|\alpha|^{2}$ e $t_{v}=|\beta|^{2}$ são as potências das transmitâncias dos estados de polarização $\hat{h}$ e $\hat{v}$, respectivamente. A partir das Equações (4-7) encontram-se:

$$
\chi=\frac{1}{2} \operatorname{atan} \frac{P_{\Delta \pm}}{P_{o p t}^{f_{1}}-P_{o p t}^{f_{2}}}
$$




$$
\begin{aligned}
& t_{h}=\frac{P_{o p t}^{f_{1}} \cos ^{2} \chi-P_{o p t}^{f_{2}} \sin ^{2} \chi}{\cos (2 \chi)} \\
& t_{v}=\frac{P_{o p t}^{f_{2}} \cos ^{2} \chi-P_{o p t}^{f_{1}} \sin ^{2} \chi}{\cos (2 \chi)}
\end{aligned}
$$

Estas equações relacionam os valores de transmitância $t_{h}$ e $t_{v}$ e o ângulo de rotação $\chi$ entre o DUT e as bases ortonormais definidas pelos sinais de entrada - o eixo da PDL. Caso $\chi=0$, as frequências $f_{1}$ e $f_{2}$ são ortogonais e não possui termo cruzado, logo o batimento $f_{\Delta \pm}$ é nulo. No entanto, se o eixo da PDL é rotacionado no equador da esfera de Poincarè, isto é, em qualquer estado de polarizaçãp linear, $\chi \neq 0$. O final da PDL em dado comprimento de onda é:

$$
P D L=\max \frac{t_{h}}{t_{v}}, \frac{t_{v}}{t_{h}}
$$




\section{5}

\section{Montagem Experimental}

Foi realizado um experimento a fim de verificar a modelagem da teoria para o método proposto para medida de PDL. A montagem experimental para a realização das medidas é representada na Figura 5.1.

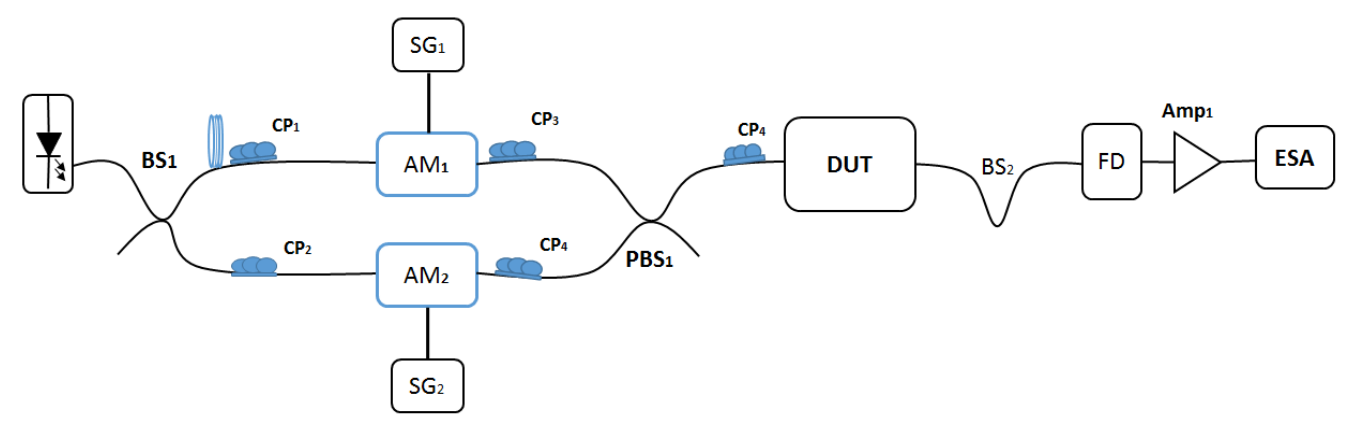

Figura 5.1: Montagem experimental realizada em para medição da PDL.

O sistema para realização das medidas consiste de uma fonte laser $D F B$ telecom de $8 d B m$ e comprimento de onda de $1500 \mu m$ seguida pelo $B S_{1}$ (50 : 50), dividindo o sinal em dois caminhos diferentes: braço 1 (mais curto), e o braço 2 (mais longo), proporcionando um atraso ao sinal que se propaga por ele. Após se dividir no $B S_{1}$, o sinal descorrelacionado pela bobina de $9 \mathrm{~km}$ é lançado no controlador de polarização $C P_{1}$, a fim de maximizar a modulação e casar a polarização com o modulador de $\mathrm{LiNiO}_{3} \mathrm{AM}_{1}$ e em seguida o sinal modulado é inserido no $C P_{3}$, este garante que as polarizações sejam ortogonais ou paralelas entre si. Após passar pelo DUT, o sinal, amplificado, é detectado com um detector $p-i-n$ com resposta de $1 G H z$ e mostrado no ESA.

\section{1}

\section{Alinhamento do DUT}

O DUT, o sistema que vai emular a $P D L$, como mostrado na Figura 5.2 , é composto por elementos de óptica bulk sendo necessário o alinhamento espacial de cada componente, antes de qualquer medida, para que as perdas ópticas sejam minimizadas. A luz é lançada em espaço livre a partir da fibra utilizando-se uma lente colimadora de índice gradual (GRIN). Após a transmissão pelos elementos de óptica bulk, a luz é coletada em fibra utilizando-se uma lente asférica de distância focal com cobertura anti-reflexiva para a região espectral de operação. Por isso é essencial que alguns passos sejam seguidos antes de iniciar o processo de medição afim de proporcionar o melhor 
alinhamento possível.

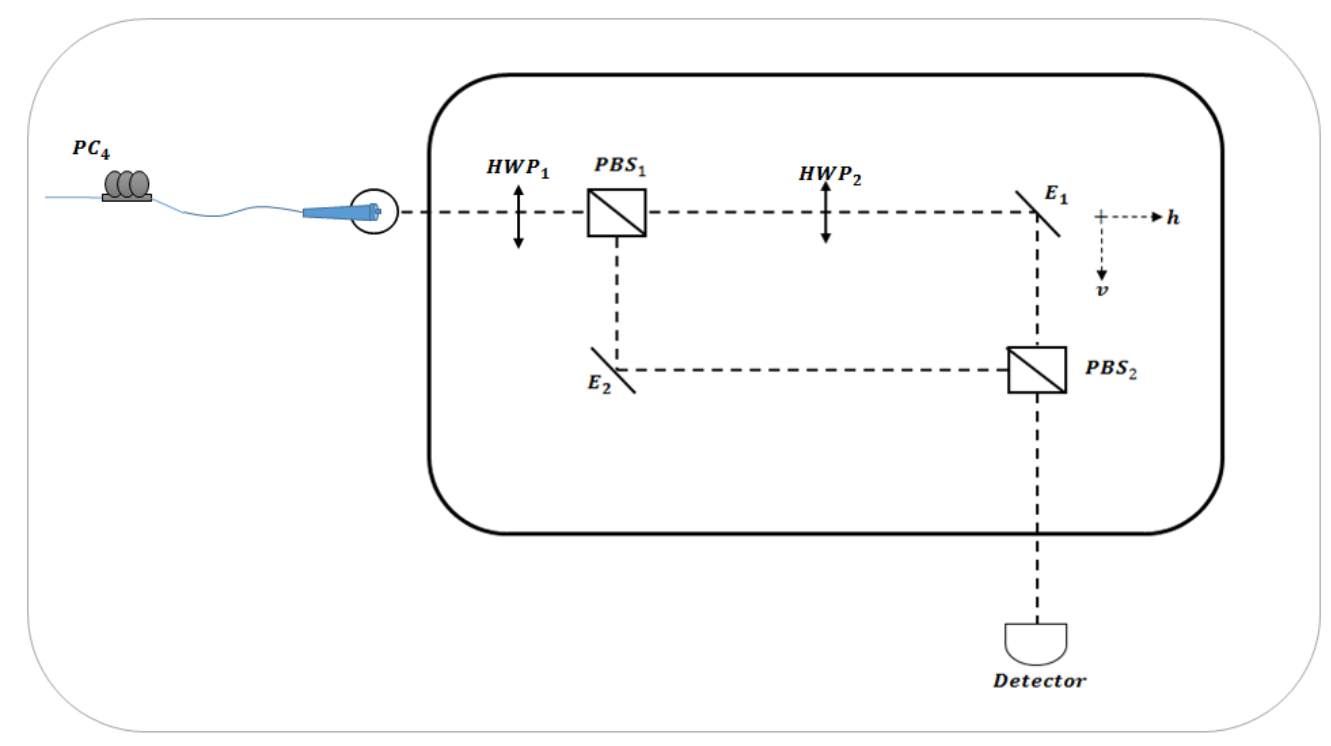

Figura 5.2: Montagem experimental para o DUT.

Após passar pela $H W P_{1}$ o é dividido no $P B S_{1}$ para que o mesmo assuma duas trajetórias distintas. O feixe transmitido pelo $P B S_{1}$, assume a trajetória horizontal e passa pela $H W P_{2}$, sendo refletido pelo espelho $E_{1}$. Já o feixe que se propaga pelo caminho vertical é refletido pelo espelho $E_{2}$ em direção $P B S_{2}$. A detecção foi feita por meio de uma lente asférica utilizada para coletar luz em fibra e detector fibrado.

O primeiro alinhamento realizado foi para o feixe na entrada do DUT, a fim de garantir que o mesmo estivesse paralelo à trilha do breadboard e o máximo possível alinhado em relação ao ângulo de elevação (plano yz). Uma vez que, os PBSs e espelhos possuem o ajuste de ângulo azimutal (plano $x y$ ), este ajuste, a priore, não precisa ser perfeito na saída da fibra, conforme a Figura 5.3. 


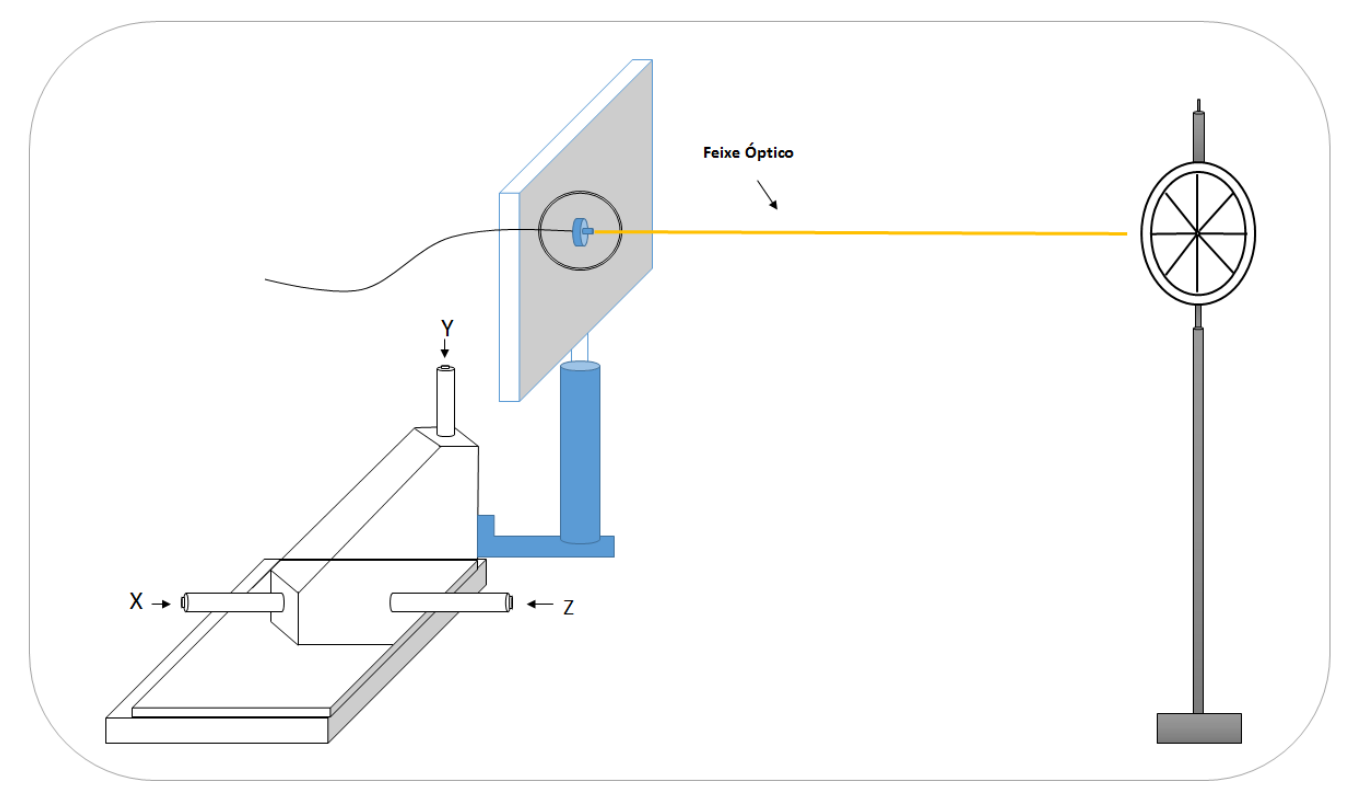

Figura 5.3: Montagem experimental para o alinhamento do feixe de entrada. Suporte de posicionamento $x y z$ para lente fibrada. Posicionamento da iris para garantir a melhor trajetória do feixe óptico.

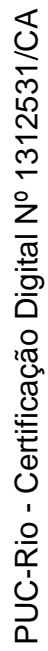

O objetivo deste ajuste é zerar o ângulo de elevação e estabelecer a altura do feixe. Para tal, inicialmente, foi estimada uma altura $h^{\prime}$ para o feixe de saída, posicionando a primeira íris nesta altura.

Em seguida, a íris 2 foi posicionada em $D$, ficando afastada da lente de saída $(D>d)$, como na Figura 5.4.

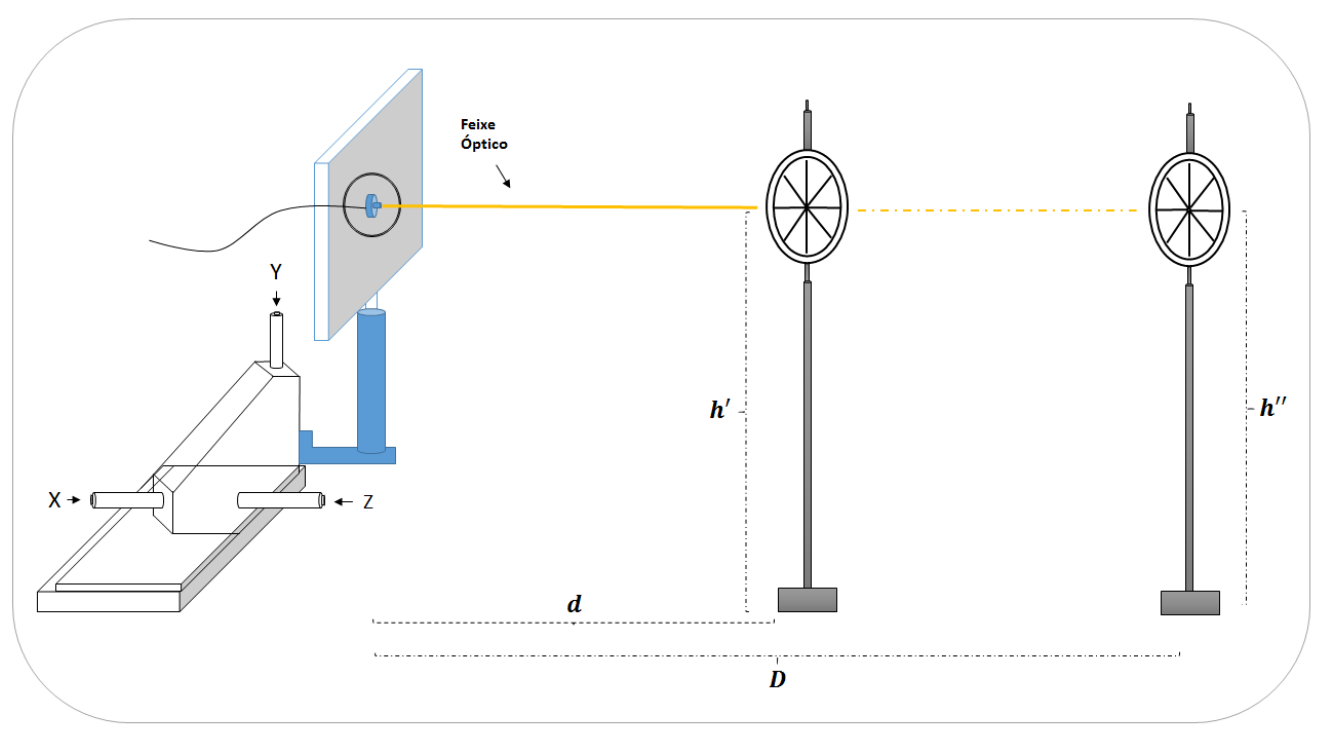

Figura 5.4: Montagem experimental a fim de garantir uma trajetória em linha reta para o feixe óptico. 
Para esta posição, a trajetória do feixe foi checada e comparada com a posição em $d$, sendo possível algumas configurações:

- O feixe está abaixo da íris em $d$ e acima em $D$ (ângulo polar positivo) $\mathrm{ou}$;

- O feixe está acima da íris em $d$ e abaixo da íris em $D$ (ângulo polar negativo), conforme a Figura 5.5.
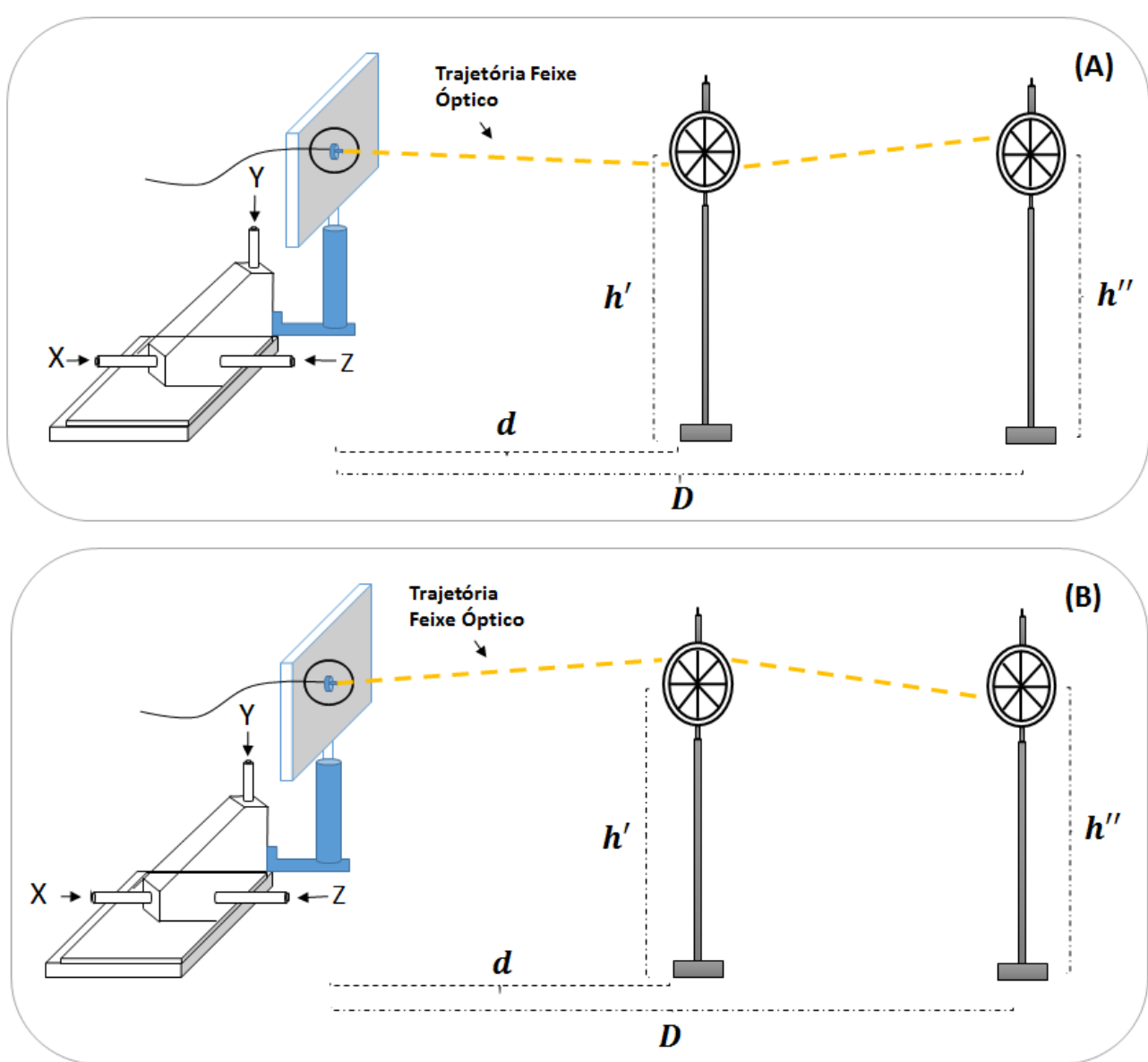

Figura 5.5: Montagem experimental para checar a trajetória do feixe através da íris 1 e 2: (A) ângulo polar positivo; (B) ângulo polar negativo.

Queremos que a altura $h^{\prime \prime}$ do feixe em $D$ seja igual à altura $h^{\prime}$, conforme a Figura 5.4. Assim, o ângulo e a altura do feixe são ajustados de maneira combinada, mantendo as duas íris fixas.

Caso ângulo polar positivo:

- Medir o feixe em $d$ e ajustar a altura, levantando-a até que o feixe atravesse a íris. 
- Medir o feixe em $D$ e ajustar o ângulo, abaixando-o, até que o feixe atravesse a íris.

- Repetir o procedimento descrito até que o feixe atravesse a íris sem alteração dos parâmetros.

Caso o ângulo polar seja negativo:

- Medir o feixe em $d$ e ajustar a altura, abaixando-a até que o mesmo esteja atravessando a íris.

- Medir o feixe em $D$ e ajustar o ângulo, levantando-o até que o mesmo esteja atravessando a íris.

- Se, em um determinado momento, o feixe atravessar ambas sem alteração de parâmetros, o mesmo converge $(\theta=0)$. Caso contrário, retornar ao incio do ajuste até feixe convergir.

Após alinhar o feixe de entrada do DUT, os componentes ópticos foram acrescentados. Sempre que for adicionar um novo elemento, retirar ou alterar qualquer um dos componentes do DUT é necessário realizar as etapas, já descritas, de ajuste da altura e ângulo do feixe em ambos os braços, sempre checando se o mesmo está paralelo em relação trilha do breadboard utilizado.

Uma vez acrescentado o $P B S_{1}$ repete o procedimento, para o feixe ser transmitido e refletido na mesma altura. O mesmo é feito com os espelhos, e ao acrescentar os $P B S s$, o ajuste do ângulo azimutal é feito para cada um dos braços até que os dois feixes estejam juntos, ou seja, colineares e espacialemente justapostos. O ajuste do ângulo azimutal no $P B S_{2}$ é semelhante ao ajuste do ângulo de elevação, porém o feixe é movido para a direita ou esquerda.

\section{2}

\section{Caracterização das Medidas}

Os sinais modulados em amplitudes com portadoras suprimidas são compostos por um par de frequência óptica: $\nu_{0} \pm f_{1} / 2$ e $\nu_{0} \pm f_{2} / 2$. Os campos ópticos são descritos por:

$$
\begin{aligned}
& \vec{E}_{1}(t)=\sqrt{\frac{P_{1}}{4}} e^{j\left[2 \pi\left(\nu_{0}-\frac{f_{1}}{2}\right) t+\phi_{0}-\phi_{1}\right]}+e^{j\left[2 \pi\left(\nu_{0}-\frac{f_{1}}{2}\right) t+\phi_{0}+\phi_{1}\right]} \hat{x} \\
& \vec{E}_{2}(t)=\sqrt{\frac{P_{2}}{4}} e^{j\left[2 \pi\left(\nu_{0}-\frac{f_{2}}{2}\right) t+\phi_{0}-\phi_{1}\right]}+e^{j\left[2 \pi\left(\nu_{0}-\frac{f_{2}}{2}\right) t+\phi_{0}+\phi_{2}\right]} \hat{y}
\end{aligned}
$$

A soma dos campos é escrita: 


$$
\begin{gathered}
\vec{E}(t)=e^{2 \pi \nu_{0} t+\phi_{0}}\left[\sqrt{\frac{P_{1}}{4}} \cos \left(2 \pi \frac{f_{1}}{2} t+\phi_{1}\right) \hat{x}+\right. \\
\left.\sqrt{\frac{P_{2}}{2}} \cos \left(2 \pi \frac{f_{2}}{2}+\phi_{2}\right) \hat{y}\right]
\end{gathered}
$$

A potência óptica do sinal possui fase independente e é obtido com a projeção do campo como $\vec{E}^{*}(t) \vec{E}(t)$, onde o operador $\langle\cdot\rangle$ é o complexo conjugado, resultando em

$$
\begin{aligned}
P(o p t) \propto & \frac{P_{1}}{8}\left[1+\cos \left(2 \pi f_{1} t+\phi_{1}\right)\right]+\frac{P_{2}}{8}\left[1+\cos \left(2 \pi f_{2} t+\phi_{2}\right)\right]+ \\
& \frac{P_{1} P_{2}}{8} \cos \left(2 \pi f_{\Delta} t+\Delta \phi\right)+\cos \left(2 \pi f_{\Delta+} t+\Delta \phi\right)
\end{aligned}
$$

Onde, $f_{1}$ e $f_{2}$ representam os batimentos entre as bandas laterais de cada fonte com fase $\phi_{1}$ e $\phi_{2}$ e $f_{\Delta-}=\left(f_{1}-f_{2}\right) / 2$ e $f_{\Delta+}=\left(f_{1}+f_{2}\right) / 2$ são os batimentos cruzados entre as bandas laterais ópticas com fase $\Delta \phi$. Como os pares de sinais são ortogonais, espera-se que o batimento óptico entre os componentes no detector seja cruzado, resultando em tons elétricos em $f_{1}$ e $f_{2}$. A Figura 5.6 mostra um sinal óptico de onda contínua em uma freqência $\nu_{0}$ se dividindo nos dois braços polarizados ortogonalmente.

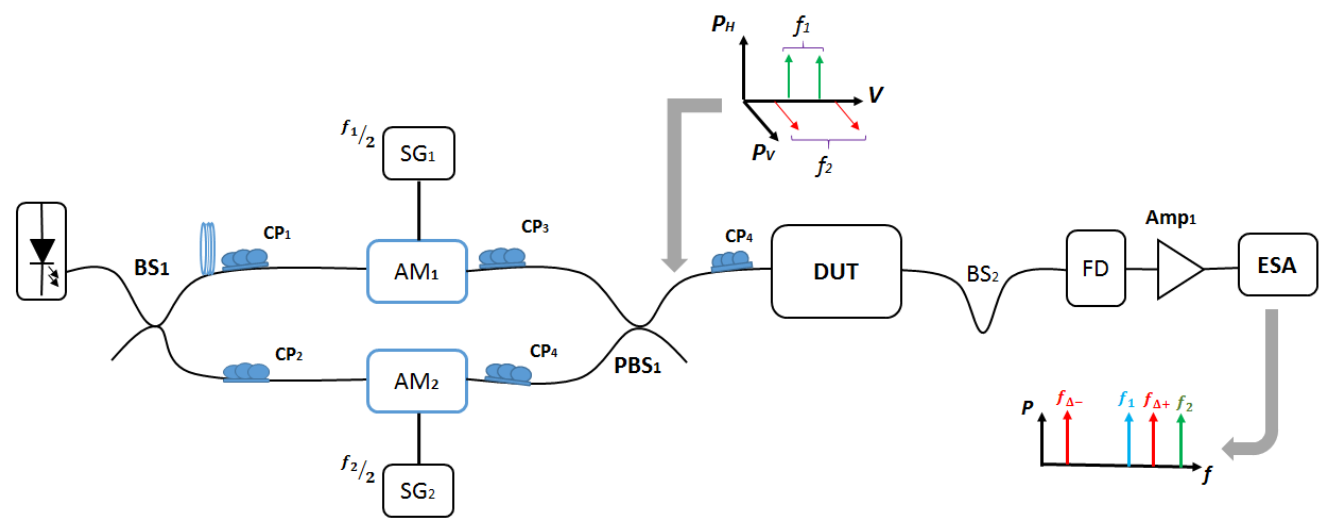

Figura 5.6: Configuração experimental, mostrando as componentes espectrais dos tons de modulação sem a presença do DUT.

Os sinais de prova são inseridos no DUT e então projetados no detector óptico e o sinal é observado com um ESA. Os tons são extraídos a partir dos espectros medidos e a PDL é encontrada por meio de processamento realizado em computador. 
O campo óptico aplicado no modulador, gera um sinal com bandas laterais de primeira ordem e portadora óptica, sendo que o espaçamento entre elas corresponde ao sinal inserido no modulador.

As portadoras ópticas, de frequências idênticas $\nu$, são moduladas pelos moduladores AM, cada uma com frequência, $f_{1}$ e $f_{2}$. São criadas bandas laterais espaçadas das portadoras de $f_{1}$ e $f_{2}$, respectivamente, $230 \mathrm{MHz}$ e $260 M H z$. A Figura 5.7 mostra o sinal modulado antes de passar pelo DUT.

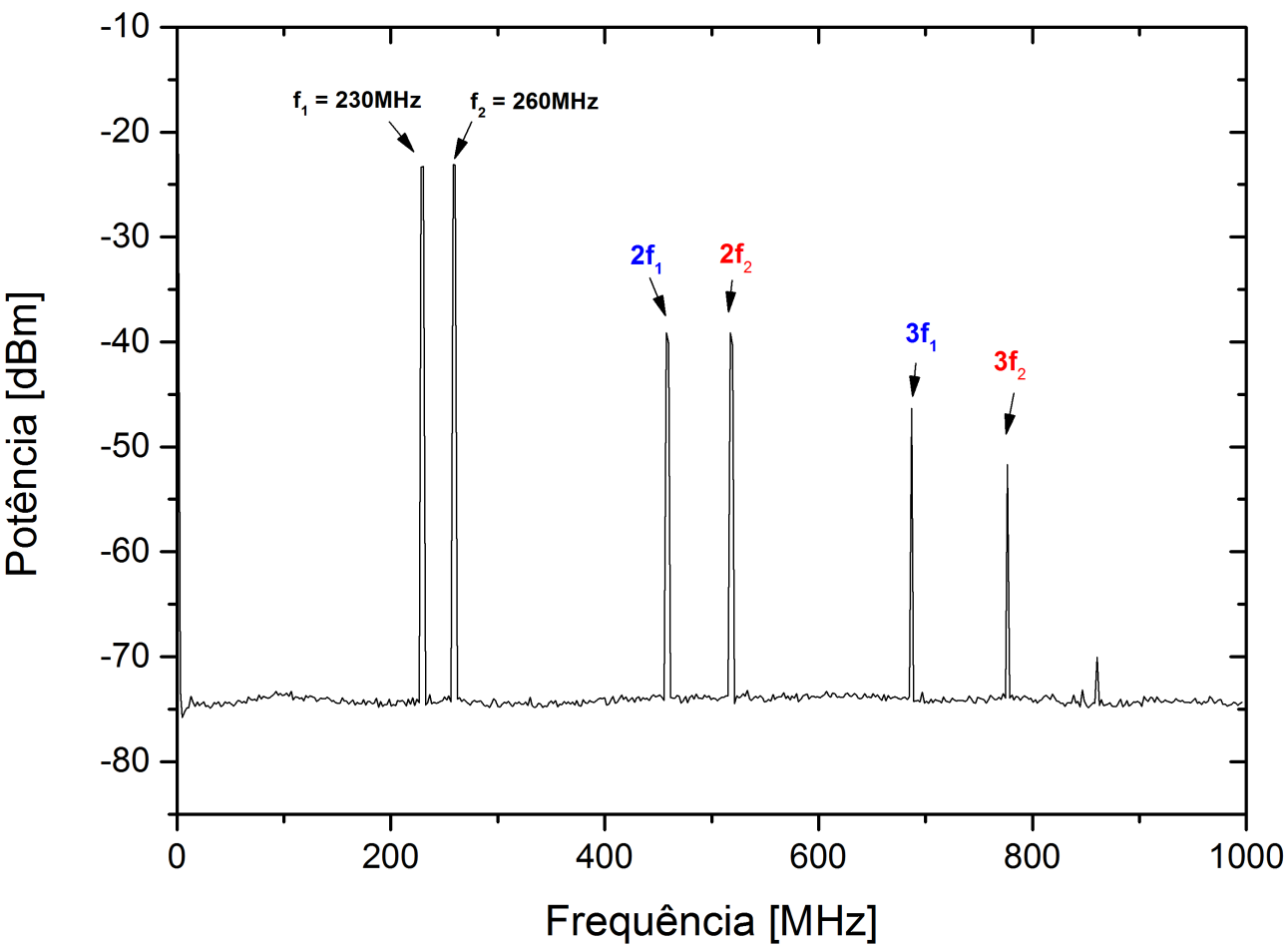

Figura 5.7: Espectro Óptico do sinal modulado e suas bandas laterias. Denominando, $f_{1}=230 \mathrm{MHz}$ e $f_{2}=260 \mathrm{MHz}$.

Antes da supressão das portadoras ópticas realizou-se o ajuste dos $P C s$, a fim de maximizar as polarizações e garantir que as mesmas sejam ortogonais.

Os $C P_{1}$ e $C P_{2}$ são utilizados para maximizar a modulação, pois os moduladores eletro-ópticos possuem um eixo de modulação. Já os $C P_{3}$ e $C P_{4}$ são usados para garantir que os sinais modulados com $f_{1}$ e $f_{2}$ sejam ortogonais entre si e casados com o $P B S$.

O modulador utilizado possui um comportamento óptico e não linear, operando em um ponto de quadratura, que é determinado por uma tensão de polarização igual a metade de $V_{\pi}$, induzindo o modulador a operar perto de 
uma região mais próxima do linear, conforme a Figura 5.8 que representa a curva de operação do modulador.

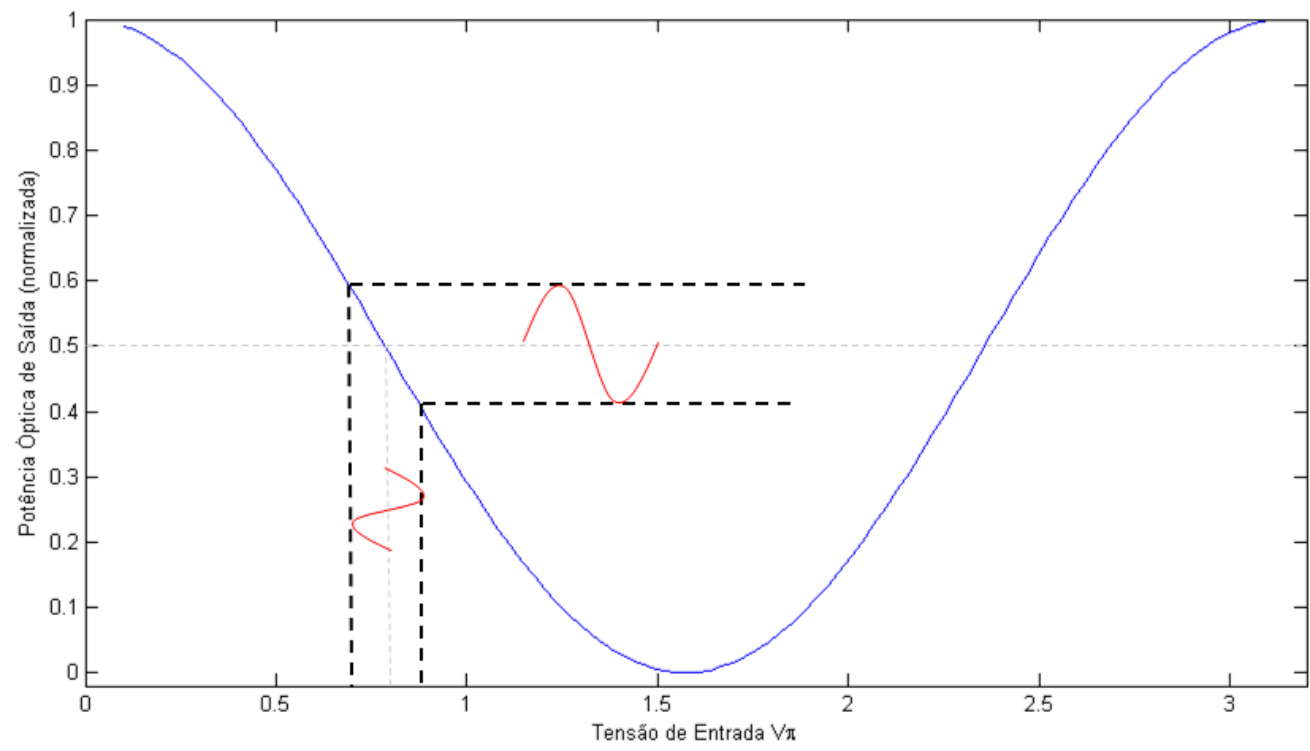

Figura 5.8: Curva de operação do modulador operando em um ponto de curvatura

Em um modulador Mach-Zhender (MZ) o sinal de entrada é dividido nos dois braços e coerentemente recombinado no dispositivo de saída. Dependendo da fase entre os campos ópticos, pode haver interferência construtiva ou destrutiva, resultando na variação da amplitude de saída (10).

O campo de de entrada $\vec{E}(t)=\operatorname{sqr} t P_{0} e^{j 2 \pi \nu_{0}} \hat{h}$ divide-se, propagando-se por ambos os braços do MZ. Os campos recombinados adiquirem fase relativa dada por $\Delta \phi(t)$, resultando:

$$
E(t)=\sqrt{P_{0}} / 2 e^{j 2 \pi \nu_{0}(t)}\left[e^{j \Delta \phi(t) / 2+e^{-j \Delta \phi(t)}}\right]
$$

A intensidade do sinal demodulado (detecção direta) é proporcional à $E_{\text {out }}^{*} E_{\text {out }}$, resultando em:

$$
I_{\text {out }} \propto P_{0} \cos ^{2} \phi_{0} / 2
$$

Mostrando a diferença de fase entre os braços do interferô metro agem no dispositivo de saída, seguindo a relação cosseno com a voltagem aplicada.

Substituindo na Equação 5-5 um sinal modulante composto por um sinal contínuo e um sinal variante no tempo em uma frequência $f, V(t)=$ 
$V_{D C}+V_{0} \cos (2 \pi f t)$, tem-se:

$$
I_{\text {out }}(t) \propto P_{o} \cos ^{2}\left[\frac{V_{b}}{2}+\frac{m}{2} \cos (2 \pi f t)\right]
$$

Onde, a voltagem bias é $V_{b}=\pi V_{D C} / V_{\pi}$ e a profundidade $\pi V_{0} / V_{\pi}$. Para pequenos valores de $m$ tem-se:

$$
I_{\text {out }}(t) \propto P_{0}\left[\cos ^{2}\left(V_{b} / 2\right)-\frac{1}{2} \sin \left(V_{b}\right) \cos (2 \pi f t)-\frac{m^{2}}{4} \cos \left(v_{b}\right) \cos ^{2}(2 \pi f t)\right]
$$

Para diferentes valores de $V_{b}$, os componentes de sinais demodulados:

- $V_{b}=0 \rightarrow P_{\text {out }} \propto P_{0} \Rightarrow$ Não há modulação;

- $V_{b}=\pi / 2 P_{\text {out }} \propto P_{0} / 2[m \cos (2 \pi f t)] \Rightarrow$ Modualção em quadratura;

- $V_{b}=\pi \rightarrow P_{\text {out }} \propto P_{0} m^{2}[1+\cos (4 \pi f t)] \Rightarrow$ Supressão de portadora.

Quando o modulador estiver operando no ponto de quadratura, a frequência $f$ de batimento oscila entre as bandas laterais e a portadora óptica sendo o sinal modulante. Quando a tensão de polarização ou bias do modulador é ajustada para um ponto de transmissão mínima, ou seja, $V_{\pi}$, a portadora é suprimida e o detector passa a "enxergar" apenas $2 f_{1}$ e $2 f_{2}$. Se a voltagem do bias for nula, e considerando um valor pequeno para $m$, não ocorre modulação e a detecção da portadora óptica resulta em uma intensidade de valor contínuo.

A Figura 5.9, mostra o espectro elétrico e óptico medido com a voltagem bias ajustada em $\pi$. Observa-se, também a supressão de portadora no espectro óptico, resultando no desaparecimento de $f$ no espectro elétrico. 

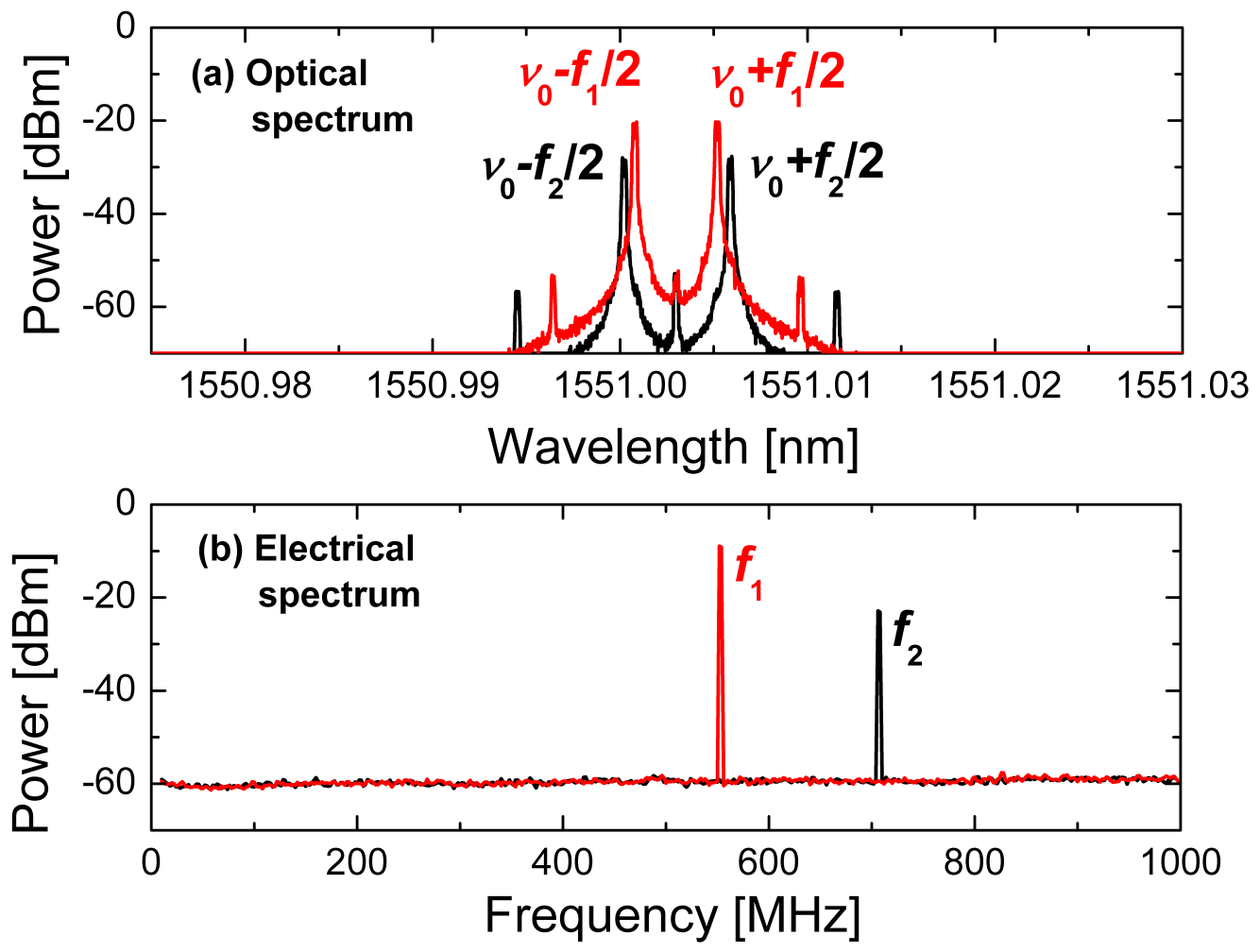

Figura 5.9: (a) O espectro óptico dos sinais modulados em amplitude com portadora suprimida. (b) O Espectro elétrico com o tom heterodino de cada braço óptico. Os traços são independentes.

A fonte laser lança um sinal de $8 d B m$ que se divide no $B S_{1}$ em $5 d B m$ para o braço $1, f_{1}$ de $260 M H z$ foi gerada e a tensão bias do modulador $A M_{1}$ foi ajustada para coincidir com o $V_{\pi}$ em $1 V$. Já o braço 2 recebe um sinal $5,24 \mathrm{dBm}, f_{2}$ de $230 \mathrm{MHz}$ gerada e a tensão $V_{\pi}$ bias do $A M_{2}$ em $0,84 \mathrm{~V}$.

Este método utiliza estados lineares de polarização na entrada do DUT fixados pela $H W P_{1}$, como mostrado na Figura 5.2, e a perda é introduzida no sistema conforme a rotação $\left(0^{\circ}\right.$ até $\left.90^{\circ}\right)$ da $H W P_{2}$ para cada estado de entrada correspondente.

O $C P_{4}$, que está na entrada do $D U T$, foi ajustado de modo que $2 f_{1}$ assuma a trajetória horizontal e $2 f_{2}$ a trajetória vertical no DUT. Após a realização dos ajustes necessários de polarização, supressão de portadora óptica e alinhamento do DUT o sistema está pronto para a caracterização das medidas.

Quando a $H W P_{1}$ estiver fixada em $0^{\circ}$ a banda lateral óptica $2 f_{1}$ se propagará pelo braço $h$, reduzindo-se à medida que o ângulo $\theta$ da $H W P_{2}$ girar à $45^{\circ}$ por tornar-se ortogonal ao polarizador emulado pelo $P B S_{2}$, e $2 f_{2}$, passando pelo braço $v$ fica constante ao longo da medida para o SOP de entrada, não havendo perda. A Figura 5.10, mostra os espectros de transmissão para o 
estado de entrada fixado em $0^{\circ}$, de acordo com o ângulo da $H W P_{2}$ que emula a perda relativa entre os braços do DUT.
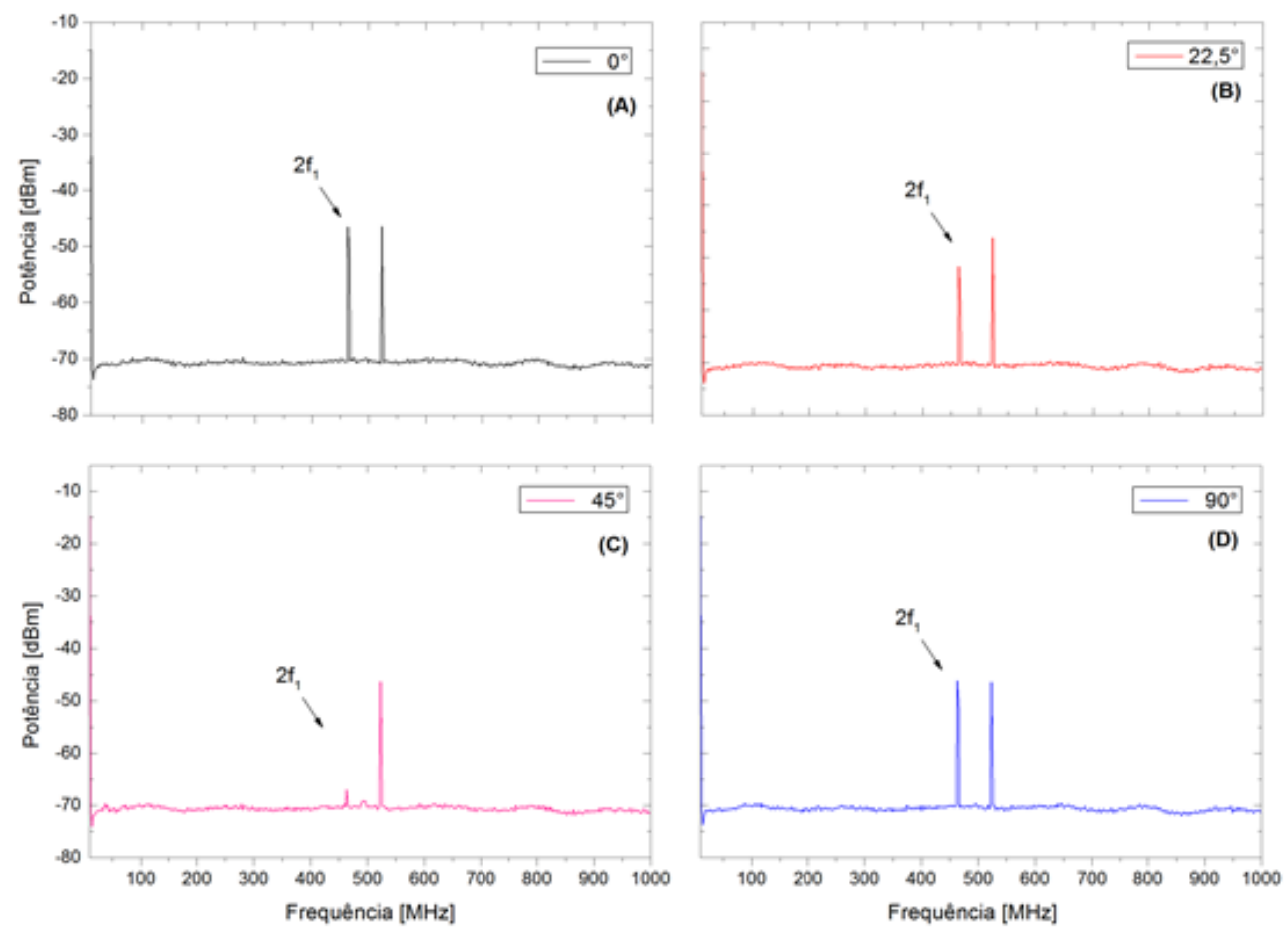

Figura 5.10: Espectro para $H W P_{1}$ fixada em $0^{\circ}, 2 f_{2}$ variando à medida que $H W P_{2}$ alcança $45^{\circ}$. (A) $H W P_{2}$ em $0^{\circ}$, ausência de PDL. (B) $H W P_{2}$ em 22, $5^{\circ}$. (C) $H W P_{2}$ em $45^{\circ}, P D L$ máxima. (D) $H W P_{2}$ em $90^{\circ}$.

Para o $S O P$ de entrada orientado à $45^{\circ}$ por meio da $H W P_{1}$, o $2 f_{2}$, que inicialmente assumia a trajetória por $v$ no $D U T$, agora assumirá o caminho $h$, adquirindo perda à medida que o ângulo $\theta$ da $H W P_{2}$ girar à $45^{\circ}$, e $2 f_{1}$ passa a assumir o caminho $v$, mantendo-se sem perda ao longo da medida. A Figura 5.11 mostra o espectro para o $S O P$ fixado em $45^{\circ}$. 
Medição de Perdas Dependentes da Polarização Utilizando Mistura de Frequências em Fotodiodos
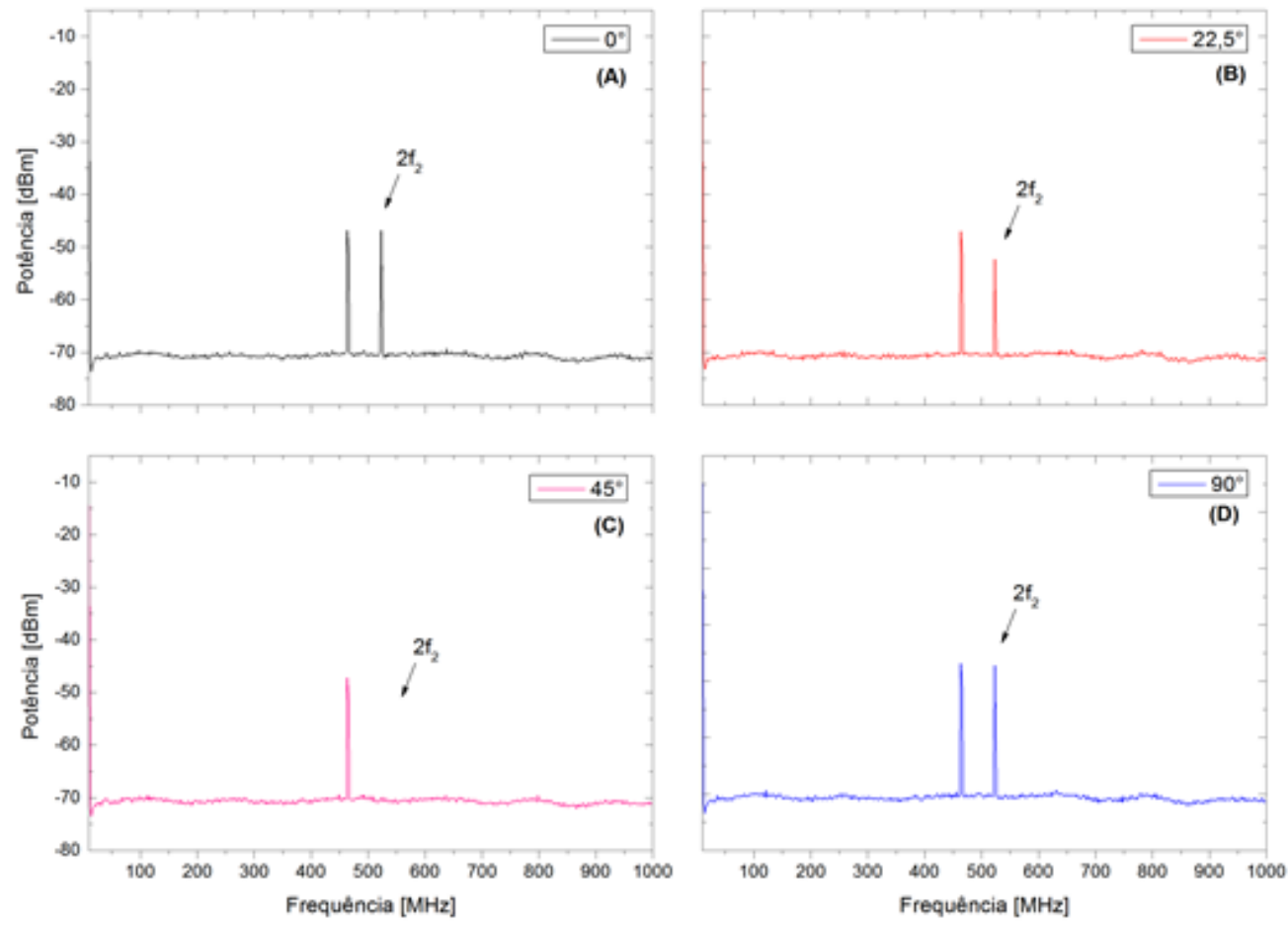

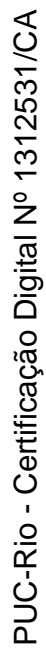

Figura 5.11: Espectro para o $S O P$ fixado em $45^{\circ}$ por meio da $H W P_{1}, 2 f_{1}$ variando à medida que $H W P_{2}$ alcança $45^{\circ}$. (A) $H W P_{2}$ em $0^{\circ}$, ausência de PDL. (B) $H W P_{2}$ em $22,5^{\circ}$. (C) $H W P_{2}$ em $45^{\circ}$, PDL máxima. (D) $H W P_{2}$ em $90^{\circ}$.

Para os demais estados estados fixados pela $H W P_{1}$, parte do sinal propaga-se por ambos os braços, surgindo os batimentos entre as duas componentes. A Figura 5.12 mostra a superposição dos espectros obtidos para diferentes valores da $H W P_{2}$. 


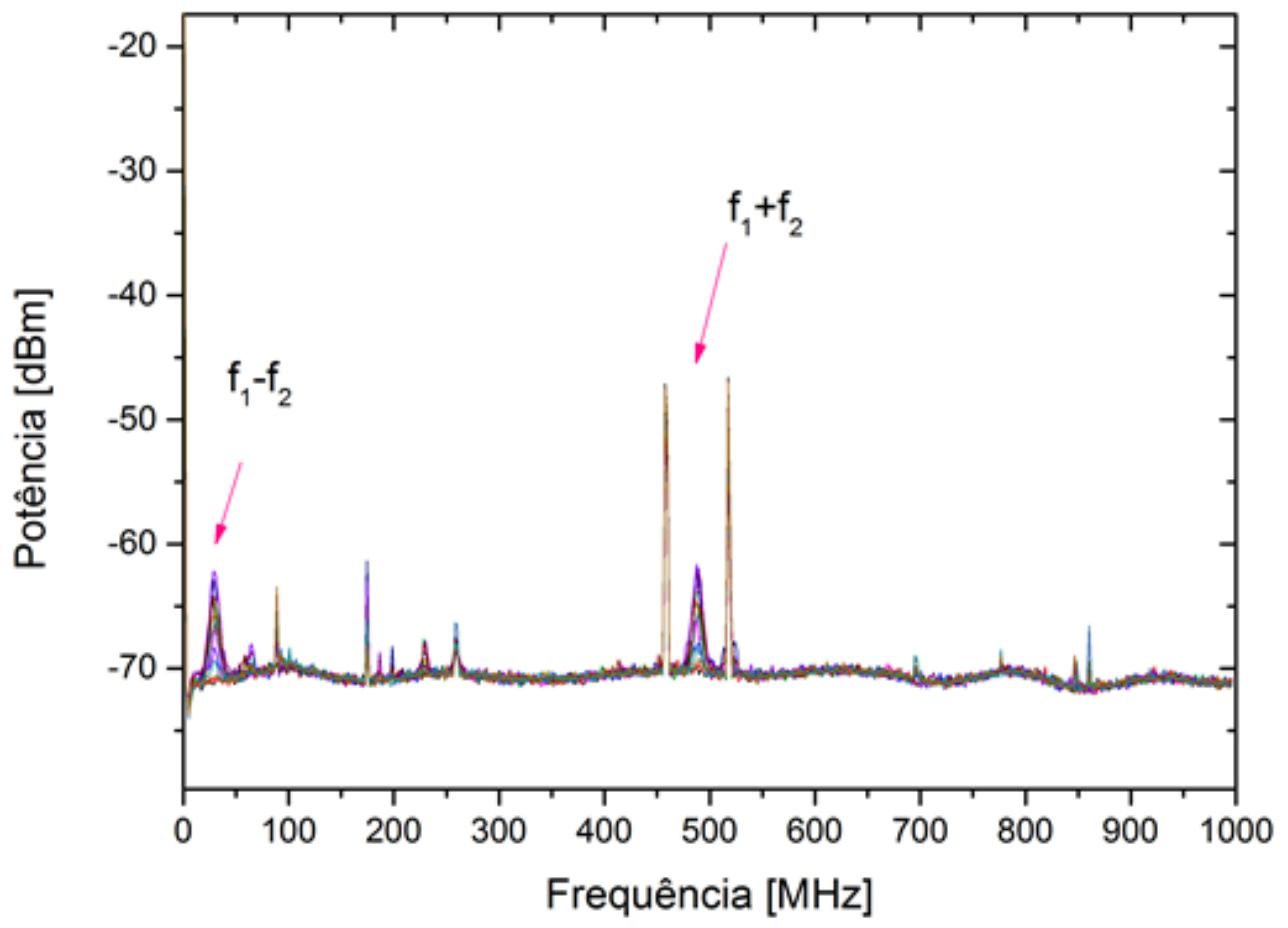

Figura 5.12: Espectro elétrico medido com os batimentos entre as componentes com a $H W P_{1}$ fixada em $22,5^{\circ}$.

À medida que as perdas são introduzidas pela $H W P_{2}$ surgem tons de batimentos cruzados, entre $f_{1}$ e $f_{2}$, que aumentam conforme o ângulo $\theta$ alcance $45^{\circ}$.

O espectro para cada $S O P$ da $H W P_{1}$ para um dado valor de $\theta$ da $H W P_{2}$ foi detectado e seu espectro medido pelo ESA e processado por um programa implementado em Python, no qual grava os espectros em arquivos .xlsx. e os dados foram analisados no Origin.

\section{3}

\section{Resultados}

Primeiramente, foram extraídos de cada medida, para os $S O P$ 's de entrada fixados pela $H W P_{1}$, os parâmetros $P_{1}$ e $P_{2}, P_{\Delta}$ e $P_{D C}$ e a partir deles calculados os valores referentes aos coeficientes de transmissão máximo e mínimo, e o $S O P$ em cada $\theta$ da $H W P_{2}$ a fim de comparar com o modelo teórico proposto.

A Figura 5.13, mostra a transmitância quando a $H W P_{1}$ fixada em $0^{\circ}$ para $2 f_{1}$ e $2 f_{2}$ em função de cada $\theta$ da $H W P_{2}$. Nota-se que a $H W P_{2}$ introduz perda em $2 f_{1}$, reduzindo-o, à medida que a mesma é rotacionada e alcança $45^{\circ}$, enquanto que $2 f_{2}$ se mantém constante, ou seja, sem perda ao longo da medida. 


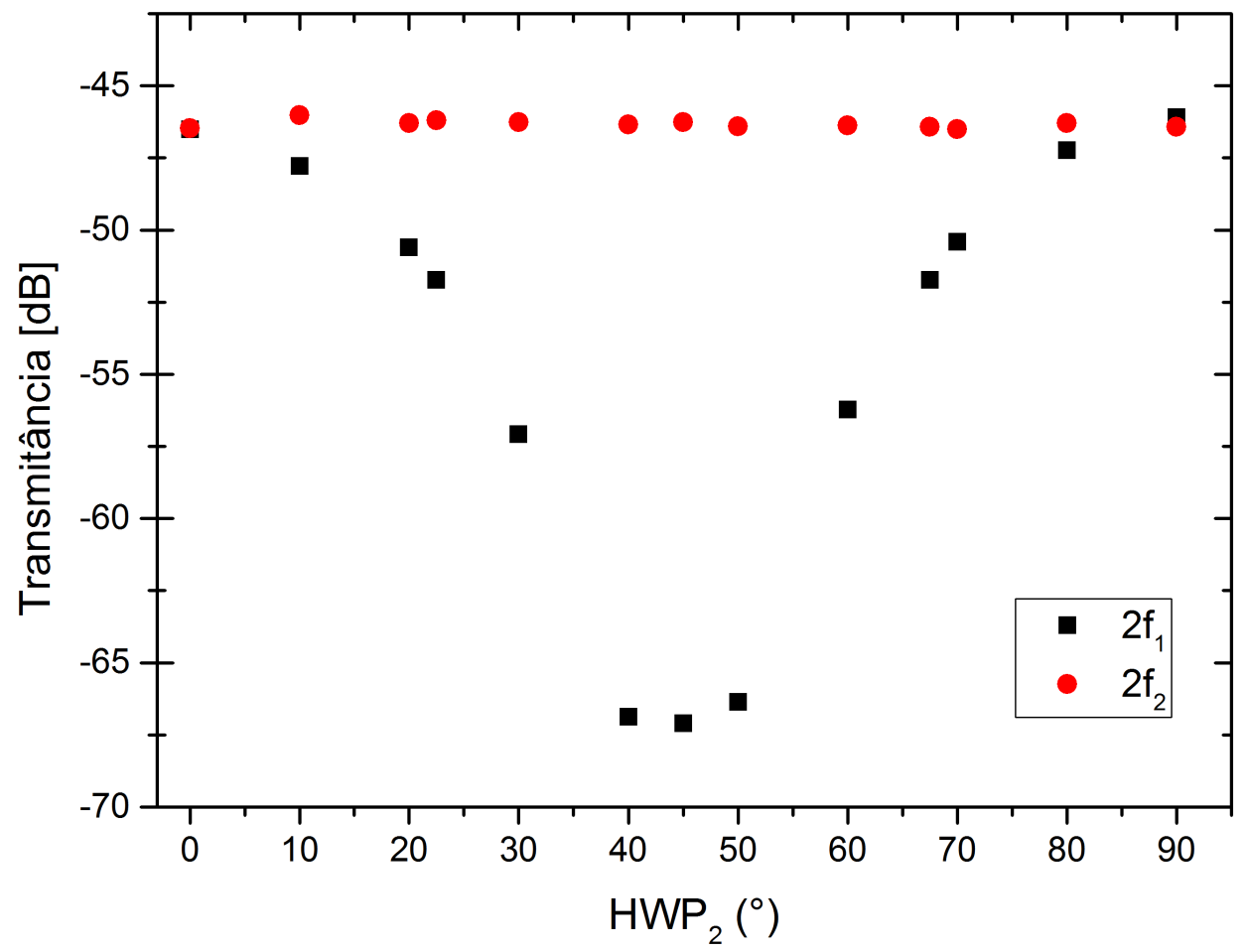

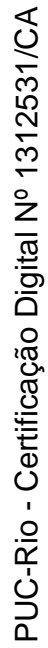

Figura 5.13: Transmitância obtida com a $H W P_{1}$ em $0^{\circ}$ para $2 f_{1}$ e $2 f_{2}$ em função da $H W P_{2}$.

A Figura 5.14, mostra a transmitância quando a $H W P_{1}$ fixada em $45^{\circ}$ para $2 f_{1}$ e $2 f_{2}$ em função de cada $\theta$ da $H W P_{2}$. Ao contrário do caso anterior, a $H W P_{2}$ introduz perda em $2 f_{2}$ reduzindo-o, à medida que a $H W P_{2}$ é rotacionada e alcança $45^{\circ}$, enquanto que $2 f_{1}$ se mantém constante, ou seja, sem perda ao longo da medida. 


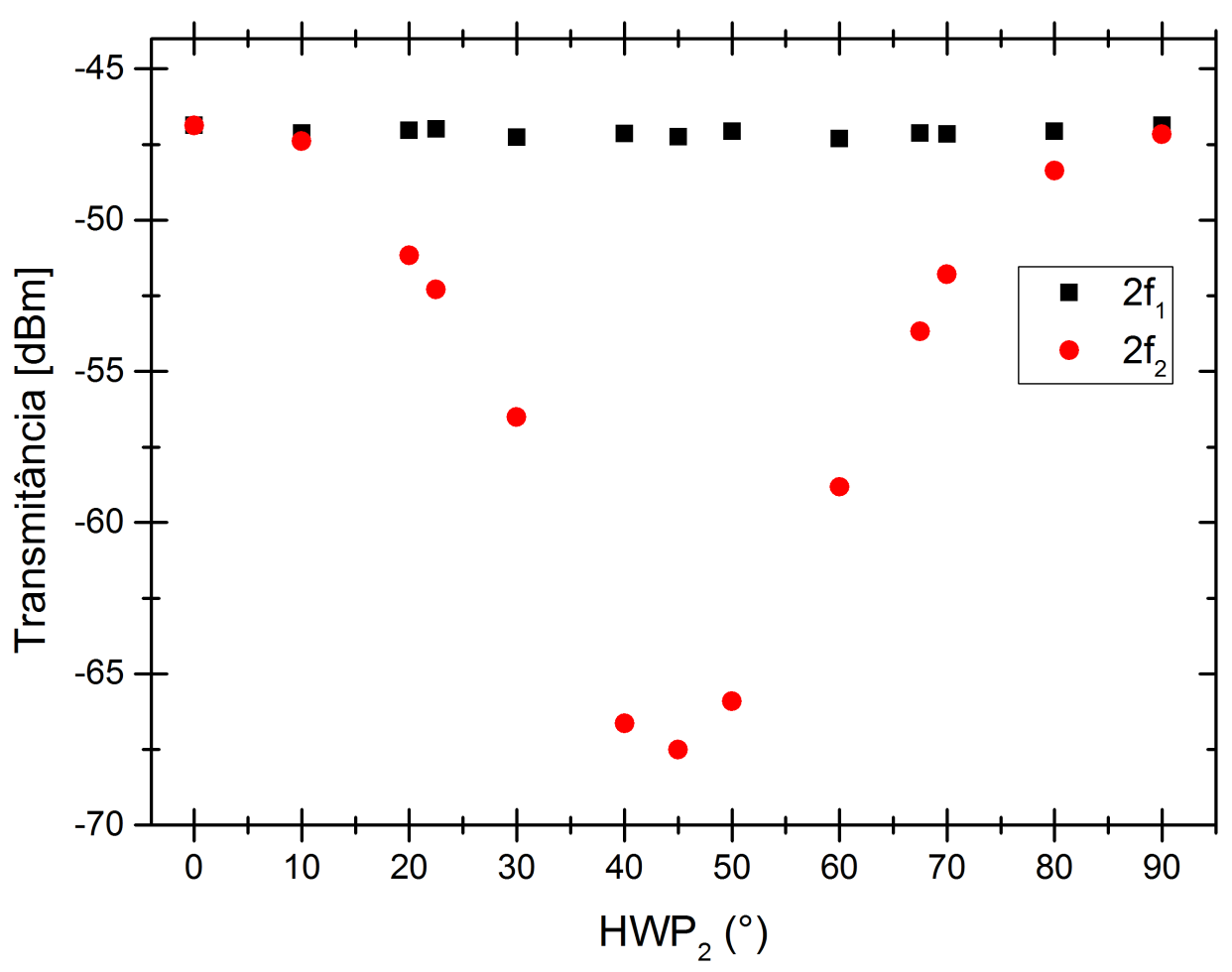

Figura 5.14: Transmitância obtida com a $H W P_{1}$ em $45^{\circ}$ para $2 f_{1}$ e $2 f_{2}$ em função da $H W P_{2}$.

Para as demais orientações fixadas pela $H W P_{1}$ surgem tons de batimento cruzado entre $f_{1}$ e $f_{2}$. A Figura 5.15, mostra a transmistância quando a $H W P_{1}$ é fixada em $22,5^{\circ}$. Observa-se que metade da potência, referente à $2 f_{1}$ e a $2 f_{2}$, passa em ambos os braços do $D U T$, reduzindo-se conforme a $H W P_{2}$ for rotacionada à $45^{\circ}$. Quando a $H W P_{2}$ estiver posicionada em $45^{\circ}$ a $P D L$ e o tom de batimento entre as moduladoras $f_{1}-f_{2}$ ser ao máximos. 


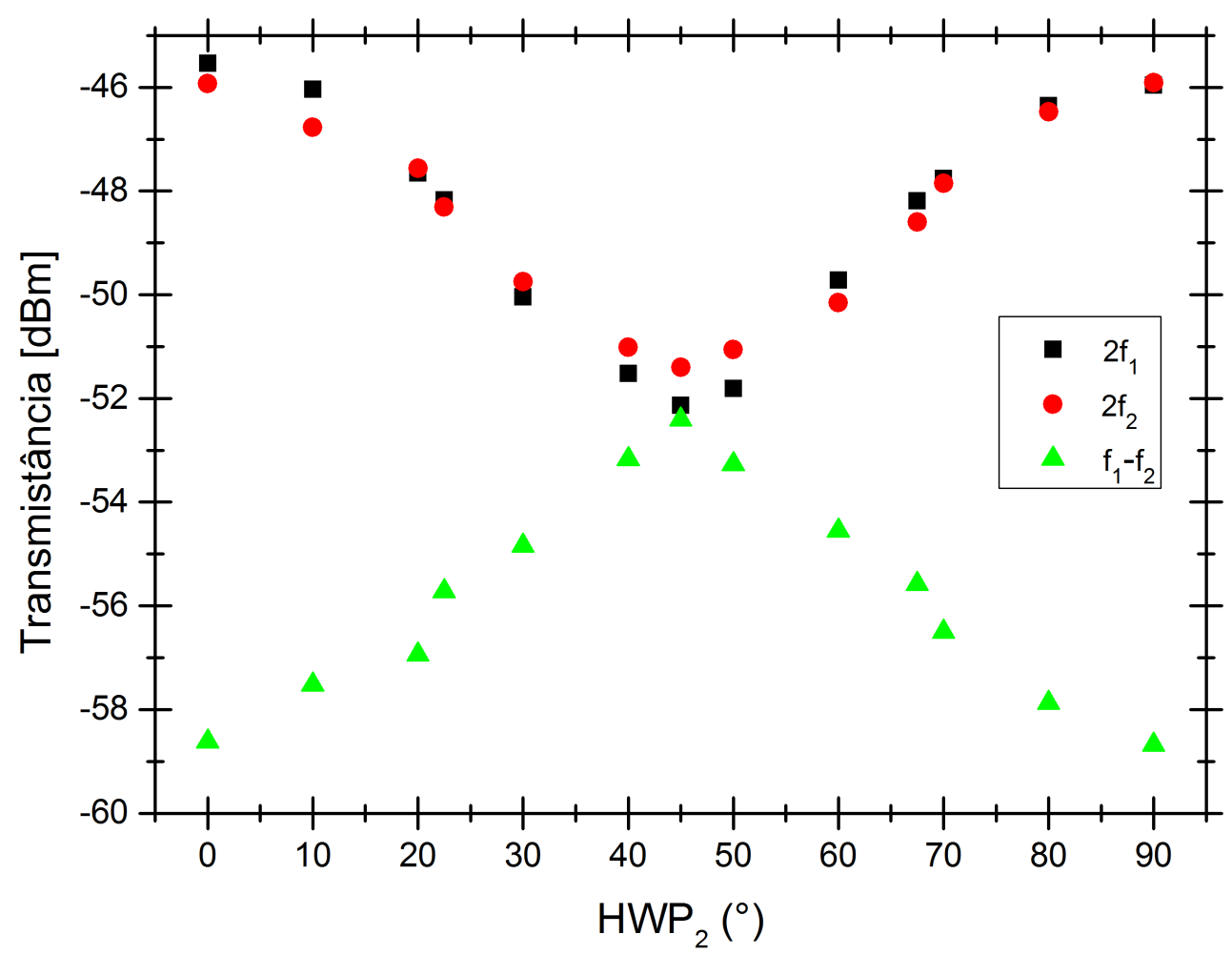

Figura 5.15: Transmitância obtida com a $H W P_{1}$ em $22,5^{\circ}$ para $2 f_{1}$ e $2 f_{2}$ em função da $H W P_{2}$.

As medidas realizadas, a partir do experimento montado em laboratório, possuem resultados que indicam concordância com o esperado pelo método.

Os coeficientes de transmissão máximo e mínimo, associados ao $t_{h}$ e $t_{v}$, foram calculados a partir das Equações (4-8) e (4-10) e o seu valor deve estar compreendido entre 0 e 1 . O valor da $P D L$, que é introduzida no sistema pela $H W P_{2}$ do DUT, foi calculada por meio da Equação (3-1), tornando-se máximo em $45^{\circ}$, e comparada com a $P D L$ esperada.

A Figura 5.16, compara os valores medidos e esperados de $P D L$ em função de $\theta$ da $H W P_{2}$ com a $H W P_{1}$ fixada em $0^{\circ}$. A $P D L$ aumenta e seu valor torna-se máximo em $45^{\circ}$, mas é limitada pela razão de extinsão do $P B S_{1}$ que é em torno de $20 d B$, não excedendo este valor. 


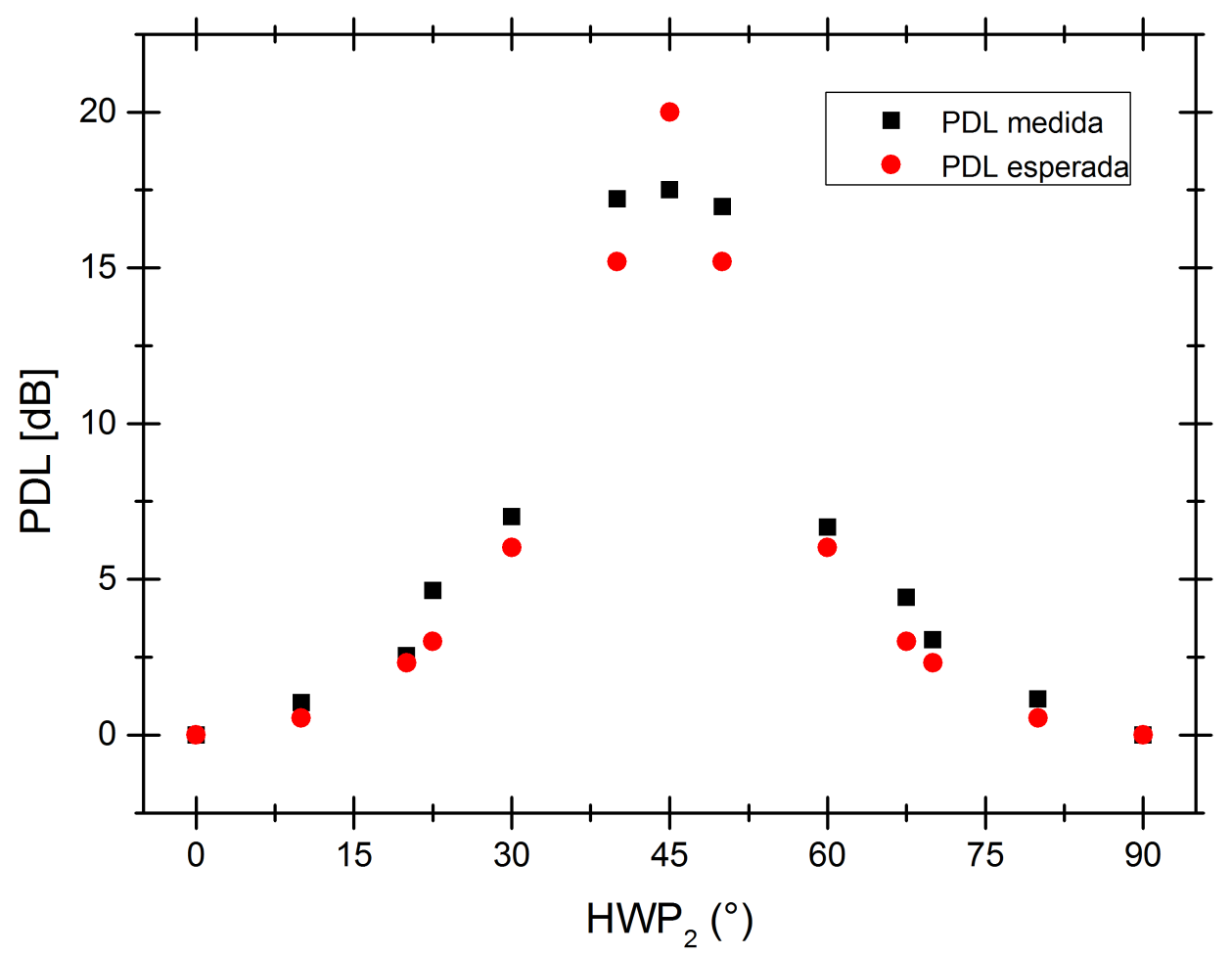

Figura 5.16: Valor da PDL medida e esperada para cada em função de cada $\theta$ da $H W P_{2}$ com a $H W P_{1}$ fixada em $0^{\circ}$.

A Figura 5.17, mostra um gráfico comparativo da $P D L$ medida e esperada em função dos ângulos da $H W P_{2}$ quando a $H W P_{1}$ estiver rotacionada em $45^{\circ}$. Alugns valores de $P D L$, como por exemplo, dos ângulos $30^{\circ}$ e $60^{\circ}$, $40^{\circ}$ e $50^{\circ}$, deveriam ter sido iguais, mas mas possivelmente houve um drift durante a caracterização das medidas ou limitação por meio da imprecisão dos ângulos das $H W P s$ de acordo coma graduação do sistema que contribuiu para a alteração dos resultados. 


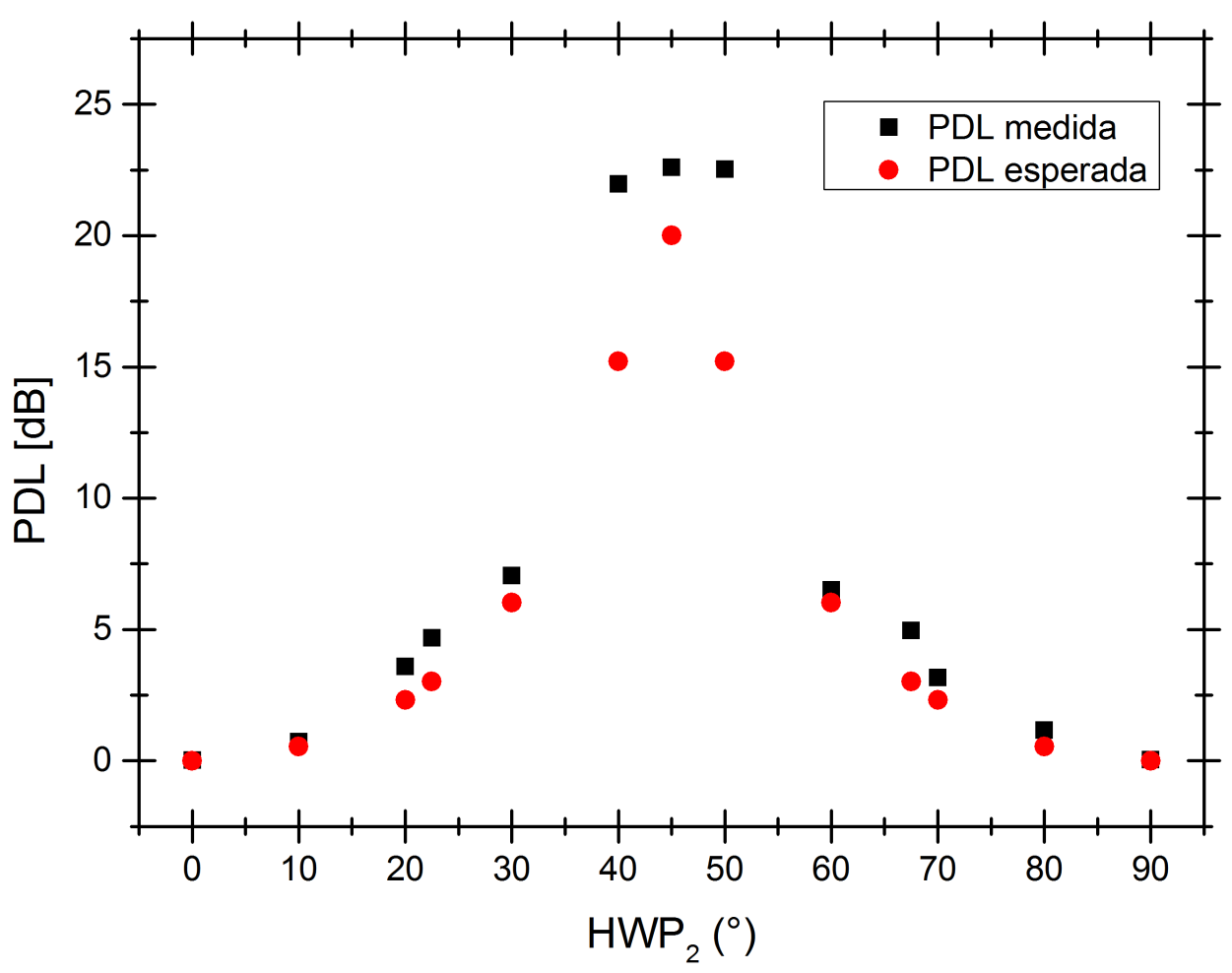

Figura 5.17: Valor da PDL medida e esperada para cada em função de cada $\theta$ da $H W P_{2}$ com a $H W P_{1}$ fixada em $45^{\circ}$.

A Figura 5.18, mostra o valor da $P D L$ medida e esperada em função dos ângulos da $H W P_{2}$ com a $H W P_{1}$ fixada em $30^{\circ}$. Os valores de $P D L$ medida para os ângulos $30^{\circ}$ e $60^{\circ}$ deriam ser idênticos, mas possivelmente algum drift no sistema durante a realização das medidas ou limitação por meio da imprecisão das HWPs de acordo coma graduação do sistema contribuiram para a alteração dos resultados. 


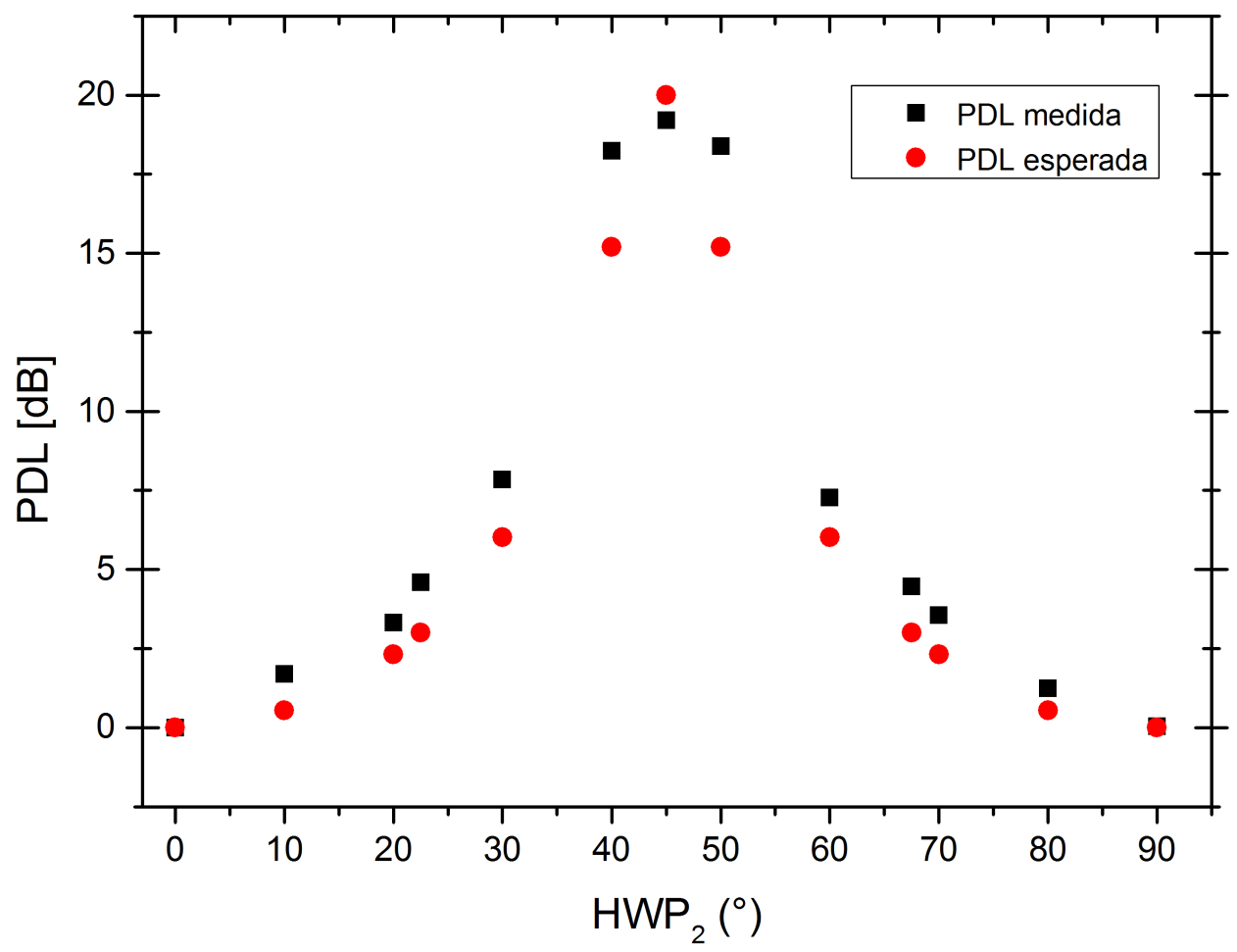

Figura 5.18: Valor da PDL medida e esperada para cada em função de cada $\theta$ da $H W P_{2}$ com a $H W P_{1}$ fixada em $30^{\circ}$.

A Figura 5.19, mostra o valor da $P D L$ medida e esperada em função dos ângulos da $H W P_{2}$. Os valores de $P D L$ medidos para os ângulos $30^{\circ} \mathrm{e}$ $60^{\circ}$ deveriam ser idênticos e a $P D L$ em $50^{\circ}$ e $60^{\circ}$ ficaram bem abaixo do valor esperado, mas um drift no sistema ou pela falta de reprodutibilidade da medida, por meio do ajuste da $H W P$ de acordo com a graduação do sistema interferem no valor da $P D L$. 


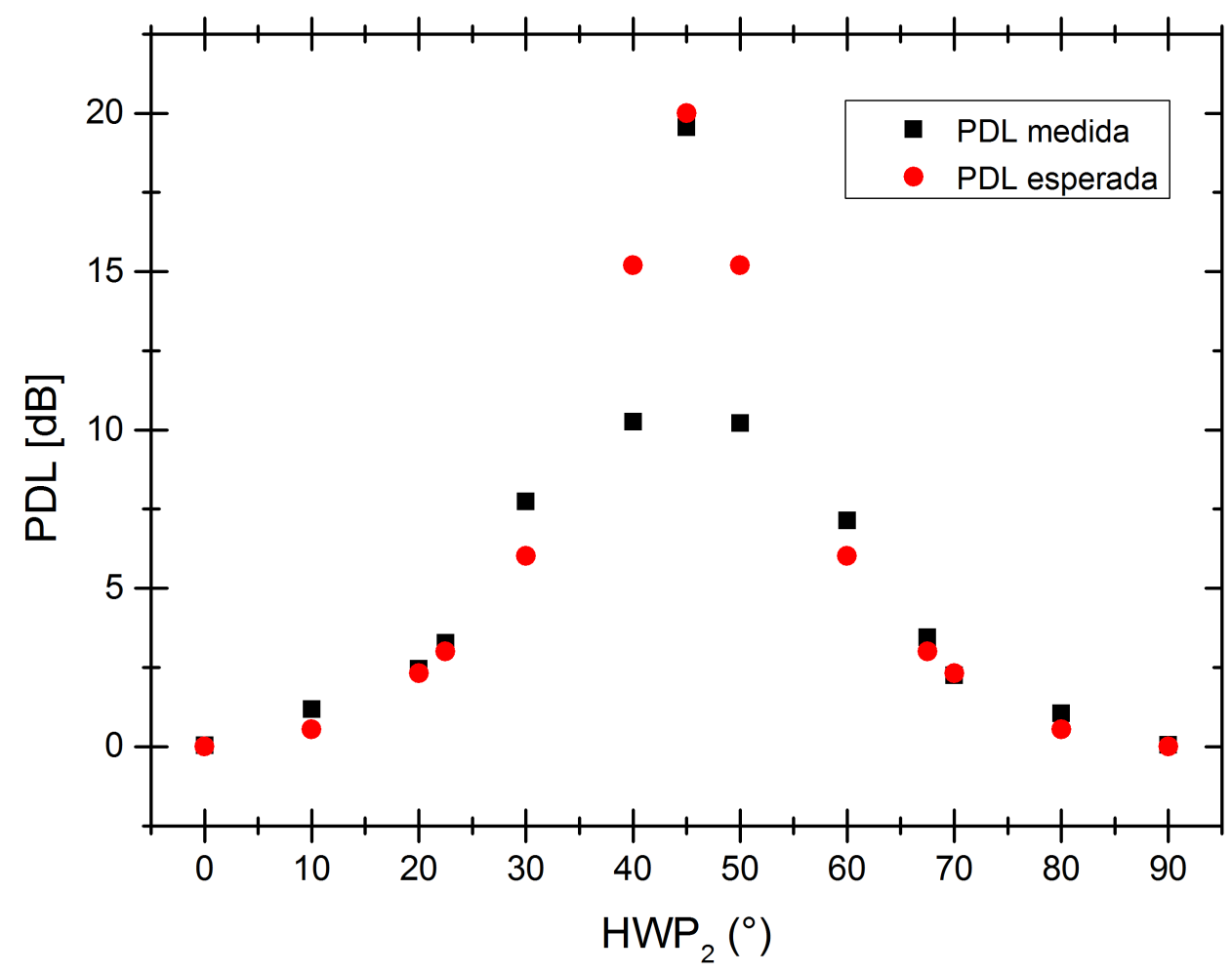

Figura 5.19: Valor da PDL medida e esperada para cada em função de cada $\theta$ da $H W P_{2}$ com a $H W P_{1}$ fixada em $20^{\circ}$.

Os $P B S^{\prime} s$ utilizados são limitados por uma característica denominada razão de extinção, que é definida como a diferença entre as duas polarizações ortogonais que passam por ele. A máxma $P D L$ encontrada, quando a $H W P_{2}$ estiver fixada em $45^{\circ}$, é limitada por essa caraterística e pelo próprio polarizador utilizado, que não absorve toda a luz em uma certa polarização, por isso, na prática, a $P D L$ não é infinita.

Outro fator limitante, que influencia nas medidas é a imprecisão dos ângulos das $H W P s$ utilizadas, ou seja, não é possível informar com certeza os ângulos rotacionados pelas $H W P^{\prime} s$,

Neste método, além do valor da $P D L$, é possível encontrar o $\chi$ e o $\delta$ da esfera, mas na montagem experimental realizada no laboratório o $\delta$, que é duas vezes $\psi$, foi restringido à zero, desconsiderando as componentes circulares, e utilizando apenas as componentes situadas no equador da esfera, conforme mostrado na Figura 2.6. O cálculo do ângulo $\chi$ foi feito por meio da Equação (??), devendo ser quatro vezes o valor do $\theta$ fixado pela $H W P_{1}$.

Quando a $H W P_{1}$ é fixada em $0^{\circ}$, o valor do ângulo de orientação na esfera de Poincaré $\chi$ deve ser $0^{\circ}$, conforme a Figura 5.20 que mostra o ângulo $\chi$ medido em função de cada $\theta$ da $H W P_{2}$. 


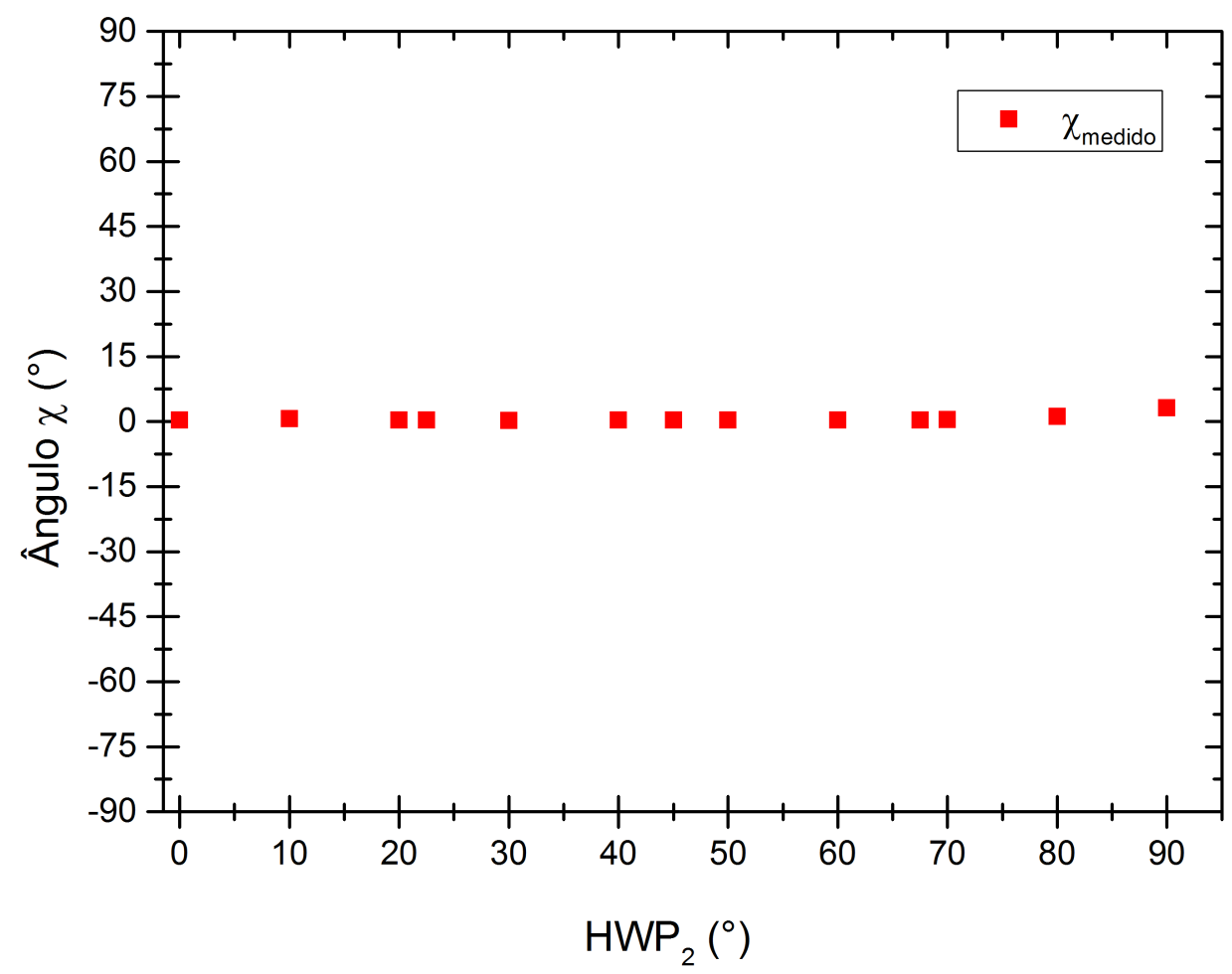

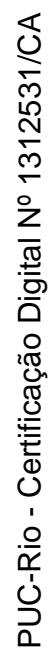

Figura 5.20: Ângulo de orientação $\chi$ na esfera de Poincaré, com a $H W P_{1}$ fixada em $0^{\circ}$, em função de cada $\theta$ da $H W P_{2}$.

Para a $H W P_{1}$ rotacionada à $45^{\circ}$, o ângulo de orientação na esfera de Poincaré $\chi$ é $0^{\circ}$, mas $\delta$ é $\pi$. A Figura 5.21 mostra mostra o ângulo de orientação $\chi$ encontrado em função de cada $\theta$ da $H W P_{2}$ quando a $H W P_{1}$ está fixada em $45^{\circ}$. 


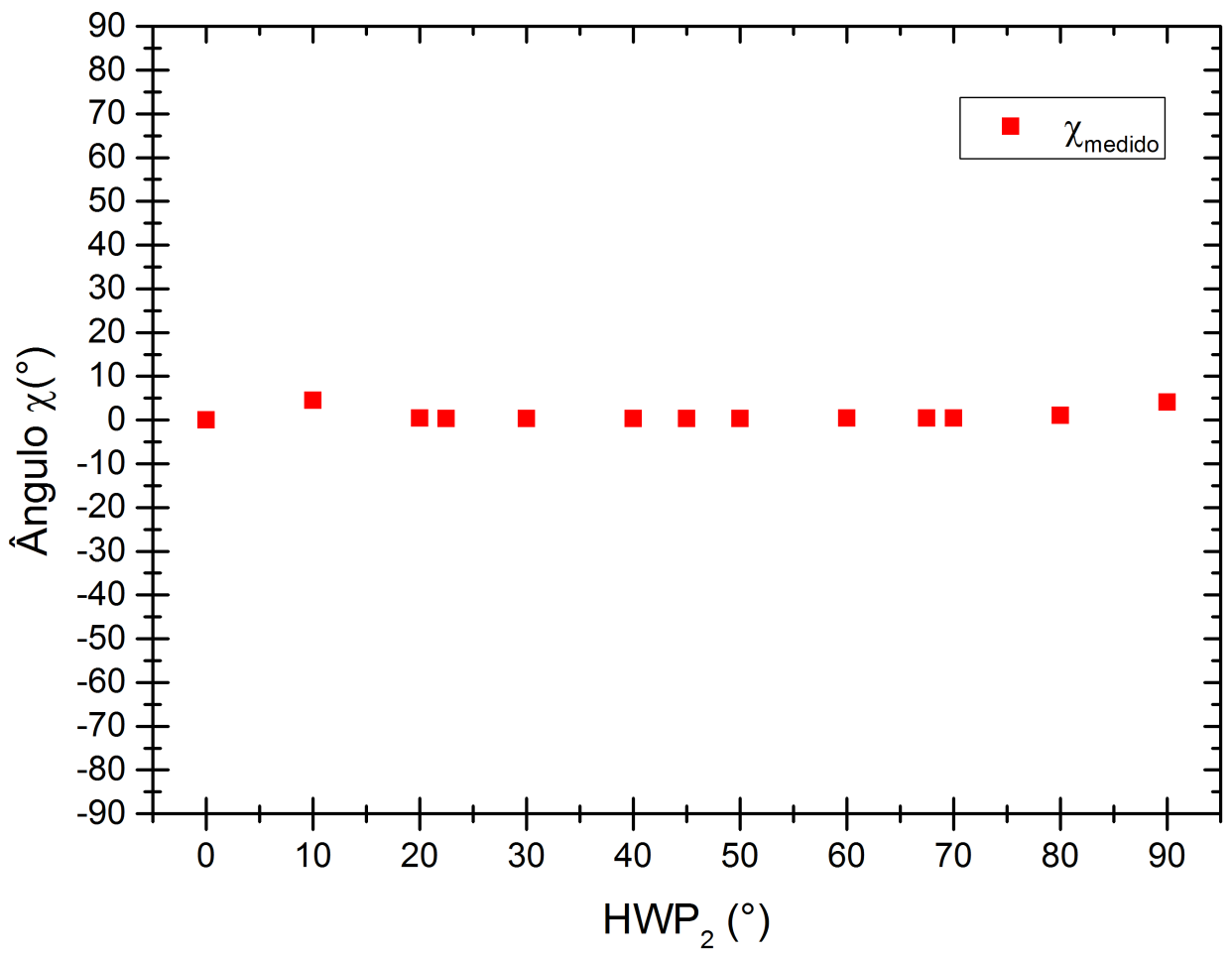

Figura 5.21: Ângulo de orientação $\chi$ na esfera de Poincaré, com a $H W P_{1}$ rotacionada em $45^{\circ}$, em função de cada $\theta$ da $H W P_{2}$.

O ângulo de orientação $\chi$ quando a $H W P_{1}$ estiver rotacionada em $20^{\circ}$ deve ser $80^{\circ}$. A Figura 5.22 mostra o ângulo de orientação $\chi$ encontrado em função de cada $\theta$ da $H W P_{2}$ quando a $H W P_{1}$ está em $20^{\circ}$. 


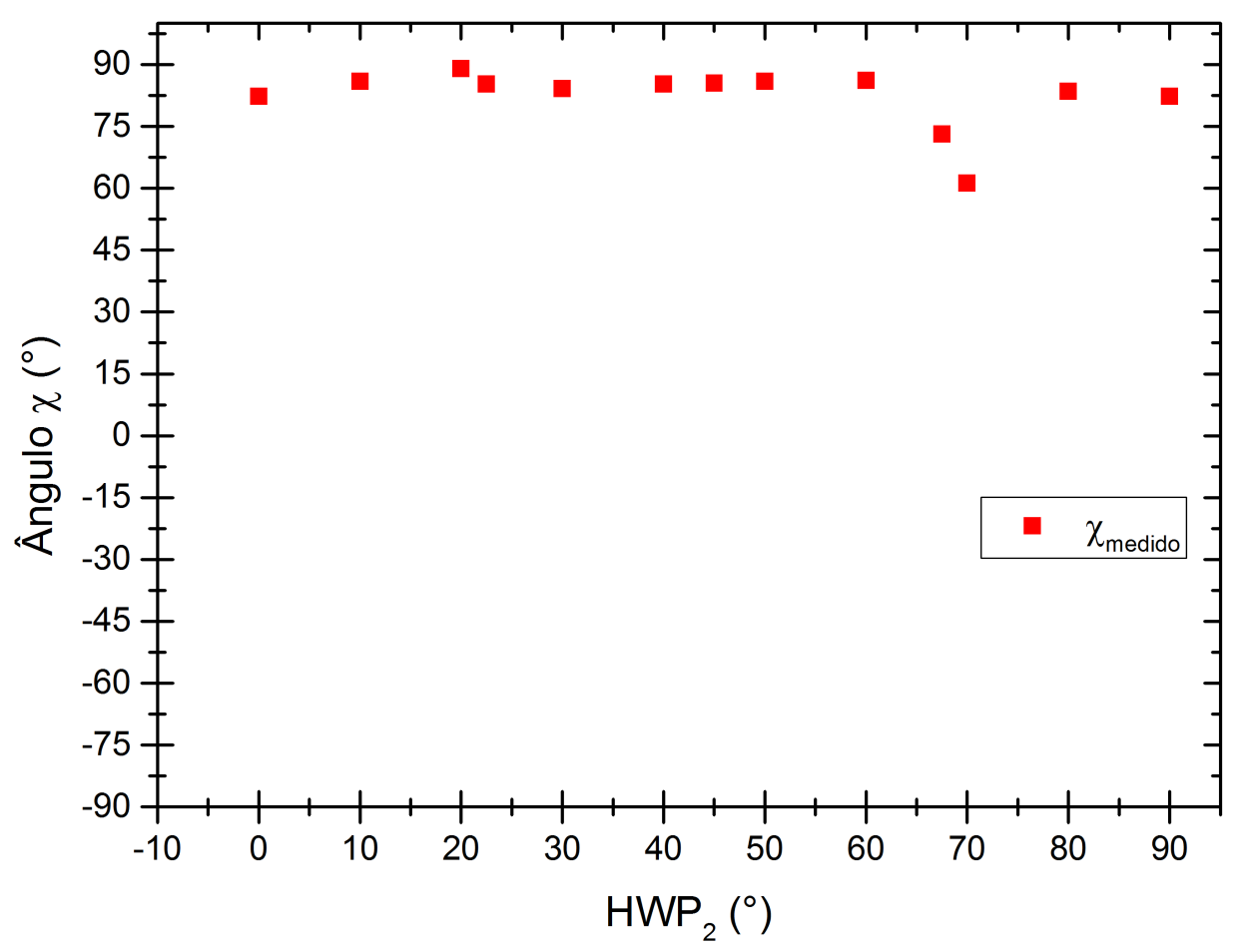

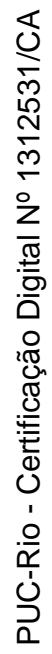

Figura 5.22: Ângulo de orientação $\chi$ na esfera de Poincaré com a $H W P_{1}$ rotacionada em $20^{\circ}$ em função de cada $\theta$ da $H W P_{2}$.

E para a $H W P_{1}$ fixada em $30^{\circ}$, o ângulo $\chi$ é $60^{\circ}$ e o $\delta$ é $\pi$, como na Figura 5.23 que mostra o ângulo de orientação $\chi$ encontrado em função de cada $\theta$ da $H W P_{2}$ quando a $H W P_{1}$ está em $30^{\circ}$. 


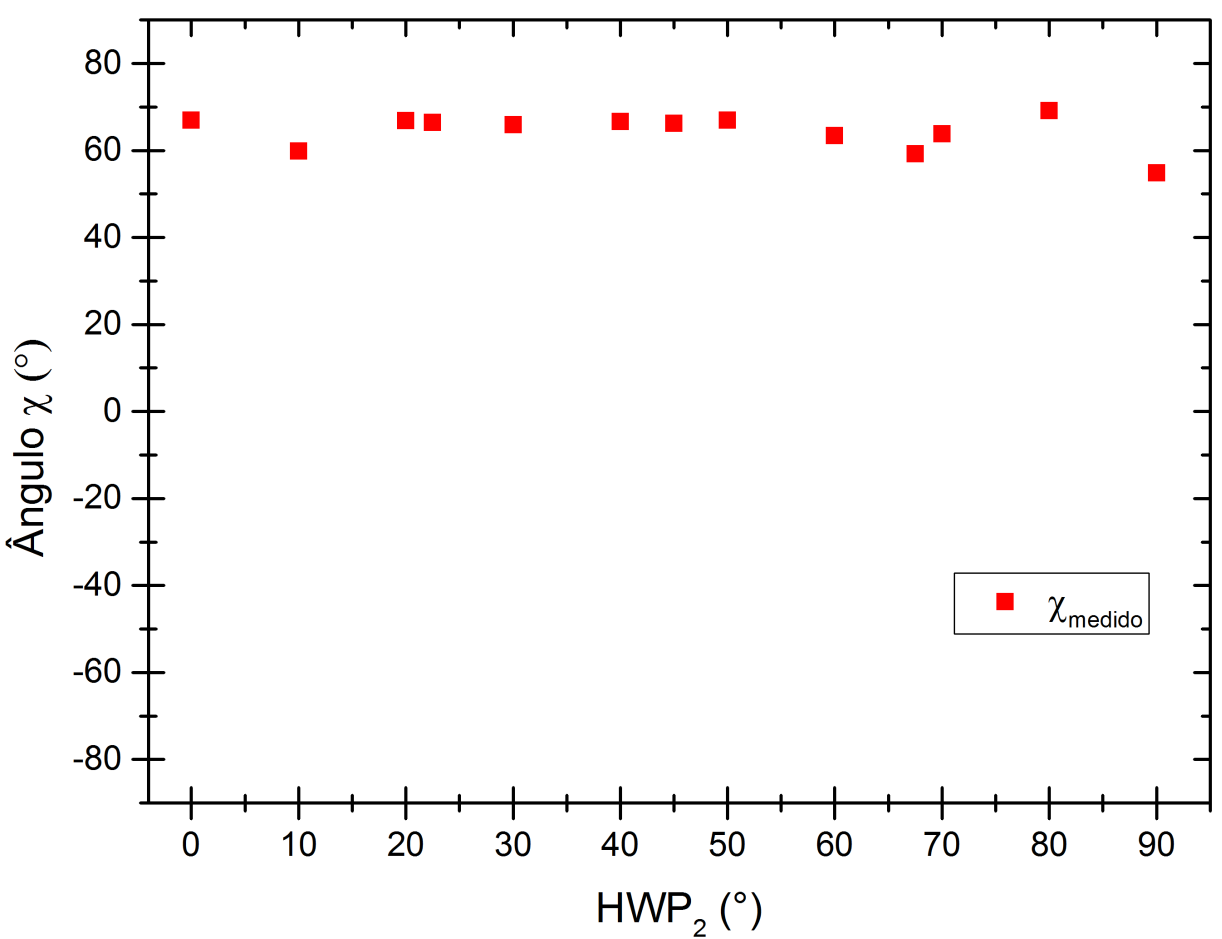

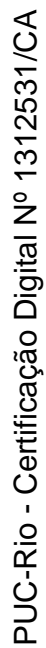

Figura 5.23: Ângulo de orientação $\chi$ na esfera de Poincaré com a $H W P_{1}$ rotacionada em $30^{\circ}$ em função de cada $\theta$ da $H W P_{2}$.

Os ângulos de orientação medidos estão coerentes e de acordo com o esperado, se confirmando com o modelo teórico proposto. 


\section{6 \\ Conclusão}

Neste trabalho, foi apresentado um método para determinação da PDL em dispositivos ópticos baseado na análise espectral de batimento heteródino de dois sinais ópticos polarizados ortogonalmente e modulados com frequências diferentes. O esquema proposto não utiliza escaneamento da polarização, nem polarímetro e possui um tempo de medida rápido, representando uma alternativa viável aos métodos tradicionais.

O modelo derivado foi verificado experimentalmente utilizando emulador de PDL capaz de gerar diversos valores de PDL e diferentes eixos.

A partir da metodologia utilizada foi possível medir os coeficientes de transmissão máximo e mínimo, e a partir deles foi calculado o valor da PDL em dB para cada ângulo fixado pela HWP durante a medida, e calcular a sua orientação na esfera de Poincaré.

Apesar das diversas tentativas para maximizar o sinal, o mesmo continuou com muito ruído. Assim, os dados extraídos durante a medida possuem bastante sensibilidade ao ruído.

Os ângulos fixados pelas HWP's possuem uma certa imprecisão ao girálos para definir o eixo de orientação na esfera e introduzir a perda no sistema, havendo uma incerteza nos parâmetros medidos e calculados.

A vantagem do método apresentado é a possibilidade de fornecer, também, a orientação da PDL na esfera de Poincaré. Porém, para o cálculo do ângulo $\delta$ na esfera é necessário alguma alteração na modelagem teórica, podendo ser realizado em um trabalho futuro. Além da medição instantânea da PDL através de uma aquisição de espectro mostrado no ESA.

Os resultados das medidas experimentais se confirmam com o esperado pelo método para medir PDL. A partir dos dados extraídos, foram encontrados os ângulos de orientação, cujo os valores estão coerente com a orientação esperada na esfera de Poincaré. 


\section{Referências Bibliográficas}

[1] COLLETT, E. Field guide to polarization, volume 15. SPIE Press, 2005.

[2] CRAIG, R. M.; GILBERT, S. L. ; HALE, P. D. Journal of lightwave technology. High-resolution, nonmechanical approach to polarizationdependent transmission measurements, journal, v.16, n.7, p. 1285, 1998.

[3] DAMASK, J. N. Polarization optics in telecommunications, volume 101. Springer Science \& Business Media, 2004.

[4] DERICKSON, D. Fiber optic test and measurement. In: FIBER OPTIC TEST AND MEASUREMENT/EDITED BY DENNIS DERICKSON. UPPER SADDLE RIVER, NJ: PRENTICE HALL, C1998., volume 1, 1998.

[5] DONG, H.; SHUM, P.; YAN, M.; NING, G.; GONG, Y. ; WU, C. Optics express. Generalized frequency dependence of output stokes parameters in an optical fiber system with pmd and pdl/pdg, journal, v.13, n.22, p. 88758881, 2005.

[6] DONG, H.; ZHOU, J.; YAN, M.; SHUM, P.; MA, L.; GONG, Y.; WU, C. Optics letters. Quasi-monochromatic fiber depolarizer and its application to polarization-dependent loss measurement, journal, v.31, n.7, p. 876-878, 2006.

[7] FAVIN, D.; NYMAN, B. ; WOLTER, G. System and method for measuring polarization dependent loss, Dez. 6 1994. US Patent $5,371,597$.

[8] GOLDSTEIN, D.; GOLDSTEIN, D. H. Polarized Light, revised and expanded, volume 83. CRC Press, 2011.

[9] HEFFnER, B. L. Photonics Technology Letters, IEEE. Deterministic, analytically complete measurement of polarization-dependent transmission through optical devices, journal, v.4, n.5, p. 451-454, 1992.

[10] OKOSHI, T.; KIKUCHI, K. Coherent optical fiber communications, volume 3. Springer Science \& Business Media, 1988.

[11] TEICH, M. C.; SALEH, B. Canada, Wiley Interscience. Fundamentals of photonics, journal, p. 3, 1991. 
Medição de Perdas Dependentes da Polarização Utilizando Mistura de Frequências em Fotodiodos

[12] ZHOU, J.; DONG, H.; ADITYA, S.; GONG, Y.; SHUM, P.; GUO, X. ; MA, L. Optical Fiber Technology. Two-states method for polarization dependent loss measurement, journal, v.13, n.2, p. 139-142, 2007.

[13] ZHU, Y.; SIMOVA, E.; BERINI, P. ; GROVER, C. P. Instrumentation and Measurement, IEEE Transactions on. A comparison of wavelength dependent polarization dependent loss measurements in fiber gratings, journal, v.49, n.6, p. 1231-1239, 2000. 